\title{
Characterization of new particulate MMC materials and bolted joints through applicable ASTM standards
}

Vinu Zacharia Mathew

West Virginia University

Follow this and additional works at: https://researchrepository.wvu.edu/etd

\section{Recommended Citation}

Mathew, Vinu Zacharia, "Characterization of new particulate MMC materials and bolted joints through applicable ASTM standards" (2003). Graduate Theses, Dissertations, and Problem Reports. 1387. https://researchrepository.wvu.edu/etd/1387

This Thesis is protected by copyright and/or related rights. It has been brought to you by the The Research Repository @ WVU with permission from the rights-holder(s). You are free to use this Thesis in any way that is permitted by the copyright and related rights legislation that applies to your use. For other uses you must obtain permission from the rights-holder(s) directly, unless additional rights are indicated by a Creative Commons license in the record and/ or on the work itself. This Thesis has been accepted for inclusion in WVU Graduate Theses, Dissertations, and Problem Reports collection by an authorized administrator of The Research Repository @ WVU. For more information, please contact researchrepository@mail.wvu.edu. 


\title{
CHARACTERIZATION OF NEW PARTICULATE MMC MATERIALS AND BOLTED JOINTS THROUGH APPLICABLE ASTM STANDARDS
}

\author{
Vinu Zacharia Mathew
}

Thesis submitted to the College of Engineering and Mineral Resources at West Virginia University for the degree of

\author{
Masters of Science \\ in \\ Mechanical Engineering \\ Dr.Jacky C.Prucz, Chair \\ Dr.Samir N.Shoukry \\ Dr.Bruce S Kang
}

Mechanical and Aerospace Engineering Department

\author{
Morgantown, West Virginia
}

October 2003

Keywords: MMC, Tension testing, Three-point bend testing, Coefficient of thermal expansion, Hardness value, Bolted joint testing of MMC's 


\begin{abstract}
Particulate reinforced metal matrix composites (PRMMC) comprise a new class of materials whose properties can be adjusted to suit a particular application. The main purpose of producing PRMMC is to achieve lightweight materials with added properties like high stiffness, high ultimate strength and hardness.

In this study we deal with PRMMC manufactured by a novel technology involving the pressure less infiltration of aluminum into a mass of ceramic reinforcement particles. Basic tests like tension test, three point bending test, hardness tests and coefficient of thermal expansion are conducted according to the ASTM standards in order to characterize the material. All these tests are conducted for the matrix alloy, for $30 \%$ and $45 \%$ reinforced MMC. It was found that due to the presence of $\mathrm{SiC}$ particles there was a considerable increase in Young's modulus, hardness and flexural strength of the material. The coefficient of the thermal expansion decreased due to the presence of the $\mathrm{SiC}$ particles. However the addition of $\mathrm{SiC}$ reinforcement reduces the ductility of the material making it very brittle.
\end{abstract}

In addition to the above tests, a design for testing of bolted joints of MMC has been developed and implemented. Various parameters like clamping force, e/d ratio and w/d ratios are varied in order to investigate the effect on mode of failure and ultimate failure load of the MMC. It has been found that the major mode of failure in PRMMC is due to net-section failure on account of its brittle nature. Also higher clamping force provides higher frictional resistance and lateral support as a result of which the ultimate failure of MMC increases even though the mode of failure remains the same. 


\section{ACKNOWLEDGEMENTS}

I would like to gratefully acknowledge the enthusiastic supervision of Dr.Jacky Prucz during this work. With his enthusiasm, his inspiration, and his great efforts to explain things clearly and simply, he helped to make learning, fun for me. Throughout my thesis-writing period, he provided encouragement, sound advice, good teaching, excellent company, and good number of innovative ideas.

I thank Dr.Shoukry for the technical discussions and for providing me with patient direction through the maze. I am also indebted to Dr.Kang for providing me with continuing motivation and encouragement. Ashok, Dave and Cliff are thanked for numerous stimulating discussions, help with experimental setup and general advice.

I am grateful to all my friends Karthik, Ram, Sam, Bobby Antony and Sailaja for being the surrogate family during my stay away from home and for their continued moral support there after.

Finally, I am forever indebted to my parents for their understanding, endless patience and encouragement when it was most required. I am also grateful to my brother Manu and my dearest friend Malini for their support. 


\section{TABLE OF CONTENTS}

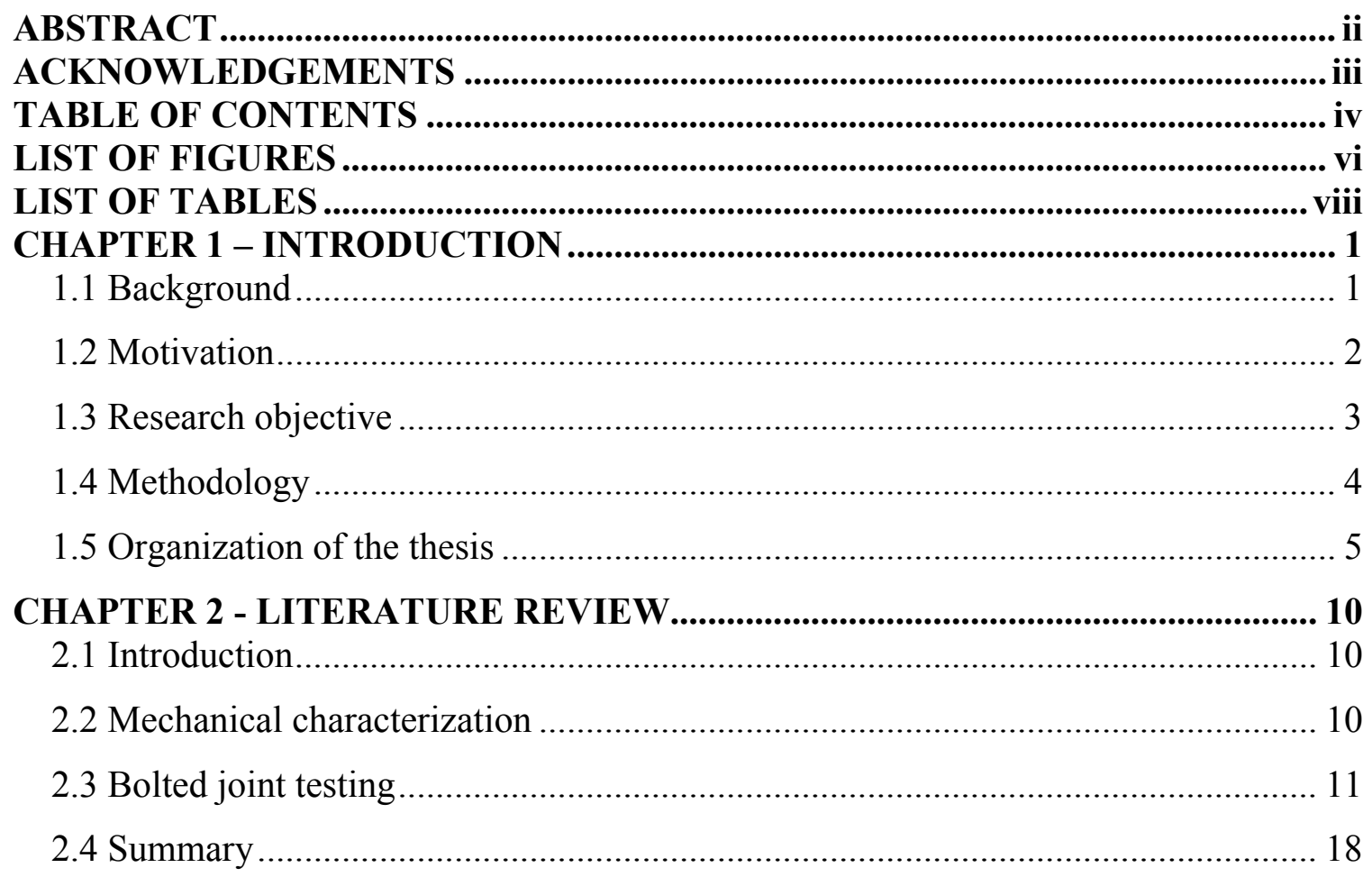

CHAPTER 3 - CHARACTERIZATION OF PARTICULATE METAL MATRIX COMPOSITE MATERIALS..................................................................................... 19

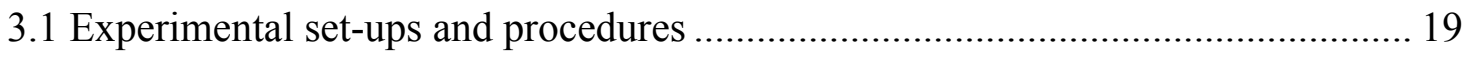

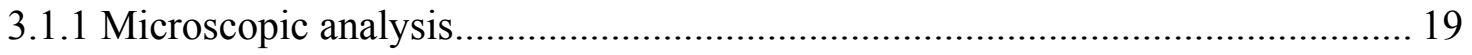

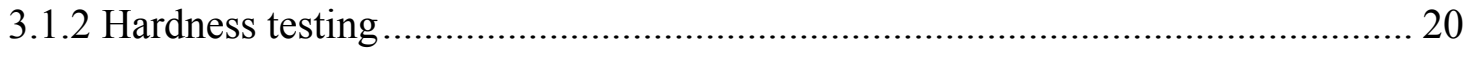

3.1.3 Tension testing ......................................................................................... 21

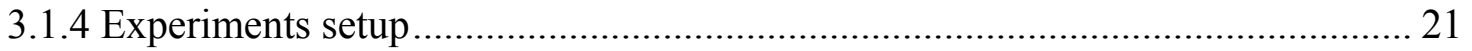

3.1.5 Theoretical model for predicting the Young's modulus ..................................... 22

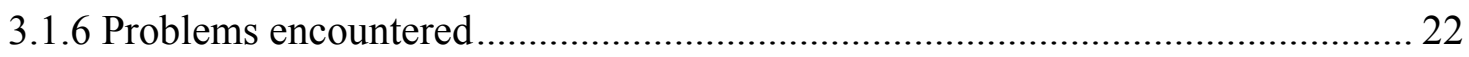

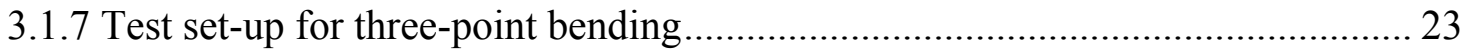

3.1.8 Experimental set-up for determining coefficients of thermal expansion............. 24

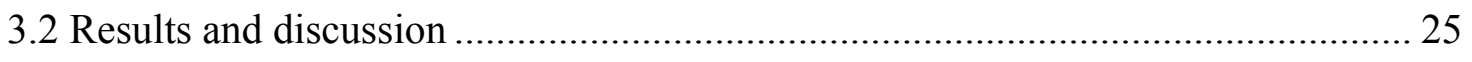

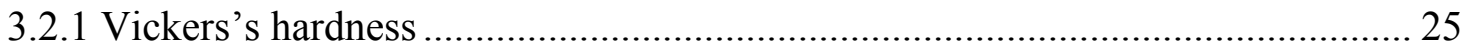

3.2.2 Young's modulus, flexural strength and strain ................................................... 27

3.2.3 Coefficient of thermal expansion .................................................................... 28

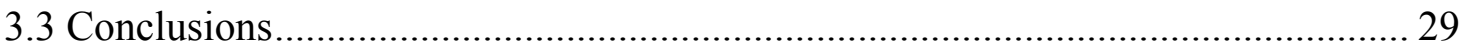




\section{CHAPTER 4 CHARECTERIZATION OF BOLTED JOINTS MADE OF PARTICULATE REINFORCED METAL MATRIX COMPOSITES.................... 43}

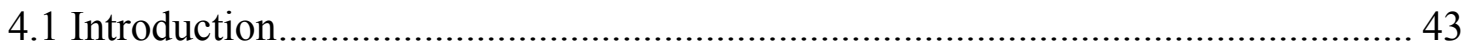

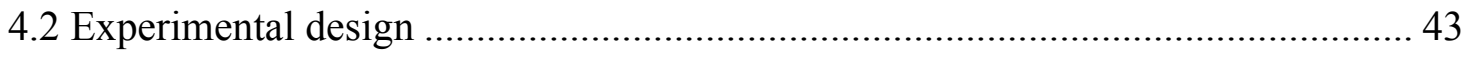

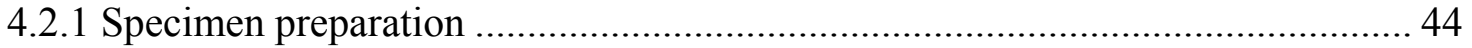

4.3 Components of the bolted joint specimens .................................................... 45

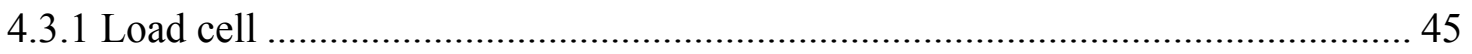

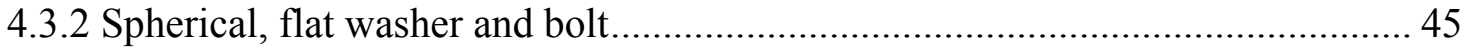

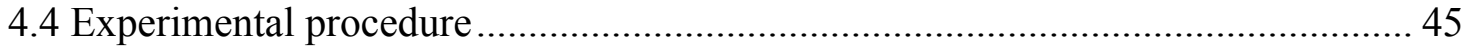

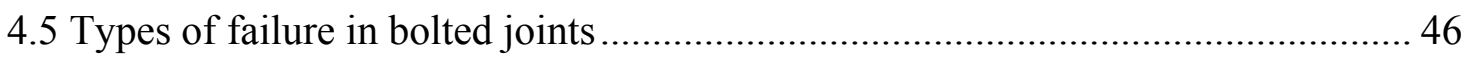

4.6 Equations for bearing and net section strength .............................................. 46

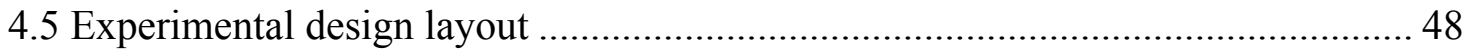

CHAPTER 5-RESULTS AND DISCUSSION FOR BOLTED JOINTS................... 54

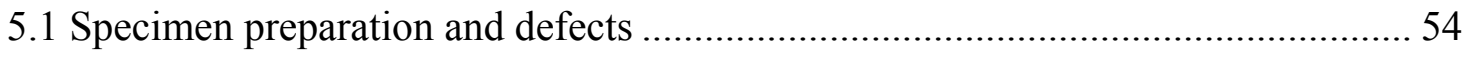

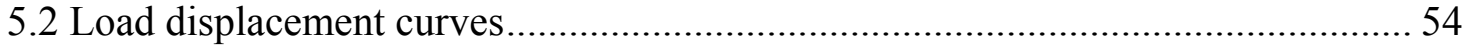

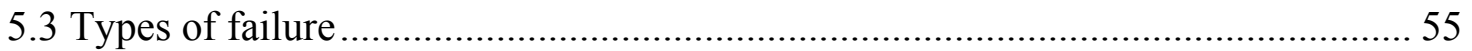

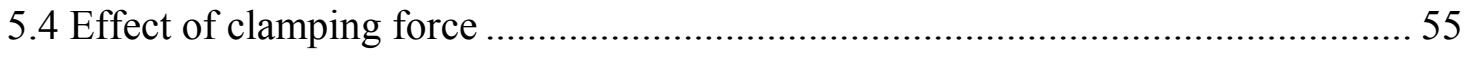

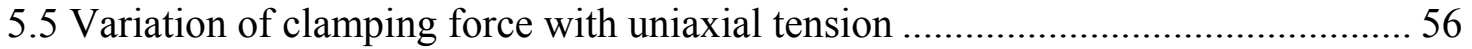

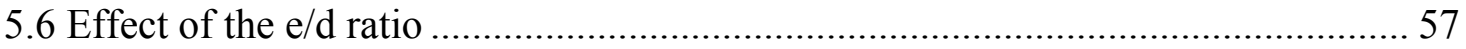

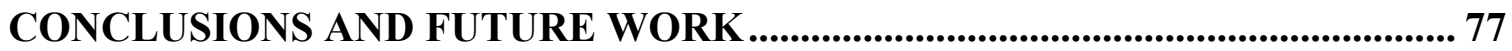

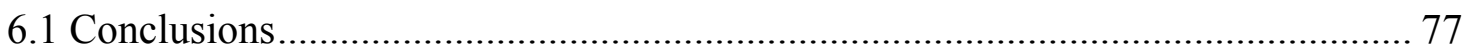

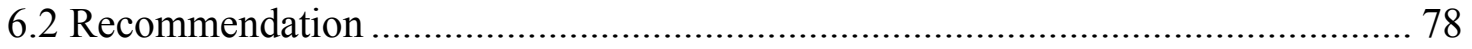

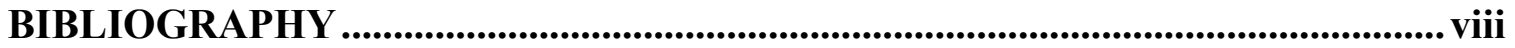

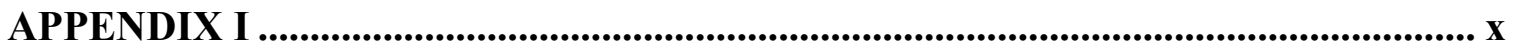

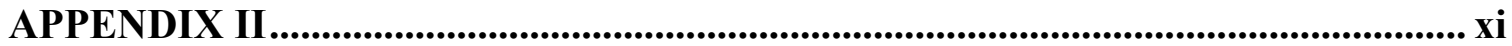

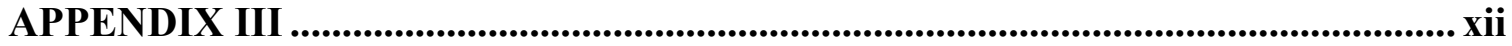

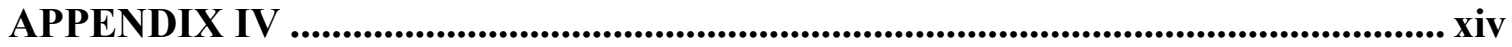

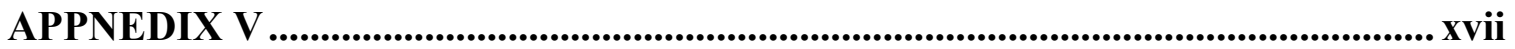

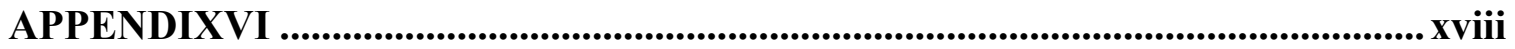




\section{LIST OF FIGURES}

Fig: 1.1 Pressure less infiltration process for producing MMC materials (www.Lanxide.com) 8

Fig: 1.2 Schematic depictions of three types of MMC materials according to type of reinforcement (Clyne \& Withers 1993).....

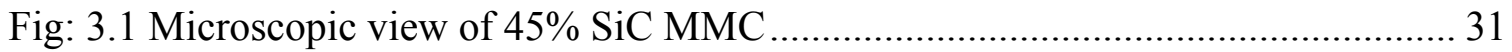

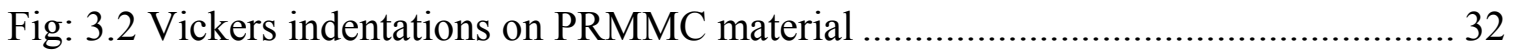

Fig: 3.3 Dimensions of dog-bone specimen for tension testing .................................. 33

Fig: 3.4 Dimensions of rectangular specimen for three-point bending tests ................... 33

Fig: 3.5 Tension testing of $30 \%$ MMC on Instron machine .......................................... 34

Fig: 3.6 Stress-strain curves for aluminum alloy matrix............................................... 35

Fig: 3.7 Stress-strain curves for MMC material with 30\% reinforcement ..................... 35

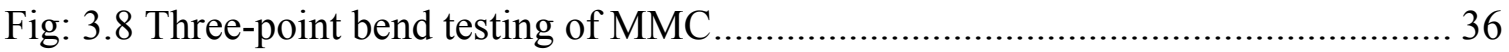

Fig: 3.9 Load deflection curve for three-point bend testing for aluminum alloy matrix . 37

Fig: 3.10 Load deflection curve for three-point bend testing for MMC with 30\%

reinforcement

Fig: 3.11 Load deflection curve for three-point bend testing for MMC with 45\%

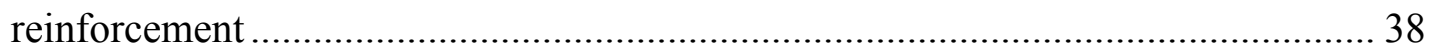

Fig: 3.12 Electro-Discharge Machine (EDM) used for cutting test specimens ............... 39

Fig: 3.13 Specimens cut by using the EDM for measuring coefficient of thermal

expansion

Fig 3.14 Thermo mechanical analyzer used for measuring coefficients of thermal expansion

Fig: 3.15 Change in dimension vs. temperature for aluminum alloy and MMC material 41

Fig: 3.16 Variation of coefficient of thermal expansion with volume fraction of reinforcing particles 42

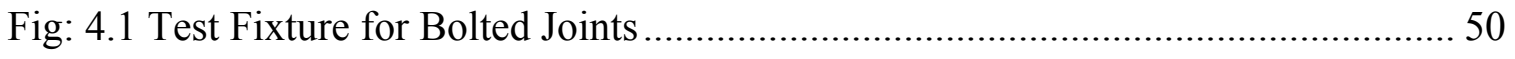

Figure 4.2 Specimen dimensions for bolted joint testing ...................................... 51

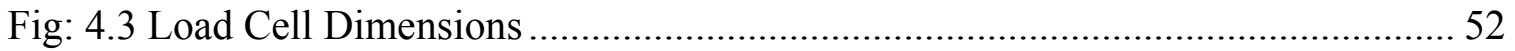

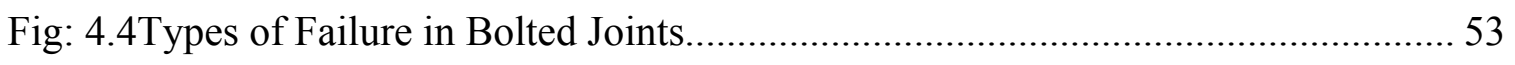

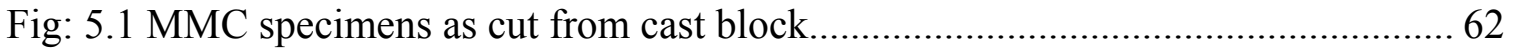


Fig: 5.2 MMC specimens with initial defect in the transverse direction ........................ 63

Fig: 5.3 MMC specimens with defect in the longitudinal direction .............................. 63

Fig: 5.4 Microscopic views of MMC specimens showing region without any $\mathrm{SiC}$ particles

Fig: 5.5 Microscopic views of MMC specimens with Vickers indentation on regions of defect........

Fig: 5.6 Microscopic views of MMC specimens with Vickers indentation on regions with

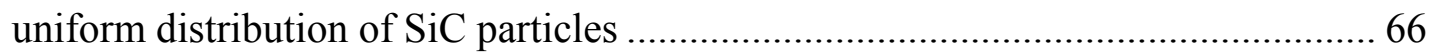

Fig: 5.7 MMC specimens prepared for bolted joint testing ....................................... 67

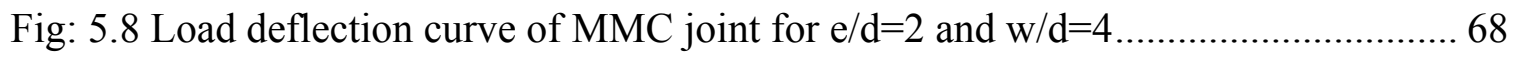

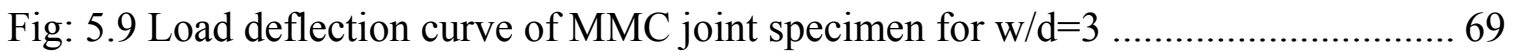

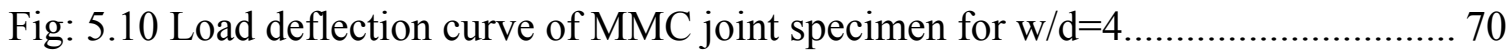

Fig: 5.11 Load deflection curve of MMC joint specimen for different clamping loads for

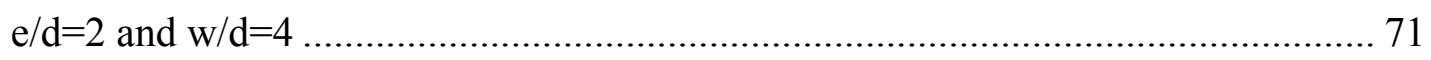

Fig: 5.12 Load deflection curve of aluminum material for $\mathrm{e} / \mathrm{d}=2$ and $\mathrm{w} / \mathrm{d}=4 \ldots \ldots \ldots \ldots \ldots . . . . .72$

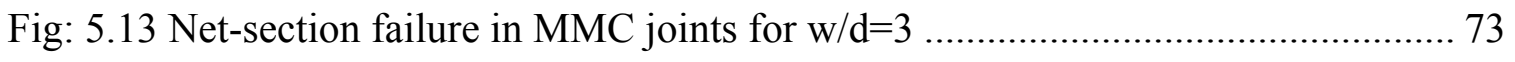

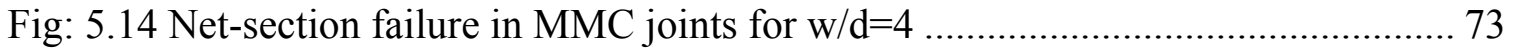

Fig: 5.15 Bearing Failure in Aluminum Joints for $\mathrm{w} / \mathrm{d}=4$....................................... 74

Fig: 5.16 Variation of clamping force with applied tension loading ........................... 75

Fig: 5.17 Variation of net-failure load of MMC joints with the e/d ratio ........................ 76 


\section{LIST OF TABLES}

Table 3.1-Micro hardness test report for (AL-10Si-1Mg (70\%)) alloy ......................... 26

Table 3.2-Micro hardness test report for 30\% MMC ..................................................... 26

Table 3.3-Micro hardness test report for 45\% MMC ................................................ 26

Table 3.4- Flexural strength for three-point bending tests for (AL-10Si-1Mg (70\%)) alloy

Table 3.5-Flexural strength for three-point bending tests for $30 \% \mathrm{SiC} \mathrm{MMC}$ specimens 28

Table 3.6-Flexural strength for three-point bending tests for $45 \% \mathrm{SiC} \mathrm{MMC}$ specimens 28

Table 3.7-Experimental results of CTE with volume fraction of reinforcing particles .... 29

Table 3.8- Comparison of experimental and theoretical results .................................... 30

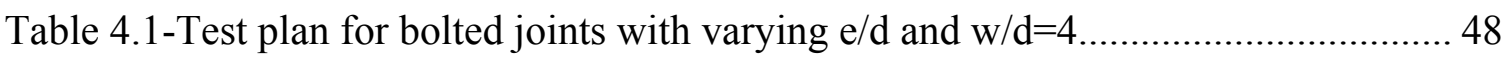

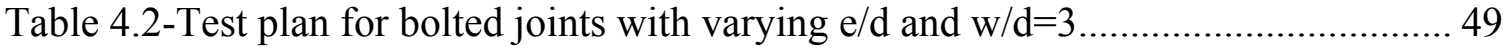

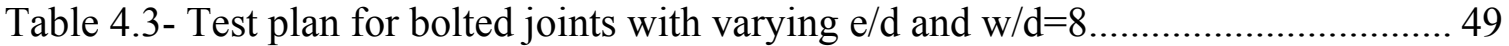

Table 5.1-Variation of the failure load of MMC joint specimens with the e/d for $\mathrm{w} / \mathrm{d}=4.0$

Table 5.2-Variation of the failure load of MMC joint specimens and aluminum joint specimens with $\mathrm{e} / \mathrm{d}$ ratio for $\mathrm{w} / \mathrm{d}=4.0$.

Table 5.3-Variation of the failure load of MMC joint specimens with the e/d ratio for $\mathrm{w} / \mathrm{d}=3.0$

Table 5.4-Variation of the failure load of MMC joint specimens with the e/d ratios for $\mathrm{w} / \mathrm{d}=8.0$ 59

Table 5.5-Variation of the tension failure load of MMC specimens with $\mathrm{w} / \mathrm{d}=1.2 \ldots \ldots . .60$

Table 5.6-Variation of the tension failure load of MMC specimens with $\mathrm{w} / \mathrm{d}=2 \ldots \ldots \ldots . .60$

Table 5.7-Variation of the tension failure load of MMC specimens with $\mathrm{w} / \mathrm{d}=3 \ldots \ldots \ldots . . .61$

Table 5.8-Variation of the tension failure load of MMC specimens with $\mathrm{w} / \mathrm{d}=4 \ldots \ldots \ldots \ldots 61$

Table 5.9-Variation of the tension failure load of MMC specimens with w/d $=5$ 61 


\section{CHAPTER 1 - INTRODUCTION}

\subsection{Background}

The term metal matrix composites (MMC) encompasses a wide range of materials that consist of a metallic alloy reinforced with a ceramic phase in the form of particles, platelets, whiskers, short fibers or continuously aligned fibers. According to the type of reinforcement, MMC's can be broadly classified into continuous MMC, whisker reinforced MMC and particulate reinforced MMC as shown in Fig 1.2 (Clyne \&Withers).

One of the various fabrication processes is depicted in Fig 1.1.Aluminum and its alloy is the most common used material for the matrix due to its low density, ease of processing and possible property improvement as a result of reinforcement (Jain and Bhanuprasad 1993). Silicon carbide is the commonly used reinforcement material because of its high modulus, broad availability and affordable (Jain and Bhanuprasad1993). The main purpose of producing metal matrix composite is to develop lightweight materials with high specific strength and stiffness. These materials possess not only high specific strength and modulii at room temperature but also excellent wear resistance, low coefficient of thermal expansion and good dimensional stability. Discontinuously reinforced metal matrix composites are much easier to fabricate than continuous reinforced composites. Consequently, production of the PRMMC material is possible at lower costs as compared to that of MMC materials with fibers. The PRMMC materials exhibit several other advantages such as.

- Manufacturing processes are less expensive, more consistent and better quality control than those of fiber reinforced MMC's.

- The properties of discontinuous reinforced composites are nearly isotropic, unlike those of composites with continuous aligned reinforcements, which are highly anisotropic. Therefore they can be used for more general purposes (Jain, Bhanuprasad 1993and Park, and Crosky2001).

- They can be produced in large quantities and large sizes, as it is often required in structural applications.

The potential market for such composites is concentrated primarily into three sectors, 
- Aircraft space, defense industries

- Automotive industry

- Sporting goods.

Typical applications for PRMMC materials in these sectors include missile fins for guidance and stability, control equipments, substrates for precision laser mirrors, pistons in diesel engines, brake calipers, bicycle frames and tennis rackets (Tham 1999, Jain1993)

\subsection{Motivation}

The development of metal matrix composites as a replacement for traditional materials in stiffness-dominated applications has been fairly slow. Early specialized applications for sports cars and aerospace industry have not lead to the anticipated expansion into broad commercial markets such as large scale automotive production. Graving applications of MMC materials are nowadays driven by environmental legislation demanding lighter vehicles with reduced level of exhaust emission.

Generally, MMC's exhibit considerable increase in strength and stiffness when compared to the original alloys. However they also display poor ductility and fracture toughness and poor fatigue properties (Tan et al). Parameters related to the reinforcing particle are volume fraction, size, shape and distribution patterns of the particles. The most important parameter is the volume fraction. Lloyd reported that the dominant factor in controlling the elastic modulus is the volume fraction of the particles, whereas the elastic modulus is relatively insensitive to the particle size and distribution (Tham et al 1999). Moreover as the volume fraction of the particle is increased, tensile and yield strength increases while ductility and fracture toughness decreases. The level of thermal residual stresses also depends on the volume fraction. Increasing the volume fraction monotonically increases the thermal residual stresses and also the dislocation densities. As of now no practical information has been published in regard with the bearing strength of PRMMC materials or how such materials will perform in bolted joints. Multiple tests have to be conducted on bolted joints of PRMMC in order to analyze the various modes of failure and various parameters that affect the strength and stiffness of such bolted connections. 


\subsection{Research objective}

The major objective of the research reported in this thesis is the material characterization of PRMMC materials made of 30\%-55\% concentration of silicon carbide particles in an aluminum alloy. Fabrication methods of aluminum matrix composites can be generally divided into solid-state and liquid state processes (Clyne et al). The most widely used method of solid state processing is powder metallurgy. This method yields discontinuous reinforced composites with high mechanical properties. It is suitable for military applications but it is too expensive for large scale production in civilian markets. The liquid state process including semi-solid process is now producing a majority of $\mathrm{MMC}$ materials for commercial applications. The Gravity mold casting, Sand casting and Squeeze casting techniques of liquid state processes have frequently been used as fabrication methods for aluminum matrix composites, but they are not suitable for high productivity in large volume applications. Liquid state process can also be divided into pressure-infiltration processes, where the reinforcement is infiltrated into the matrix metal by pressure applied either by a piston or by an inert gas, and with out infiltration pressure. . PRIMEX CONCENTRATETM feedstock is produced by a novel technology involving the pressure less infiltration of aluminum into a mass of ceramic reinforcement particles. A schematic view of the novel technology for producing MMC is shown in Fig: 1.1 (www.Lanxide.com). Such infiltration is accompanied by the in-situ formation of a unique surface coating on all the reinforcing particles. The coating promotes complete particle wetting and attractive melt flow characteristics, important features for subsequent foundry use. Typical reinforcement levels in the primex concentrate is $40-50 \%$ by volume, with the balance being an aluminum alloy matrix.

The work described in this thesis is focused on PRMMC material produced by pressure less infiltration, especially its mechanical behavior in bolted connections. Various properties of this material such as stiffness, hardness and its microscopic structure have been analyzed first in order to get a better picture of its basic characteristics as compared with conventional aluminum. Microscopical characteristics such as the distribution of the silicon carbide particles, typical patterns of porosity and manufacturing induced cracks, 
which are likely to affect the performance of the material under various testing conditions have been studied and documented before coupon testing.

Tension tests have been conducted according to ASTM standards in order to evaluate the corresponding strength and stiffness properties of the material. The Vickers hardness test was conducted in order to determine the hardness of the material and a thermomechanical analyzer has been utilized to determine the coefficient of thermal expansion of the material. The Young's modulus of the material obtained from experimental results is compared with values obtained form semi-empirical models like Halpin-Tsai and the Rule of Mixtures.

\subsection{Methodology}

This work is focused on mechanical characterization of a particulate metal matrix composite (PRMMC) material consisting of a 30\% silicon carbide concentration of particles in aluminum alloy manufactured by the PRIMEX CAST ${ }^{\mathrm{TM}}$ foundry process. The main results sought by this research were the yield strength and the stiffness of the material as well as their dependence on micro structural parameters like the particle size, shape and distribution along with volume fraction of the particles, which is the dominant factor. The stress stain curves are plotted from the load deflection data obtained by conducting the tension tests. The effect of volume fraction on the Young's modulus of the material is observed. The most commonly used model for predicting the elastic modulus of composites is the Rule of Mixtures. (Jain et al 1993). The iso-strain rule of mixture is based on the assumption of equal strain in the matrix and reinforcement, whereas the iso-stress rule of mixture is based on the assumption of equal stresses in the matrix and the reinforcement. The experimental values are usually lower than those calculated by using the iso-strain rule of mixtures relations and higher than those calculated by using the iso-stress rule of mixtures. However other micro-mechanical models like modified Tsai-Halpin and Hashin-Shtrikman models agree well with the experimental results for particulate reinforced metal matrix composites. Various strengthening models, like shear lag model, or modified shear lag model, were originally developed to predict the composite stiffness while dislocation models like Orowan, forest hardening, elastic peg and punching model were developed originally to analyze the 
hardening mechanism of 2 phase metals. Three-point bending tests were also performed on the PRMMC material in order to evaluate the flexural strength and strain according to ASTM -D790.The Vickers hardness test is conducted on the PRMMC material according to ASTM-E384. The coefficient of thermal expansion is evaluated according to the procedures described in ASTM E-831. A plot of the linear expansion of the material versus the temperature is obtained by using a thermo mechanical analyzer. The experimental results were compared to corresponding values and published data, so that they can be validated. Certain results obtained from the tension test, such as the ultimate strength and the yield strength of the material were used to calculate the bearing strength of the material. Ultimately, an ideal edge distance and bolt spacing ratio have been identified for the test material, which can be utilized for improving bolted joint applications. The effect of the clamping force on the strength of a bolted connection was also investigated. The strain levels at certain locations around the hole were measured for various types of material failures in the joint.

\subsection{Organization of the thesis}

\section{Chapter1-Introduction}

In this chapter the motivation, the research objective and the methodology of the work are presented along with the organization of the thesis. The introduction barely outlines the nature of the work involved and the approach taken to complete the work.

\section{Chapter2-Literature review}

This chapter contains reviews of all the previous work related to particulate reinforced metal matrix composites, which includes both experimental and theoretical. It also discusses the various standards used for testing of the material and also the various theoretical models used and the reasons for using them. An extensive study of bolted joints on steel and aluminum are also made in the literature study. Based on the test conducted on steel and aluminum and based on the empirical equations derived from these test, a study on bolted behavior in PRMMC is conducted. The literature gives us an insight into the various parameters that affect the strength of a bolted connection. 


\section{Chapter3-Mechanical Characterization of PRMMC}

This chapter includes a detailed description of the various testing procedure adopted in order to characterize the material. It also gives a description of the various testing machines used, standards adopted and also a description related to the preparation of the specimens prior to testing. The outputs are obtained in the form of plots, which are to be analyzed. The Young's modulus of the material is determined along with the ultimate strength and yield strength of the material. The experimental values are compared with theoretical models like the Rule of Mixtures and Halpin-Tsai equations to validate the results. Microscopical analysis is done in order to evaluate the distribution of the silicon carbide reinforcement and determine the size of the particles. Tests are also conducted to determine the coefficient of thermal expansion and hardness of the material.

\section{Chapter 4-Experimental Design lay out for testing for bearing strength}

A design for a bolted joint is made and tested according to standards specified for aluminum and steel. Detailed description of problems related to machining of the material and specimen preparation are undergone in this chapter, mentioning the various tools required for such material. A design lay out of experiments required to determine the ideal e/d ratio and w/d ratio are underdone to determine the bearing strength of the material. The various effects of clamping force on the strength of bolted connection along with stresses around the hole are also considered. The various parameters are varied so as to account for all modes of failures as mentioned by Winter and other researchers based on studies on steel and aluminum.

\section{Chapter5-Results and discussion}

The results obtained from testing are analyzed and compared with theoretical values and effect of various parameters on bolted strength connection is considered. An ideal e/d ratio and w/d is determined for the material along with the bearing strength of the material. Different types of modes of failures are analyzed and identified. Bearing strength of the material is determined. Variation of clamping force on bolted joint behavior and effect of clamping force is characterized. 


\section{Chapter6-Conclusions and future work}

This chapter concludes all the work done on the material analyzing the results obtained and recommends new concepts that have to be adopted in order to get better results. Based on the problems encountered during testing, new methods and properties of the materials are recommended. 


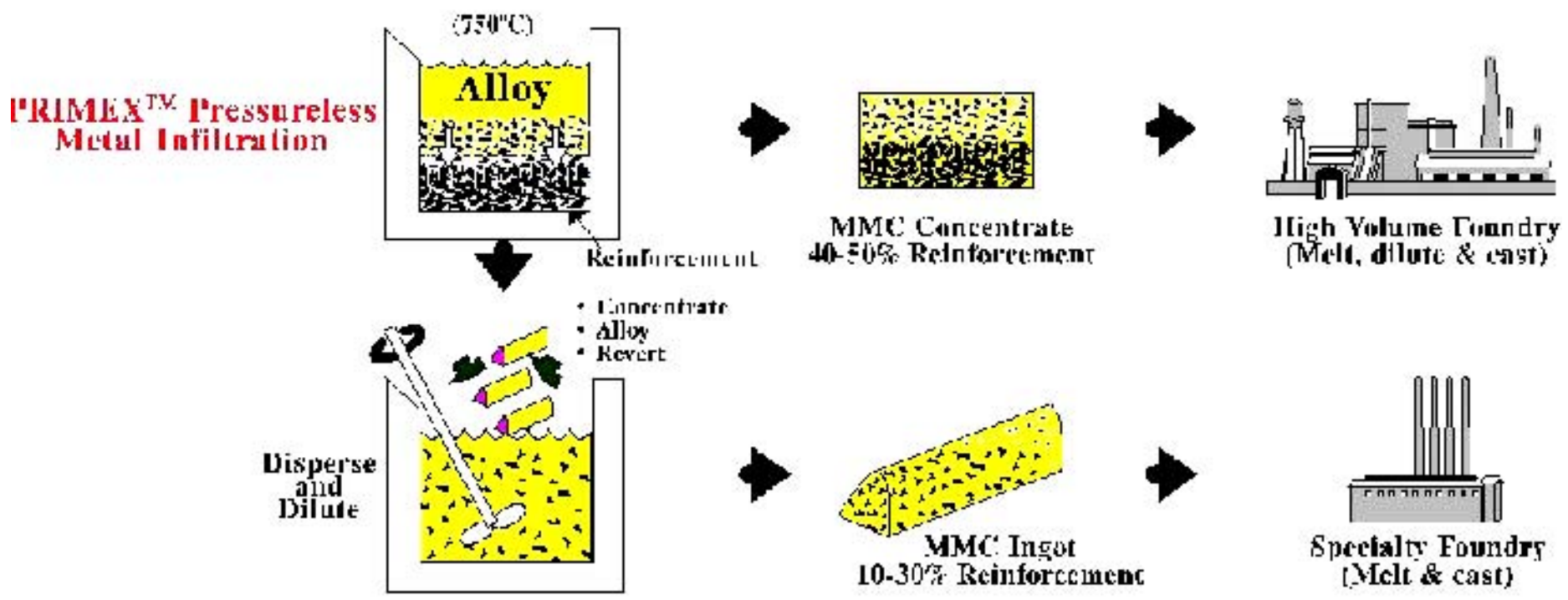

Fig: 1.1 Pressure less infiltration process for producing MMC materials

(www.Lanxide.com) 

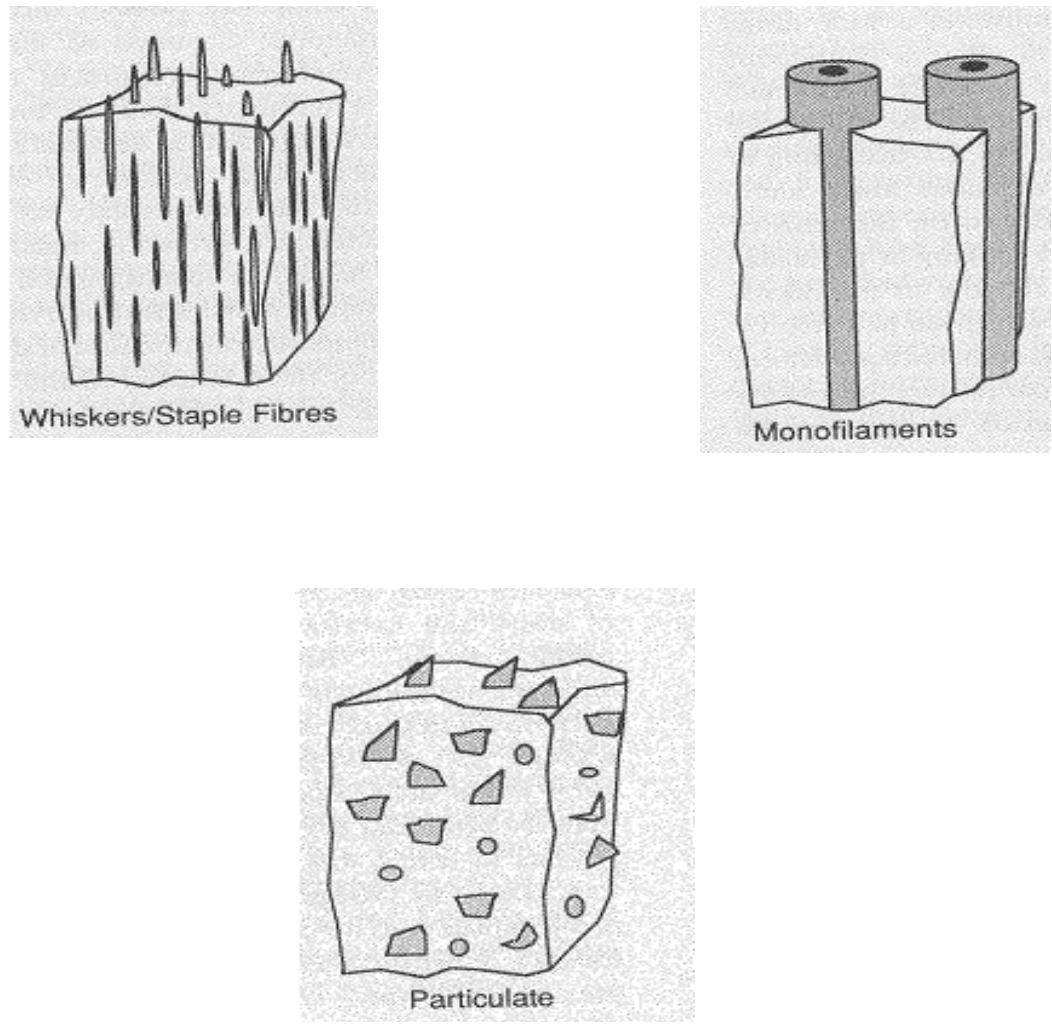

Fig: 1.2 Schematic depictions of three types of MMC materials according to type of reinforcement (Clyne \& Withers 1993) 


\section{CHAPTER 2 - LITERATURE REVIEW}

\subsection{Introduction}

The emergence of metal matrix composites stretch back to the ancient civilization when copper awls were made by repeated lamination and hammering process, which gave rise to high levels of elongated non-metallic inclusions. Among the first composites materials to attract scientific as well as practical attention were dispersion metallic alloys on which extensive research was conducted during the early 1950's. "Metal matrix composites (MMC's) are a diverse class of materials that consist of a metallic alloy material typically reinforced with a ceramic phase in the form of particles, platelets whiskers, short fibers and continuously reinforced fibers" (Clyne and Withers 1993). MMC's are used in structural applications, applications requiring wear-resistance, thermal management and are usually made of titanium alloys or aluminum alloys reinforced with silicon carbide, alumina, carbon or graphite.)

\subsection{Mechanical characterization}

The intrinsic advantage that MMC's have over unreinforced alloy is the improvement of mechanical properties stiffness and strength of the composite material. Various researchers have conducted experiments in order to evaluate the basic material properties of PRMMC's. Most research has been conducted on evaluating the Young's modulus, hardness, ultimate strength and yield point of material for various particle concentration and different methods of manufacturing of the composite material. In addition to this, various models have been formulated in order to explain the stress strain characteristics of metal matrix composites. These models vary from the rule of mixture to the shear lag model, to the modified shear lag model and to the Eshelby's approach.

Yang (Yang et al 1990) performed microscopical analysis and tests on aluminum alloy reinforced with $\mathrm{SiC}$ particles in order to establish trend with variables such as volume fraction size and aspect ratio. The values obtained are compared with finite elements models used to predict the Young's modulus of the composite material. Yang finally concluded that the yield strength and Young's modulus varies highly with the volume fraction of the material. 
Lee (LEE et al 2000) also conducted similar tension tests on PRMMC's and was able to identify a similar increase in strength and Young's modulus of material with increase in volume fraction. However as the volume fraction increase, there is a decrease in ductility and fracture toughness of the material as reported by Park (park et al 2001) . He concluded that the Young's modulus increase as particle volume fraction is increased, but at a progressively decreasing rate. The decrease in rate of stiffening with increasing particle volume fraction is attributed to an increase in the number of fractured particles present in the composite.

Tan (Tan et al 2001) conducted test to investigate the influence of $\mathrm{SiC}$ and alumina particles on the mechanical properties and damage evolution of aluminum alloy Al-2618. His test results showed that $\mathrm{SiC}$ particles reinforcement has advantages over alumina reinforcement in both strength and ductility and finally came to the conclusion that the strength of the composite is decided by the balance between reinforcing particle sharing load and making discontinuity in the load.

Jain (Jain et al 1993) investigated on the influence of $\mathrm{SiC}$ volume fraction on elastic modulus and hardness of material and compared it with theoretical models like rule of mixtures, modified Tsai-Halpin and Hashin-Shrikman models. The shear lag model can be used for short fibers and is based on the principle that the load is transferred from the matrix to the reinforcement by means of interfacial shear stresses. The Eshelbys approach (Clyne\&Withers) is accurate for ellipsoidal inclusions for particulate reinforced composites and it is based on misfit strain that occurs as a result of misfit between the shapes of the constituents (matrix and reinforcement, i.e. fiber, whisker or particle), such a misfit can arise due to temperature or due to mechanical loading of the material. The Eshelby method expresses the stiffness tensor of the composite in terms of the matrix and inclusions. Fractography revealed that as the volume fraction of $\mathrm{SiC}$ particles increases, there is more evidence of defects such as micro voids and secondary cracking which leads to lower ductility for higher volume fractions.

\subsection{Bolted joint testing}

The use of bolts for connecting members is older than iron and steel construction itself. George Winter (Winter 1956) conducted 574 test on bolted connection is light gage steel, 
covering considerable ranges of pertinent variables such as bolt diameter, sheet thickness, mechanical properties of sheet and edge distances. Winter was able to identify four types of failure loads, which are in satisfactory agreement with test values. The series of tests reported by him was intended to provide information for the development of reliable design methods for connection by means of "hand tight" black bolts in light-gage, cold formed construction.

A total number of 574 tests were made, of which 526 tests were on single bolt specimens and 48 on two-bolt specimens (Winter 1956). The following variables were considered for testing; bolt diameter ranging from $1 / 4$ in. to 1 in.; steel thickness ranging from 0.035 in. to 0.1644 in.; edge distance ranging from $1.25 \mathrm{~d}$ to $9.0 \mathrm{~d}$; variation in ratio $\left(\frac{d}{s}\right)$ (where $\mathrm{s}=$ bolt spacing perpendicular to direction of stress, or on single bolts, the full width of sheet); variation in mechanical properties of steel; variation in mechanical properties of bolts; type of connection, i.e. single shear (SS) and double shear (DS).

All tests were conducted on a Baldwin Southward hydraulic testing machine of 400,000 lb. capacity and displacement was measured by a data acquisition system attached to the machine. All bolts were made "hand Tight" and were tightened using a torque wrench and was tightened to two-thirds the twist torques of the bolts. All bolt holes were punched oversize by the following amounts: $1 / 32$ " for $1 / 4$ inch bolts and $3 / 8$ " for $1 / 2$ inch bolts and $1 / 16$ " for all bolts of larger diameter. Four distinct types of failures were observed in his testing.

Type 1: Longitudinal shearing of the sheet along two practically parallel planes whose distance equals the bolt diameter, this type occurred for relatively short edge distance e (Winter 1956). It was noticed that this type of failure occurred for specimens where the e/d ratio did not exceed 3.5 and based on the experimental results it is seen that the test results group in a satisfactory manner around the straight line 


$$
\left(\frac{P_{f}}{\sigma_{y}}\right)=1.40 \mathrm{e} \quad \text { Where }
$$

$\mathrm{P}_{\mathrm{f}}=$ Experimental ultimate load or failure load;

$\sigma_{\mathrm{y}}=$ Yield strength;

$\mathrm{t}=$ Thickness of material;

$\mathrm{e}=$ Edge distance from the center of hole;

2) Type-2: Oblique shear-tearing: This was prominent in case where the $(e / d)$ ratio exceeded 3.5. The failure is that of bearing and it was found that the equation 3.1 was not sufficient to determine the bearing strength and based on the results for $(e / d) \geq 3.5$, the following equation was established. It is seen that, up to $(e / d)=3.5$, the bearing stress ratio increases with e/d ratio and is satisfactorily represented by the straight line

$$
\left(\frac{\sigma_{b}}{\sigma_{y}}\right)=1.4 *\left(\frac{e}{d}\right) \quad \text { Where }
$$

$\sigma_{\mathrm{b}}=$ Bearing strength;

$\sigma_{\mathrm{y}}=$ Yield strength;

And for $\left(\frac{e}{d}\right)>3.5$

$\sigma_{b}=4.9 * \sigma_{y}$

Eq. 2.3 merely sets an upper limit for $\sigma_{b}$,corresponding to $e / d=3.5$ and indicates that for longer edge distances this value failure no longer occurs by simple shearing in planes parallel to the force, but originates in local over stressing in the neighborhood of the bolt and continues progressively in a complex manner. It is also noted that the transition from the one process to the others occurs by no sharp means and has been expressed in the above manner just for the sake of simplicity and easy understanding.

Type-3: Transverse tearing: In conventional steel structures it is accepted procedure to permit the full allowable stress in tension on the net section, on the assumption that the effect of elastic stress concentration at bolt holes is rendered insignificant by plastic stress concentration. However the results of the present test prove complete disregard of stress 
concentration is not warranted in bolted connections in light gage steel connections. Comparative evaluation showed that net section failure correlated better with the tensile strength of the material rather than the yield strength of the material. It is seen that the $\mathrm{d} / \mathrm{s}$ ratio has a decided influence on the failure stress and that within the investigated range this relation is satisfactorily represented as shown below. As seen from Eq. 2.4 the upper limit for net section failure is the tensile strength of the material

$\sigma_{\text {net }}=\left(0.10+3.0 *\left(\frac{d}{s}\right)\right) \sigma_{t} \leq \sigma_{t} \quad$ Where

$\sigma_{\text {net }}=$ Net-section failure strength

$\mathrm{d}=$ Diameter of hole

$\mathrm{s}=$ Hole spacing

Type 4: Bolt shear type: The bolt type shear failure occurs when the design shear limit of the bolt is lower than the bearing strength or shear capacity of the bolted connection. Preliminary investigations show that the strength of connections, which failed in bolts, correlated better with the tensile strength of the material rather than with the yield stress of the bolt material. Winter concluded that all design formulae for the above type of failures can applied to single and double shear connections and to single bolts as well as to multiple bolts arranged in a line either parallel or perpendicular to the force although no investigations were made of the last mentioned type. Fisher and Struik (1974) indicate a similar relationship in terms of the ultimate strength of the component.

Thomas and Bennette (Thomas et al 1981) concluded that the equations provided by Winter in 1956 provide a reasonable lower bound to the test results for 250-grade steel, for the situation where the direction of the bolt force is perpendicular to the end of the member.

Chong and Matlock (Chong and Matlock 1976) conducted similar test as done by Winter (Winter 1956), except with out using any washers in order to compare the strength of the bolted connections with washers to that with out washers. The testing procedure closely followed that of Winter, about 80 tests were conducted among which 23 were bolted with washers to serve as confirmatory test. As reported by Winter four modes of failure were 
observed by Chong and Matlock as well, by varying the edge distances and spacing of the bolts. As expected the dimensionless parameters (e/d) and (d/s), governed the strength of the bolted connections and from the data obtained, the following empirical formulas were derived.

Table 2.1. -Comparison of bolted joints with and with out washers

\begin{tabular}{|c|c|c|}
\hline $\begin{array}{c}\text { Compared item } \\
\text { (1) }\end{array}$ & $\begin{array}{l}\text { Without washer } \\
\text { (2) }\end{array}$ & $\begin{array}{l}\text { With washer } \\
\text { (3) }\end{array}$ \\
\hline $\begin{array}{l}\text { Bearing stress at } \\
\text { failure }\end{array}$ & $\begin{array}{l}\left(\frac{F_{p}}{F_{y}}\right)=1.08\left(\frac{e}{d}\right) \text { for }(e / d \leq 2.5) \\
\left(\frac{F_{p}}{F_{y}}\right)=2.70 \text { for }(e / d \geq 2.5)\end{array}$ & $\begin{array}{l}\left(\frac{F_{p}}{F_{y}}\right)=1.4\left(\frac{e}{d}\right) \text { for }(e / d \leq 3.5) \\
\left(\frac{F_{p}}{F_{y}}\right)=2.70 \text { for }(e / d \geq 2.5)\end{array}$ \\
\hline $\begin{array}{l}\text { Tensile stress or } \\
\text { Net-section } \\
\text { failure }\end{array}$ & $\left.\left(\frac{F_{\text {net }}}{F_{u}}\right)=0.6-0.66(r)+2.92\left(\frac{d}{s}\right) \leq 1\right)$ & $\left(\frac{F_{n e t}}{F_{u}}\right)=1.0-0.9(r)+3 * r\left(\frac{d}{s}\right) \leq 1$ \\
\hline $\begin{array}{l}\text { Allowable shear } \\
\text { stress on bolts }\end{array}$ & $S_{b}=0.6 * S_{t b}$ & $S_{b}=0.6 * S_{t b}$ \\
\hline
\end{tabular}

Based on the experimental results Chong Matlock arrived at the following conclusion 1) The bearing stress at failure $F_{p}$ is independent of bolt arrangement. Testing of one, two, or three bolts of the same kind, fastened either perpendicular to or along the line of action, gave about the same value of $F_{p}$ per bolt

2) Bearing stress depends on e/d ratio as shown in Table 2.1. The maximum bearing stress at failure for bolts with out washer is about $45 \%$ less than those with washer.

3) Tensile stress on the net section at failure is a function of $r, F_{u}$ and $d / s$ as shown in the table. 
Puthi and Flesischer (Puthi et al 1999) conducted a series of tests on 25 bolted connections to check whether the Euro code 3 can also be used to for steel grade S460. The experimental failure loads are compared with those determined from Euro code 3 and the results interpreted. In addition to increasing the data base for steel, the aim of this investigation was to confirm the limiting range of edge distance and bolt spacing for steel grades $\mathrm{S} 235, \mathrm{~S} 355$. The edge distance used was $\mathrm{e}=1.2 \mathrm{~d}$ which is the minimum allowed in EC3. The test series consists of 25 specimens in which only the edge distance e, bolt spacing $\mathrm{p}$ and plate width $(\mathrm{p}+\mathrm{e})$ were varied. The values "e" and " $p$ " are varied not only within the allowable limits of EC3, but also outside them. The tests were carried out using a $1000 \mathrm{KN}$ testing machine, the load deflection curve obtained by using a displacement transducer (LVDT) W 50.

The design bearing resistance according to EC3 is:

$F_{b, R d}=\frac{2.5 \alpha f_{u} d t}{\gamma_{M B}}$ with $\gamma_{M B}=1.25 \quad$ Where

$\mathrm{d}=$ bolt diameter.

The factor $\alpha$ is a form factor, determined as follows

$$
\alpha=\operatorname{Min}\left[\begin{array}{l}
\left(\frac{e}{3 d}\right) \\
\left(\frac{p}{(3 d-0.25)}\right) \\
\left(\frac{F_{u b}}{F_{u}}\right) \\
1
\end{array}\right]
$$


Eq.2.5 is applicable within the limits of $\left(\frac{e}{d}\right) \geq 1.2$ and $\left(\frac{p}{d}\right) \geq 3$. When these are reduced to edge distance $\mathrm{e}=1.2 \mathrm{~d}$ or bolt spacing $2.4 \mathrm{~d}$, the bolt bearing design resistance is reduced to $2 / 3$ times the value in Eq.2.5.

The design ultimate resistance of the net cross section at bolt holes is given in EC3 as:

$$
\mathrm{N}_{\mathrm{u}, \mathrm{Rd}}=0.9 \mathrm{~A}_{\mathrm{net}} \mathrm{f}_{\mathrm{u}} / \gamma_{\mathrm{M} 2} \text { with } \gamma_{\mathrm{M} 2}=1.25
$$

After conducting the experiments on the specimens the committee came to the following major conclusions that EC3 requires a reduction of the design bearing resistance of bolted connections loaded in shear when the edge distance $\mathrm{e}<1.5 \mathrm{~d}$ or bolt spacing $\mathrm{p}<3.0 \mathrm{~d}$. Also it has been found that for $\mathrm{e}=1.2 \mathrm{~d}$ or $\mathrm{p}=2.4 \mathrm{~d}$, the design resistance has to be reduced to $2 / 3$. In addition they also found that, the minimum edge distance and bolt spacing can be reduced to $e=0.9 \mathrm{~d}$ and $\mathrm{p}=1.8 \mathrm{~d}$ as compared to a minimum edge distance and bolt spacing of $1.5 \mathrm{~d}$ and $3.0 \mathrm{~d}$ according to EC3.

Rogers and Hancock (Roger et al 2000) conducted a detailed analysis of the required procedure used to identify the cause of a connection failure. According to them misidentification of failure modes and misuse of data can lead to serious errors in the accuracy and application of design equations. It was concluded that Australian $/ \mathrm{New}$ Zealand (AS/NZS 4600) and American iron and steel institute (AISI 1996 edition, 1997 design standards) cannot be accurately used to predict the failure mode of thin-sheet bolted connections loaded in shear. Typically, net-section failure is predicted when test results reveal that bearing distress in the sheet metal is the controlling mode of failure. Further recommendations are made concerning the current procedure to identify the netsection failure and bearing failure modes. In addition, a detailed discussion is provided of the test data that was used in the development of the AS/NZS 4600 and AISI design equations for net section failure at connections.

An additional mode of failure in bolted connections which was not distinctly defined by Winter (Winter 1956) but has been observed by many other researchers in Winter's work. 
The new failure mode namely block-shear rupture is an entirely separate mode of failure involving a combination of both net section failure and end tear out. Test specimens that have failed by this mode should not be grouped with test specimens that failed either by net section or end tear out. A design procedure that can be used to estimate the ultimate load carrying capacity of a bolted connection that fails by block-shear rupture has been recently approved for inclusion in the AISI specification (1996 edition).End tear out failure is best predicted by equation presented in Euro code 3(design 1996), which also has been recommended by Rogers and Hancock (Roger 1998a, 1998b).

Srivastan and Menzemer (Srivastan et al) evaluated the bearing strength and permanent hole deformations for several commonly used aluminum alloys. The contribution of sheet evaluation and bolt preload on bearing strength were evaluated. In the set of experiments the edge distance "e" to the bolt diameter was set at a large value of four and a lower bound resistance to shear was formulated.

\subsection{Summary}

Based on the literature study conducted above the MMC specimens are tested in order to get their basic properties like Young's modulus and flexural strength. After characterizing the material, a design for testing of MMC's as bolted joint can be developed with varying parameters like e/d, w/d and clamping force. The experimental results can be compared to the values of net-section and bearing strength formulae derived from Euro-code and ANSI code. 


\section{CHAPTER 3 - CHARACTERIZATION OF PARTICULATE METAL MATRIX COMPOSITE MATERIALS}

\subsection{Experimental set-ups and procedures}

Particulate reinforced metal matrix composites (PRMMC'S) are a class of materials with a strong potential for applications in the automotive and aerospace industries. The major objective of the work is to characterize a new composite material whose basic composition is $30 \%-55 \%$ particles of silicon carbide $(\mathrm{SiC})$ reinforcement in aluminum alloy (AL-10Si-1Mg (70\%)). Standard tension tests have been conducted on this material in order to measure its Young's modulus and ultimate strength Tests were also conducted to determine the coefficient of thermal expansion. The microscopic structure of selected specimen has been analyzed in order to determine the distribution of the SiC particles within the matrix, the particle size and possible defects within the matrix.

\subsubsection{Microscopic analysis}

Microscopic analysis of selected specimens of the above cast composite material was performed by optical microscopy (Appendix I). An Image analyzer was used to examine the distribution of the $\mathrm{SiC}$ particles within the aluminum matrix. The strength and mechanical properties of any particle reinforced metal matrix composites (PRMMC'S) will depend on the particle distribution, particle size, particle flaws, surface irregularities, and particle- matrix bonding which to a large extend depends on the type of manufacturing process. It is therefore, necessary to conduct a microscopic analysis on the new material in order to gain better understanding of its micro structural characteristics. The microscopic analysis provides us information regarding the arrangement of the $\mathrm{SiC}$ particles within the aluminum matrix, the size of the particles and their aspect ratios, which are likely to influence the Young's modulus of the material.

The specimen to be observed under the microscope is placed on a mold and allowed to set for some time. The mold is then polished on various grits of sand paper and finally with alumina solution according to standard procedures and is then viewed under an optical microscope. The size of the silicon carbide particles is then determined by using 
vision gage software, following the placing of the specimen under an optical microscope. Fig 3.1 displays the microscopic structure of the particulate composite material for $45 \%$ $\mathrm{SiC}$ volume fraction.

\subsubsection{Hardness testing}

Vickers hardness test was conducted on the PRMMC specimen and aluminum and the HV (Vickers hardness) of the composite material was compared with that of the alloy. The indenter employed in the Vickers test was a square-based pyramid whose opposite sides meet at an apex angle of 136 degree. A typical indent on a PRMMC material is displayed in Fig-3.2.According to ASTM E384 (Vol. 03.01), standard test method for micro hardness of materials, several critical steps must be followed in such testing to obtain the correct hardness of the material. The testing machine must be carefully prepared making to ensure that there is no rocking or lateral movement of the indenter or the specimen while the load is being applied. The indenter should contact the specimen gradually at a velocity within the range of $15-70 \mu \mathrm{m} / \mathrm{s}$. The time of application of the full test load should be 10-15 seconds unless otherwise specified (ASTM E834). Prior to the measurement, the indenter should be examined for symmetry. If one leg of the diagonal is noticeably longer than the other leg of the same diagonal, resulting in deformed indentation, misalignment is probably present and should be rectified. Before conducting the test, calibration of the test machine must be conducted by using standardized hardness test blocks. About five indentations must be made on the material by using the diamond indenter and placed under an optical microscope to measure the diagonal length of the indent. The Vickers hardness number HV was calculated by using the following formulae
H.V $=1.8544\left(\mathrm{P} / \mathrm{d}^{2}\right)$;
Where
$\mathrm{P}=$ Force in kilogram - Force;
$\mathrm{d}^{2}=$ Area of indentation; 


\subsubsection{Tension testing}

Particulate reinforced MMC'S are comparable to any isotropic material and so the (ASTM E8M) standards for metal testing can be directly used for testing these materials. Dog bone specimens are cut from blocks of the cast material and machined to dimensions specified by the ASTM standards. Dog bone specimens are also made from the original aluminum alloy used as matrix in order to measure its modulus and ultimate strength and compare the results with those obtained for MMC' material.

\subsubsection{Experiments setup}

Tension tests were conducted dog-bone specimens of the PRMMC materials according to the procedures outlined in ASTM-E8M. The dimensions of the dog-bone specimen are as shown in Fig-3.3. The Young's modulus of the material and its ultimate strength were determined through these tension experiments. All the dimensions are measured to the nearest 0.001 -inch by using vernier calipers. The tests were carried out on a hydraulic served Instron machine equipped with digital data acquisition hardware and software. The Instron machine has a total load capacity of $10000 \mathrm{lbs}$. The specimens were clamped in the machine using hydraulic wedge grips as shown in Fig-3.5. These wedge grips facilitates the achievement of uniform pressure distribution on top and bottom part of specimen, while the clamping load tightens as uniaxial load is applied. Strain is measured using an extensometer attached to the center of the dog-bone specimen (Appendix II) Special care was taken to check for alignment of the specimen during the loading, since any possible misalignment can lead to eccentricity of loading and thus yield inaccurate test values. Specimens in which the ultimate failure occurred at a distance less than $2 \mathrm{w}$ from the neck-section of the dog-bone specimen ( $\mathrm{w}=$ width of specimen), have been disregarded, since such failure is not representative of the true properties of the material. The strain is measured using an extensometer, which is attached to the center of the specimen. The load is applied under a constant displacement rate of $0.05 \mathrm{strain} / \mathrm{sec}$ until failure occurs. The Young's modulus of the material is determined from a data acquisition system which is attached to the testing machine. All the results obtained for the PRMMC material were compared with those of corresponding matrix alloy. 


\subsubsection{Theoretical model for predicting the Young's modulus}

Different models have been proposed for predicting the elastic modulus of MMC material and all of them are based on the assumption that the bond between the matrix and the particles is perfect. The Simple models like Rule of Mixtures or Inverse Rule of Mixtures, which is appropriate to predict the Young's modulus of fiber, reinforced composite materials cannot be used in the case of PRMMC materials since they yield only a upper bound or a lower bound. However the modified Halpin_Tsai equations, can predict accurately the Young's modulus for PRMMC materials with low reinforcement volume ratios. The Halpin-Tsai Equation is given by

$E_{2}=E_{m}\left[\frac{1+\zeta \eta V_{f}}{1-\eta V_{f}}\right]$

where;

$\eta=\frac{\left(E_{f} / E_{m}\right)-1}{\left(E_{f} / E_{m}\right)+\zeta}$

$\mathrm{E}_{2}=$ Elastic modulus of material;

$\mathrm{E}_{\mathrm{m}}=$ Elastic modulus of matrix;

$E_{\mathrm{f}}=$ Elastic modulus of fiber'

$\zeta=$ Aspect ratio (1 for particulates);

$\mathrm{V}_{\mathrm{f}}=$ Volume fraction of particulates;

\subsubsection{Problems encountered}

In tension testing of PRMMC specimens, due to the highly brittle nature of the material it was very difficult to obtain a proper fracture at the center of the dog bone specimen. Most of the fracture lines occurred at distances less than $2 \mathrm{w}$ from the neck-section of the dogbone specimen. Consequently the ultimate failure values obtained from these tests may not be not representative of the actual material properties of the PRMMC material. Slight misalignment can also lead to improper fracture; however care was taken to avoid any misalignment by using special wedge grips while testing the tension specimen. Due to the 
brittle nature of the PRMMC material, three point-bending tests are likely to provide more reliable results than tension results, as the fracture is likely to occur more towards the center of the specimens, and away from the boundaries.

\subsubsection{Test set-up for three-point bending}

Three point bending tests were conducted metal matrix composite samples according to the standard procedures outlined in ASTM -D790. The dimensions of the test specimens are shown in Fig- 3.4. Three samples were tested in order to measure the flexural stress to failure and elastic modulus of the material in the longitudinal direction. The tests were carried with a hydraulic Instron machine. The digital acquisition system recorded the time-history of the mid-span deflection values and the load applied on the specimen. The test was carried out on a hydraulic served Instron machine with the data acquisition capturing the displacement and load taken by the specimen. Fig-3.8 shows the three-point bending fixture for testing of metal matrix composite. From the ultimate failure load and flexural strain obtained, we can determine the flexural strength of the material. The loading is done at a rate of $0.1 \mathrm{inch} / \mathrm{min}$ as specified by ASTM standards.

\section{Flexural stress at break:}

$\sigma=3 P L / 2 b d^{2} \quad$ Where;

$\sigma=$ Longitudinal stress at midpoint of span, on bottom or top surface

$\mathrm{P}=\mathrm{Load}$ at a given point on the load deflection curve (lb);

$\mathrm{L}=$ support span (in);

$\mathrm{b}=$ width of beam tested (in);

$\mathrm{d}=$ depth of beam tested (in);

\section{Flexural strain:}

$\varepsilon_{f}=\frac{6 D d}{L^{2}} \quad$ Where;

$\varepsilon_{f}=$ Strain in the outer surface at mid-point location (in/in); 
$\mathrm{D}=$ maximum deflection of the center of the beam (in);

$\mathrm{L}=$ support Span (in);

$\mathrm{d}=$ depth of beam tested (in);

\section{Young's modulus}

$E_{b}=\frac{L^{3} m}{4 b d^{3}}$

Where;

$E_{b}=$ Young's modulus of material;

$\mathrm{m}=$ Slope of load deflection curve;

$\mathrm{b}=$ width of beam tested (in);

$\mathrm{d}=$ depth of beam tested (in);

\subsubsection{Experimental set-up for determining coefficients of thermal expansion}

The coefficient of thermal expansion of the material is determined according to the ASTM E83-93 standard. The experimental setup used for this purpose is based on a thermo- mechanical analyzer as shown in Fig 3.14. The technical details of the setup are as shown below.

Sample size: Diameter or side $2 \mathrm{~mm}$, thickness $2 \mathrm{~mm}$, and maximum mass $200 \mathrm{mg}$.

Temperature range: Room temperature to 200 degree centigrade

Heating rates: For aluminum the heating rate is 20 degree centigrade for a min

Crucibles: Aluminum oxide and platinum

Resistance: Heating: Indirect

Atmosphere: Inert gas (argon, nitrogen, helium) or air.

The data can be collected at a sampling rate of 2.0 seconds per point, with the temperature increasing at a rate of 10 degree centigrade per minute. The temperature can be increased from room temperature to a maximum of 1000 degree centigrade. The test specimens are very small and cannot be machined by using ordinary cutting tools. Consequently, non-conventional machining processes, such as electro discharge machining (EDM), is used to cut these specimens out of cast blocks of MMC material. The EDM can be used also to cut the specimens to desired sizes, with a fine finish despite 
lower electric conductivity of the material in the presence of silicon carbide particles. A photo of the EDM is shown in Fig-3.12 where as test specimens cut by using EDM for measuring the coefficient of thermal expansion are shown in Fig-3.13.

\subsection{Results and discussion}

\subsubsection{Vickers's hardness}

Tables 3.1, $3.2 \& 3.3$ displays the HV value of aluminum alloy without the particle reinforcement as well as with $30 \%$ and $45 \%$ reinforcement of $\mathrm{SiC}$ particles. As one may expect, the H.V values representing the hardness of the material increase with the volume fraction of $\mathrm{SiC}$ particles. The Vickers hardness of the aluminum alloy is 53.304, whereas for $30 \% \& 45 \%$ MMC materials are 80.7121 and 90.092 , respectively. The increase in $\mathrm{H} . \mathrm{V}$ hardness is due to the higher hardness value of the $\mathrm{SiC}$ particle in the aluminum alloy. Most of the literature (Manoj et al) also shows an increase of $6 \%$ hardness value for an increase in 5-30\% increase in volume fraction of reinforcing particles. Further increase in volume fraction beyond $45 \%$ does not show an increase in hardness values. 
Table 3.1-Micro hardness test report for (AL-10Si-1Mg (70\%)) alloy

\begin{tabular}{|c|c|c|c|c|c|c|c|}
\hline No & $\begin{array}{l}\text { Load } \\
\text { (kg-f) }\end{array}$ & $\mathrm{d} 1(\mathrm{~mm})$ & $\mathrm{d} 2(\mathrm{~mm})$ & Mean d $(\mathrm{mm})$ & $\begin{array}{l}\text { Hardness Value } \\
(\mathrm{H} . \mathrm{V})\end{array}$ & $\begin{array}{l}\text { Average } \\
\text { Hardness } \\
\text { Value }\end{array}$ & $\begin{array}{l}\text { Standard } \\
\text { deviation }\end{array}$ \\
\hline 1 & 1 & 0.164 & 0.183 & 0.174 & 61 & \multirow{5}{*}{61} & \multirow{5}{*}{2.08} \\
\hline 2 & 1 & 0.172 & 0.180 & 0.176 & 60 & & \\
\hline 3 & 1 & 0.175 & 0.180 & 0.177 & 59 & & \\
\hline 4 & 1 & 0.170 & 0.175 & 0.173 & 62 & & \\
\hline 5 & 1 & 0.175 & 0.167 & 0.171 & 63 & & \\
\hline
\end{tabular}

Table 3.2-Micro hardness test report for 30\% MMC

\begin{tabular}{|c|c|c|c|c|c|c|c|}
\hline No & $\begin{array}{l}\text { Load } \\
\text { (kg-f) }\end{array}$ & $\mathrm{d} 1$ (mm) & $\mathrm{d} 2(\mathrm{~mm})$ & Mean d (mm) & $\begin{array}{l}\text { Hardness Value } \\
(\mathrm{H} . \mathrm{V})\end{array}$ & $\begin{array}{l}\text { Average } \\
\text { Hardness } \\
\text { Value }\end{array}$ & $\begin{array}{l}\text { Standard } \\
\text { deviation }\end{array}$ \\
\hline 1 & 1 & 0.131 & 0.129 & 0.130 & 109 & \multirow{5}{*}{106} & \multirow{5}{*}{5.54} \\
\hline 2 & 1 & 0.131 & 0.133 & 0.132 & 106 & & \\
\hline 3 & 1 & 0.135 & 0.136 & 0.135 & 101 & & \\
\hline 5 & 1 & 0.135 & 0.136 & 0.135 & 101 & & \\
\hline 5 & 1 & 0.130 & 0.128 & 0.129 & 111 & & \\
\hline
\end{tabular}

Table 3.3-Micro hardness test report for 45\% MMC

\begin{tabular}{|c|c|c|c|c|c|c|c|}
\hline No & $\begin{array}{l}\text { Load } \\
\text { (kg-f) }\end{array}$ & $\mathrm{d} 1$ (mm) & $\mathrm{d} 2(\mathrm{~mm})$ & Mean d (mm) & $\begin{array}{l}\text { Hardness Value } \\
(\mathrm{H} . \mathrm{V})\end{array}$ & $\begin{array}{l}\text { Average } \\
\text { Hardness } \\
\text { Value }\end{array}$ & $\begin{array}{l}\text { Standard } \\
\text { deviation }\end{array}$ \\
\hline 1 & 1 & 0.128 & 0.114 & 0.121 & 127 & \multirow{5}{*}{126} & \multirow{5}{*}{1.76} \\
\hline 2 & 1 & 0.125 & 0.117 & 0.124 & 125 & & \\
\hline 3 & 1 & 0.127 & 0.117 & 0.122 & 124 & & \\
\hline 4 & 1 & 0.127 & 0.115 & 0.123 & 126 & & \\
\hline 5 & 1 & 0.129 & 0.116 & 0.122 & 124 & & \\
\hline
\end{tabular}




\subsubsection{Young's modulus, flexural strength and strain}

Figs-3.6 and 3.7 display the stress-strain curve at failure for matrix alloy and $30 \%$ reinforced MMC. These plots indicate that the matrix alloy yields before breaking, while the MMC specimen's fail suddenly. The elastic modulus of the material has also been found to increase with the increase in $\mathrm{SiC}$ reinforcement. The reduced ductility can be attributed to the presence of $\mathrm{SiC}$ particles within the matrix. The percentage strain to failure for $30 \% \mathrm{MMC}$ is 0.5 while that for the matrix alloy is almost 2. The Young's modulus of the matrix alloy is $11.146 \mathrm{Msi}$ while that of the $30 \% \mathrm{SiC}$ and $45 \% \mathrm{SiC} \mathrm{MMC}$ materials are 15.31 Msi and 18.30 Msi respectively. Tables 3.4, 3.5 and 3.6 present the average flexural strength values of the matrix alloy, the $30 \%$ reinforced $\mathrm{SiC} \mathrm{MMC}$ and the $45 \%$ reinforced MMC. The flexural strength of the matrix alloy is $31.79 \mathrm{Ksi}$ while that of the $30 \% \mathrm{SiC}$ and the $45 \% \mathrm{SiC}$ MMC materials are $38.18 \mathrm{Ksi}$ and $45.50 \mathrm{Ksi}$. The flexural strains for matrix alloy is found to be high as compared to that of $30 \%$ and $45 \%$ reinforced MMC, which shows the reduced ductility of the PRMMC. These results tally very well with the Young's modulus calculated using the Tsai-Halpin equation, assuming an aspect ratio of 1 for the $\mathrm{SiC}$ particles.

Table 3.4- Flexural strength for three-point bending tests for (AL-10Si-1Mg (70\%)) alloy

\begin{tabular}{|c|c|c|c|c|c|c|c|}
\hline No: & $\begin{array}{l}\text { Load to } \\
\text { failure } \\
\text { (lbs) }\end{array}$ & $\begin{array}{l}\text { Flexural } \\
\text { strength at } \\
\text { failure } \\
\text { (Ksi) }\end{array}$ & $\begin{array}{l}\text { Flexural } \\
\text { strain at } \\
\text { failure }\end{array}$ & $\begin{array}{l}\text { Young's } \\
\text { modulus } \\
\text { (Msi) }\end{array}$ & \multirow{4}{*}{$\begin{array}{l}\text { Average } \\
\text { flexural } \\
\text { strength } \\
\text { (Ksi) } \\
31.79\end{array}$} & \multirow{2}{*}{$\begin{array}{l}\text { Average } \\
\text { flexural } \\
\text { strain } \\
\\
0.020\end{array}$} & \multirow[t]{2}{*}{$\begin{array}{l}\text { Average } \\
\text { Young's } \\
\text { modulus } \\
(\mathrm{Ksi}) \\
11.15\end{array}$} \\
\hline 1 & 74.286 & 31.70 & 0.020 & 12.71 & & & \\
\hline 2 & 67.024 & 28.59 & 0.014 & 8.59 & & & \\
\hline 3 & 82.254 & 35.10 & 0.027 & 12.13 & & & \\
\hline
\end{tabular}


Table 3.5-Flexural strength for three-point bending tests for $30 \% \mathrm{SiC}$ MMC specimens

\begin{tabular}{|c|c|c|c|c|c|c|c|}
\hline No: & $\begin{array}{l}\text { Load to } \\
\text { failure } \\
\text { (lbs) }\end{array}$ & $\begin{array}{l}\text { Flexural } \\
\text { strength } \\
\text { at failure } \\
\text { (Ksi) }\end{array}$ & $\begin{array}{l}\text { Flexural } \\
\text { strain at } \\
\text { failure }\end{array}$ & $\begin{array}{l}\text { Young's } \\
\text { modulus } \\
\text { (Msi) }\end{array}$ & $\begin{array}{l}\text { Average } \\
\text { flexural } \\
\text { strength } \\
\text { (Ksi) }\end{array}$ & $\begin{array}{l}\text { Average } \\
\text { flexural } \\
\text { strain }\end{array}$ & $\begin{array}{l}\text { Average } \\
\text { Young's } \\
\text { modulus }\end{array}$ \\
\hline 1 & 190.41 & 41.26 & 0.0060 & 15.78 & \multirow{3}{*}{38.18} & \multirow{3}{*}{0.005} & \multirow{3}{*}{15.31} \\
\hline 2 & 172.26 & 37.47 & 0.0049 & 15.45 & & & \\
\hline 3 & 157.40 & 35.80 & 0.0042 & 14.70 & & & \\
\hline
\end{tabular}

Table 3.6-Flexural strength for three-point bending tests for 45\% SiC MMC specimens

\begin{tabular}{|c|c|c|c|c|c|c|c|}
\hline No & $\begin{array}{l}\text { Load to } \\
\text { failure } \\
\text { (lbs) }\end{array}$ & $\begin{array}{l}\text { Flexural } \\
\text { strength } \\
\text { at failure } \\
\text { (Ksi) }\end{array}$ & $\begin{array}{l}\text { Flexural } \\
\text { strain at } \\
\text { failure }\end{array}$ & $\begin{array}{l}\text { Young's } \\
\text { modulus } \\
(\mathrm{Msi})\end{array}$ & \multirow{4}{*}{$\begin{array}{l}\text { Average } \\
\text { flexural } \\
\text { strength } \\
\text { (Ksi) } \\
45.50\end{array}$} & \multirow{3}{*}{$\begin{array}{l}\text { Average } \\
\text { flexural } \\
\text { strain } \\
\\
0.0025\end{array}$} & \multirow{3}{*}{$\begin{array}{l}\text { Average } \\
\text { Young's } \\
\text { modulus } \\
\\
18.30\end{array}$} \\
\hline 1 & 182.68 & 43.140 & 0.0024 & 18.33 & & & \\
\hline 2 & 194.85 & 46.187 & 0.0026 & 18.46 & & & \\
\hline 3 & 198.78 & 47.117 & 0.0027 & 18.12 & & & \\
\hline
\end{tabular}

\subsubsection{Coefficient of thermal expansion}

The coefficient of thermal expansion has also been calculated for the matrix alloy and the $\mathrm{SiC}$ reinforced MMC's up to a maximum temperature of $200^{\circ} \mathrm{C}$ as suggested by the manufacturer's (Appendix $V$ ). All the graphs show that the variation of dimension to temperature change is linear. Fig 3.15 show the linear variation of the change in dimension with temperature change for $\mathrm{Al}$ alloy matrix, 30\% and $45 \% \mathrm{SiC} \mathrm{MMC}$ material. It can be easily inferred that the conductivity of the material decreases with increase in $\mathrm{SiC}$ volume fraction at the same time maintaining the thermal stability of the material. The values of coefficient of thermal expansion values are obtained directly from the data acquisition system of the Thermo-mechanical analyzer. The coefficient of thermal expansion values for aluminum alloy and MMC material has been shown in 
Table 3.7. Fig-3.18 shows the variation of the coefficient of thermal expansion with varying volume fractions of the reinforcing particles of the PRMMC material.

Table 3.7-Experimental results of CTE with volume fraction of reinforcing particles

\begin{tabular}{|l|l|}
\hline Material type & Coefficient of thermal expansion \\
\hline Matrix alloy & $22.3 \mu \mathrm{m} / \mathrm{m}^{\circ} \mathrm{C}$ \\
\hline $\begin{array}{l}30 \% \\
\text { reinforced }\end{array}$ & $17.8 \mu \mathrm{m} / \mathrm{m}^{\circ} \mathrm{C}$ \\
MMC & \\
\hline $\begin{array}{l}45 \% \\
\text { reinforced } \\
\text { MMC }\end{array}$ & $11.9 \mu \mathrm{m} / \mathrm{m}^{\circ} \mathrm{C}$ \\
\hline
\end{tabular}

\subsection{Conclusions}

Based on the experimental tests conducted on the matrix alloy and on the $\mathrm{SiC}$ reinforced MMC specimens, the following conclusions can be drawn. The results obtained are shown in Table 3.8 .

1) Increased hardness of the reinforced $M M C$ as compared to the original matrix due to $\mathrm{SiC}$ reinforcement.

2) Increase in Young's modulus and flexural strength as compared to matrix alloy.

3) Decrease in coefficient of Thermal expansion due to low conductivity of $\mathrm{SiC}$ particles.

4) Low ductility of MMC as compared to matrix alloy. 
Table 3.8- Comparison of experimental and theoretical results

\begin{tabular}{|l|l|l|l|l|}
\hline Material type & $\begin{array}{l}\text { Experimental } \\
\text { Young's } \\
\text { modulus } \\
\text { (Msi) }\end{array}$ & $\begin{array}{l}\text { Theoretical } \\
\text { Young's } \\
\text { modulus } \\
\text { (Msi) }\end{array}$ & $\begin{array}{l}\text { Flexural } \\
\text { strength } \\
\text { Ksi) }\end{array}$ & Ductility \\
\hline Matrix alloy & 11.146 & 11.146 & 31.79 & 2.012 \\
\hline $30 \%$ MMC & 15.31 & 15.97 & 38.179 & 0.509 \\
\hline $45 \%$ MMC & 18.30 & 20.13 & 45.499 & 0.269 \\
\hline
\end{tabular}

These results obtained can be compared to the values provided by the Lanxide Corporation for $30 \%$ reinforcement of $\mathrm{SiC}$ particles. The experimental results obtained by us tally very well with the company results which is shown in Appendix V. The experimental results obtained by testing are also compared with Al-MMC materials produced by other fabrication methods (Appendix VI).For all fabrication methods a similar increase in Young's modulus, tensile strength and hardness with increasing volume fraction of $\mathrm{SiC}$ particles can be noticed. Similarly the coefficient of thermal expansion decreases for increasing volume fraction of reinforcing particles. 

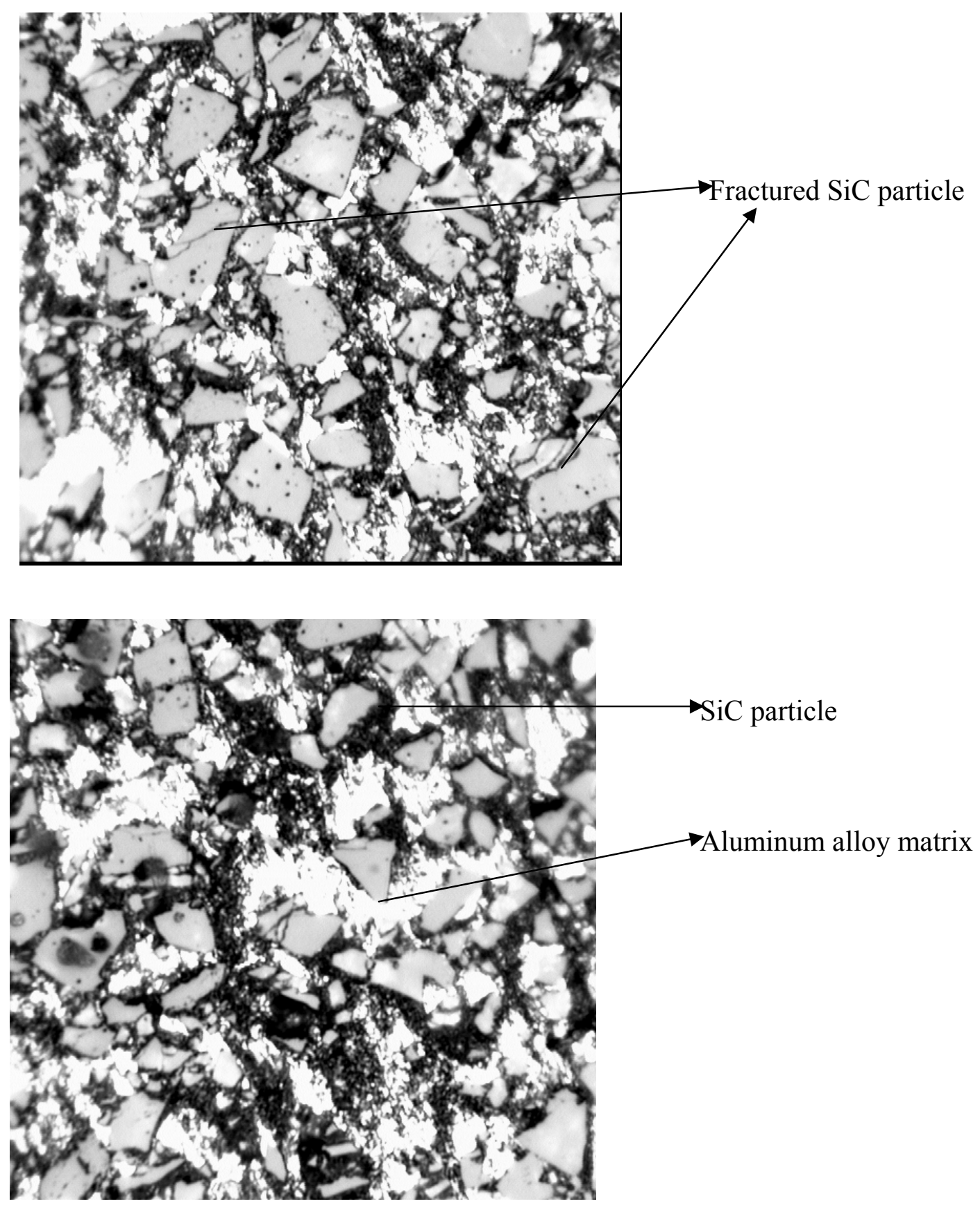

Fig: 3.1 Microscopic view of $45 \% \mathrm{SiC} \mathrm{MMC}$ 


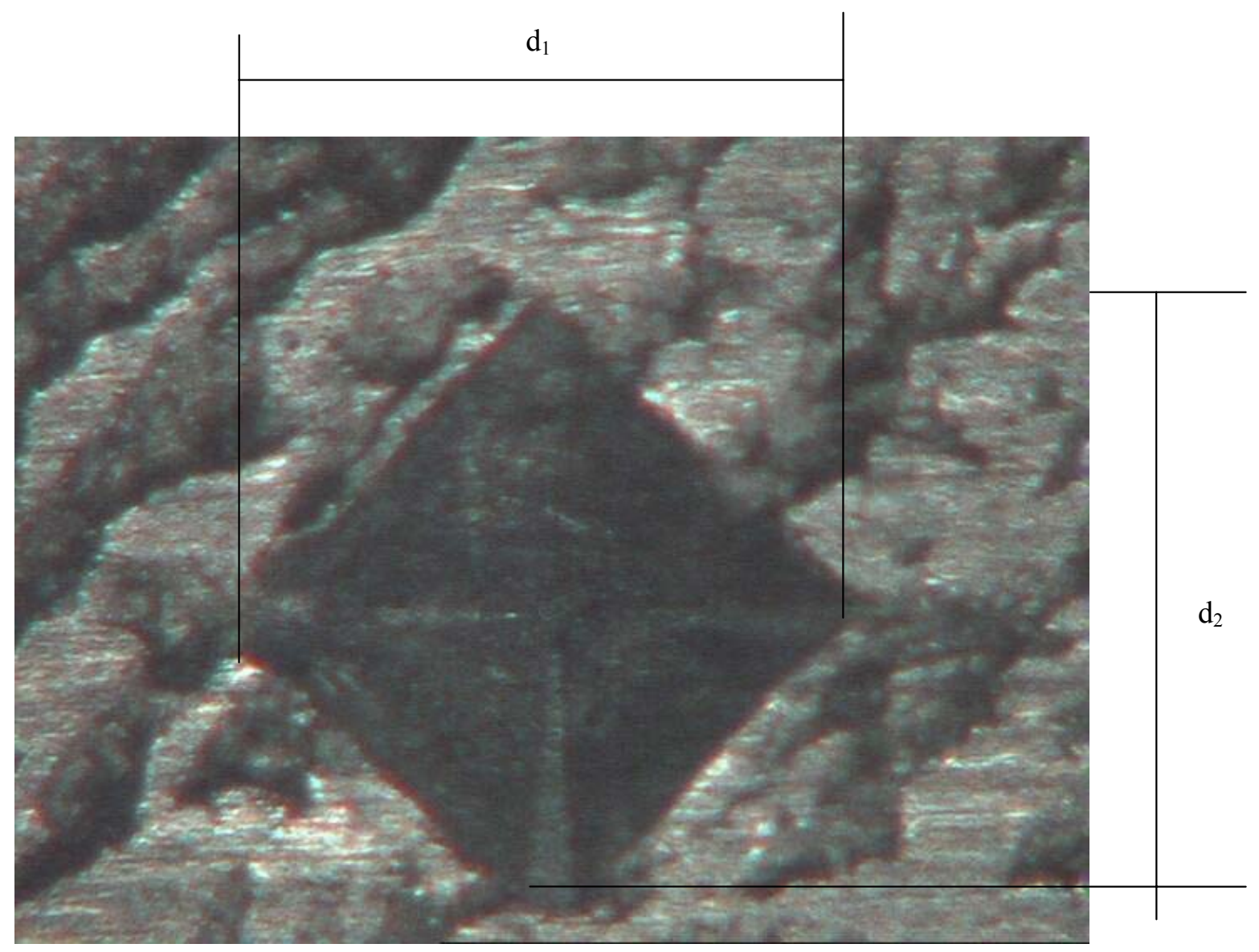

Fig: 3.2 Vickers indentations on PRMMC material 

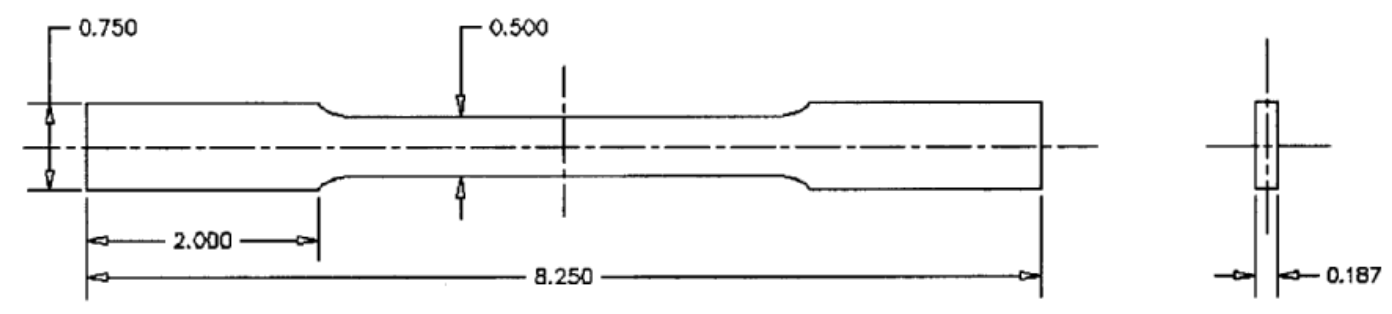

Fig: 3.3 Dimensions of dog-bone specimen for tension testing
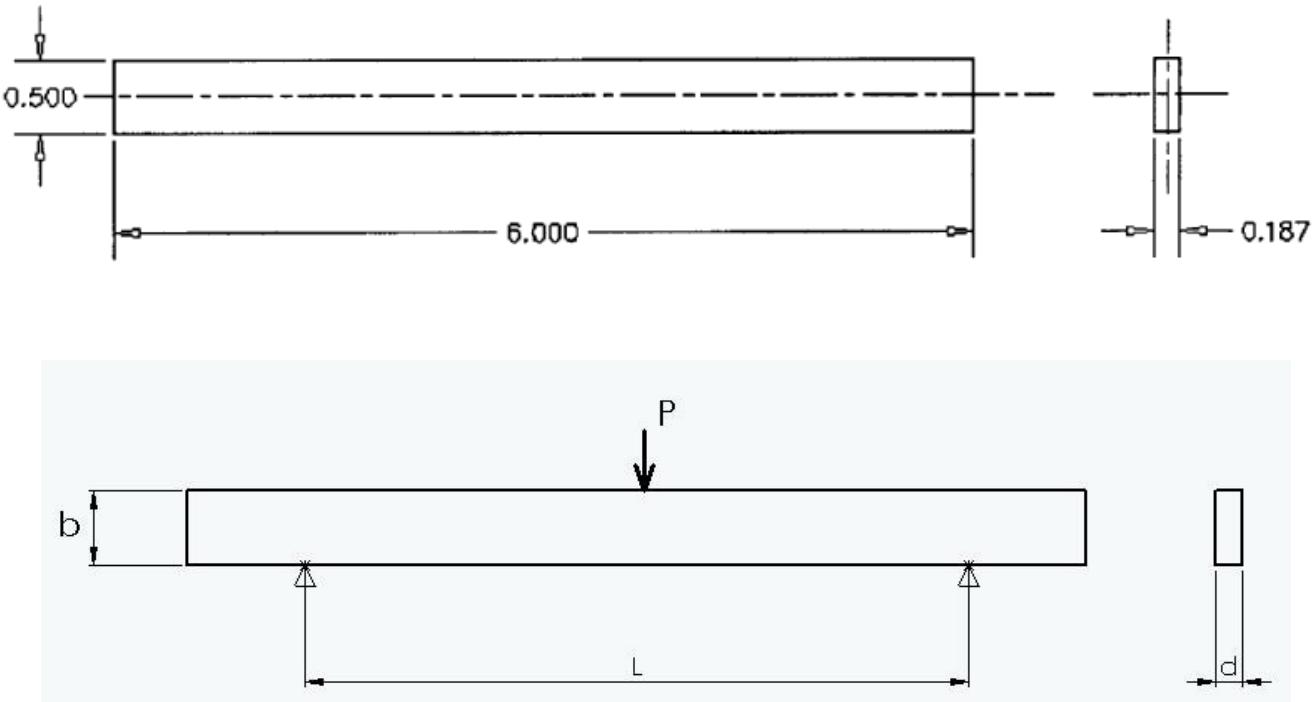

Fig: 3.4 Dimensions of rectangular specimen for three-point bending tests 


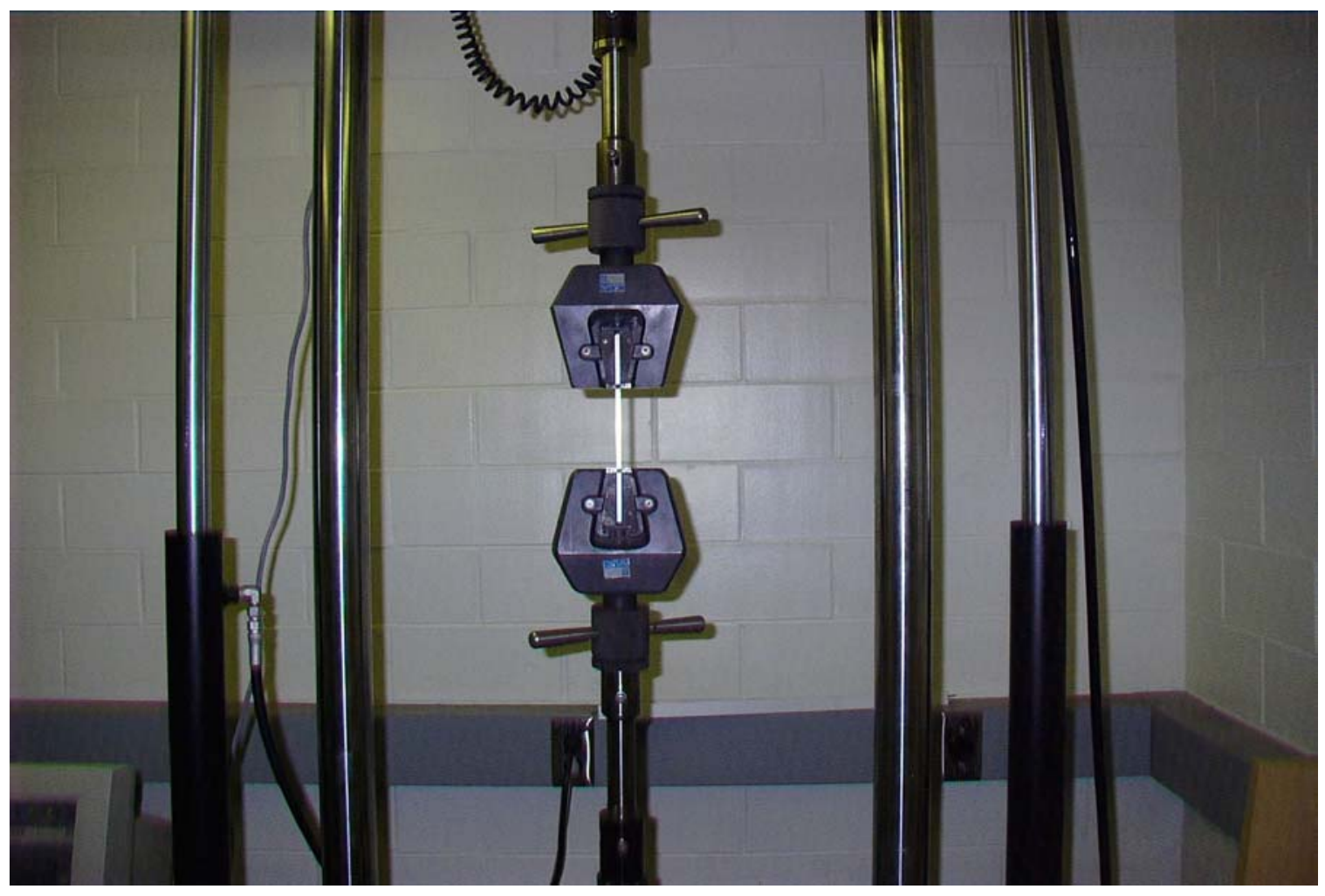

Fig: 3.5 Tension testing of $30 \% \mathrm{MMC}$ on Instron machine 


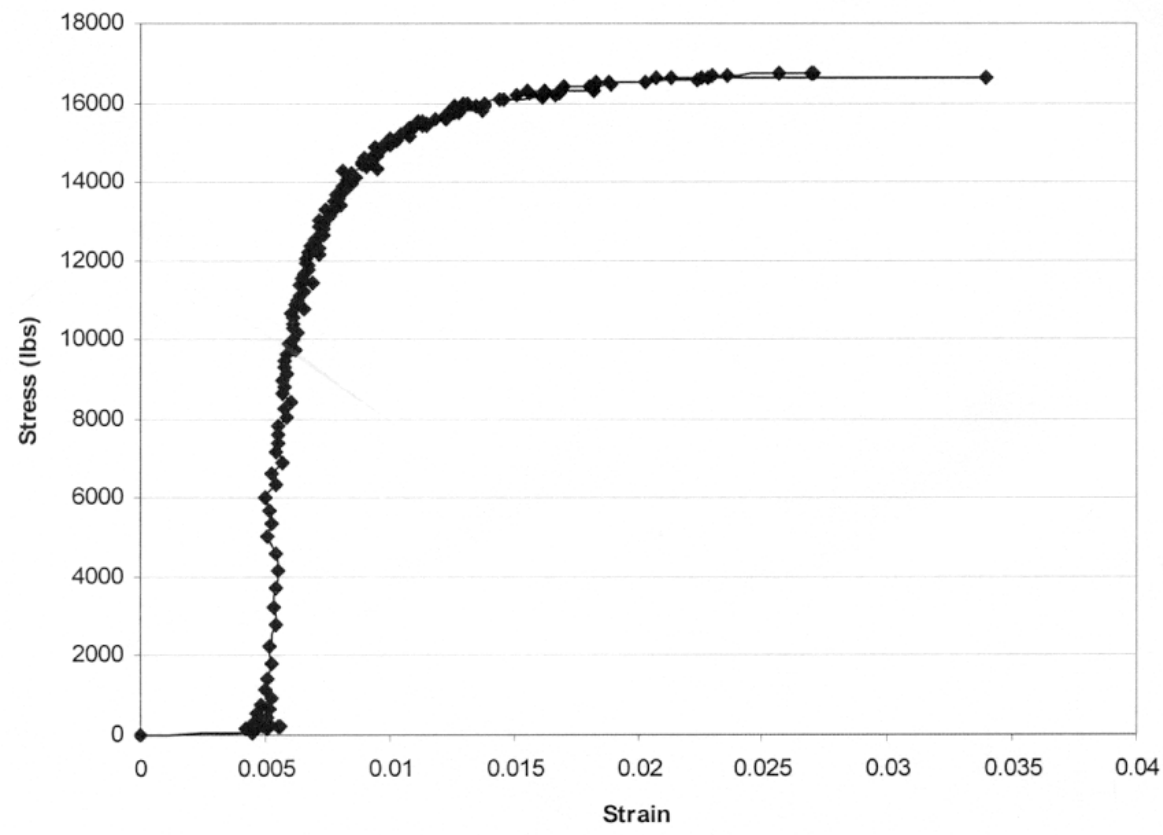

Fig: 3.6 Stress-strain curves for aluminum alloy matrix

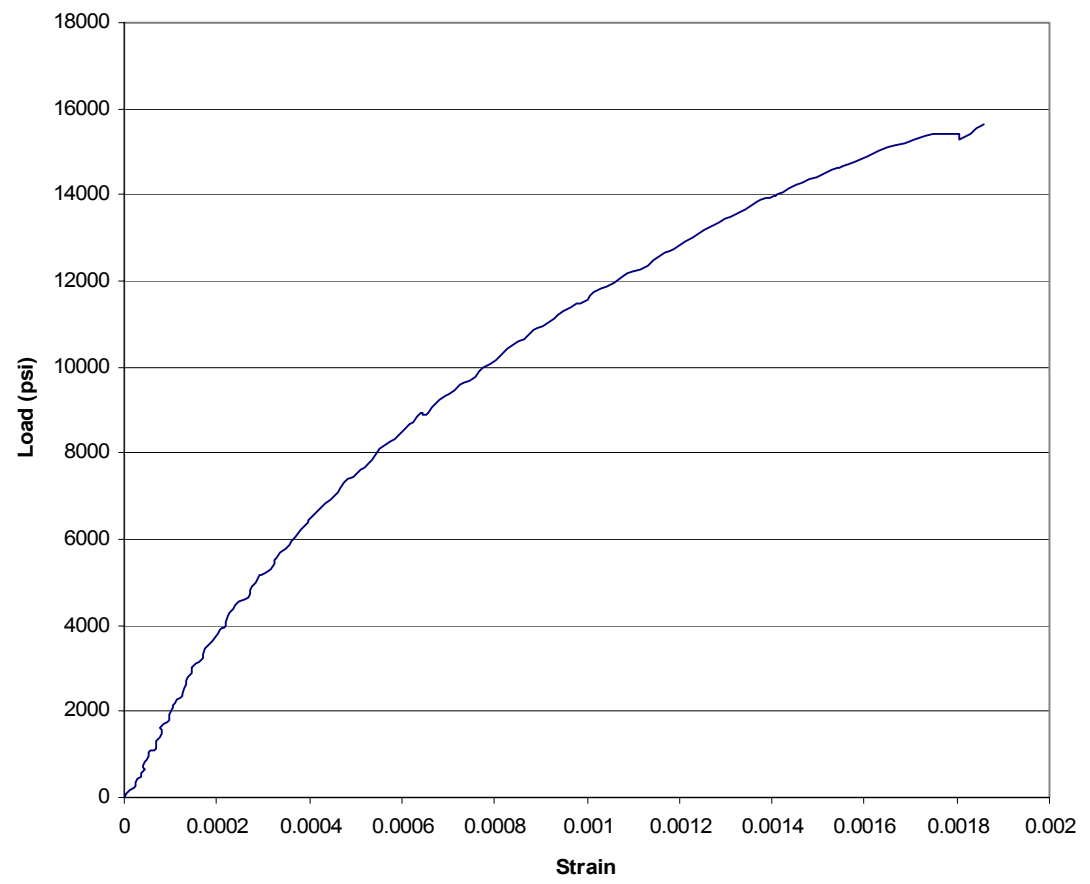

Fig: 3.7 Stress-strain curves for MMC material with 30\% reinforcement 


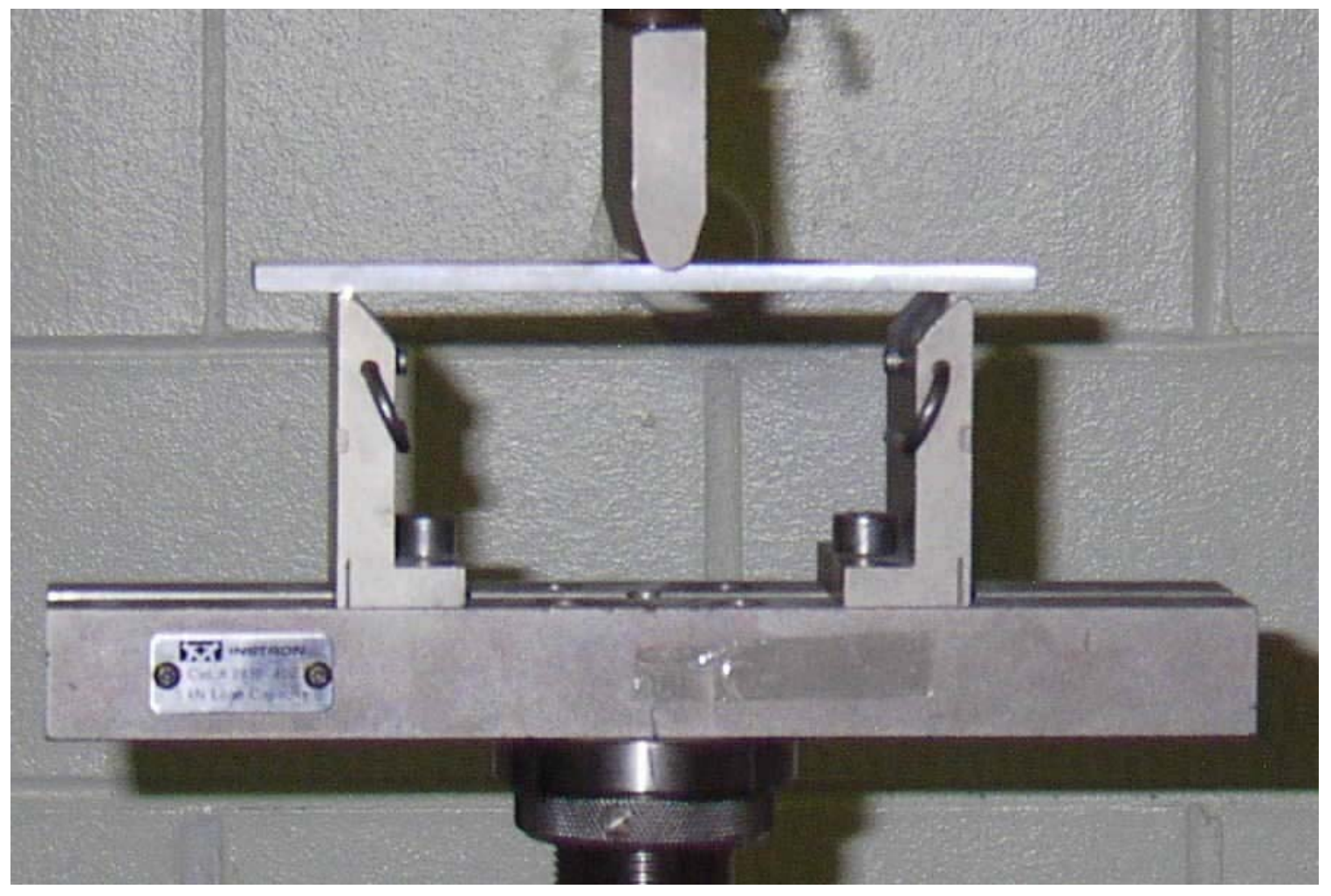

Fig: 3.8 Three-point bend testing of MMC 


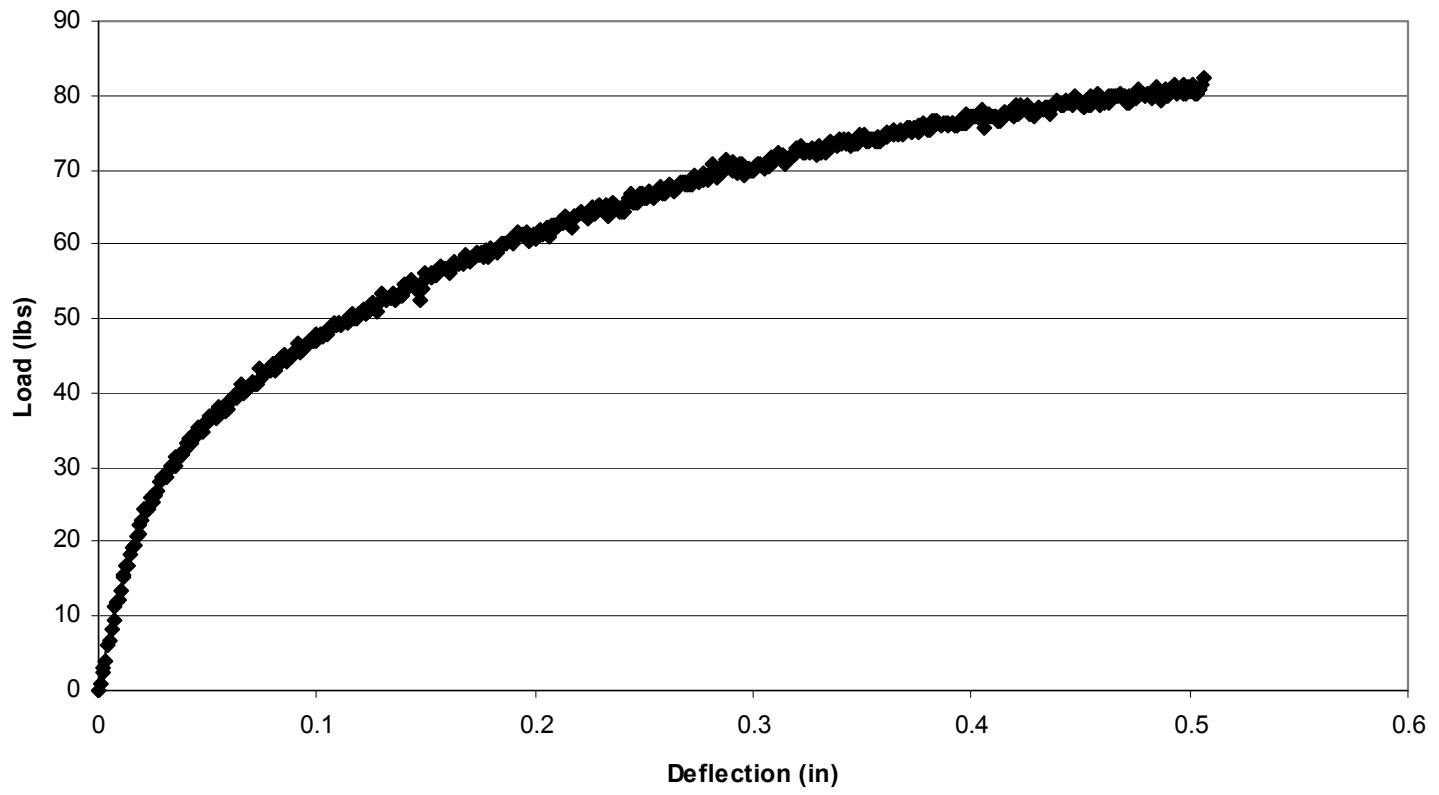

Fig: 3.9 Load deflection curve for three-point bend testing for aluminum alloy matrix

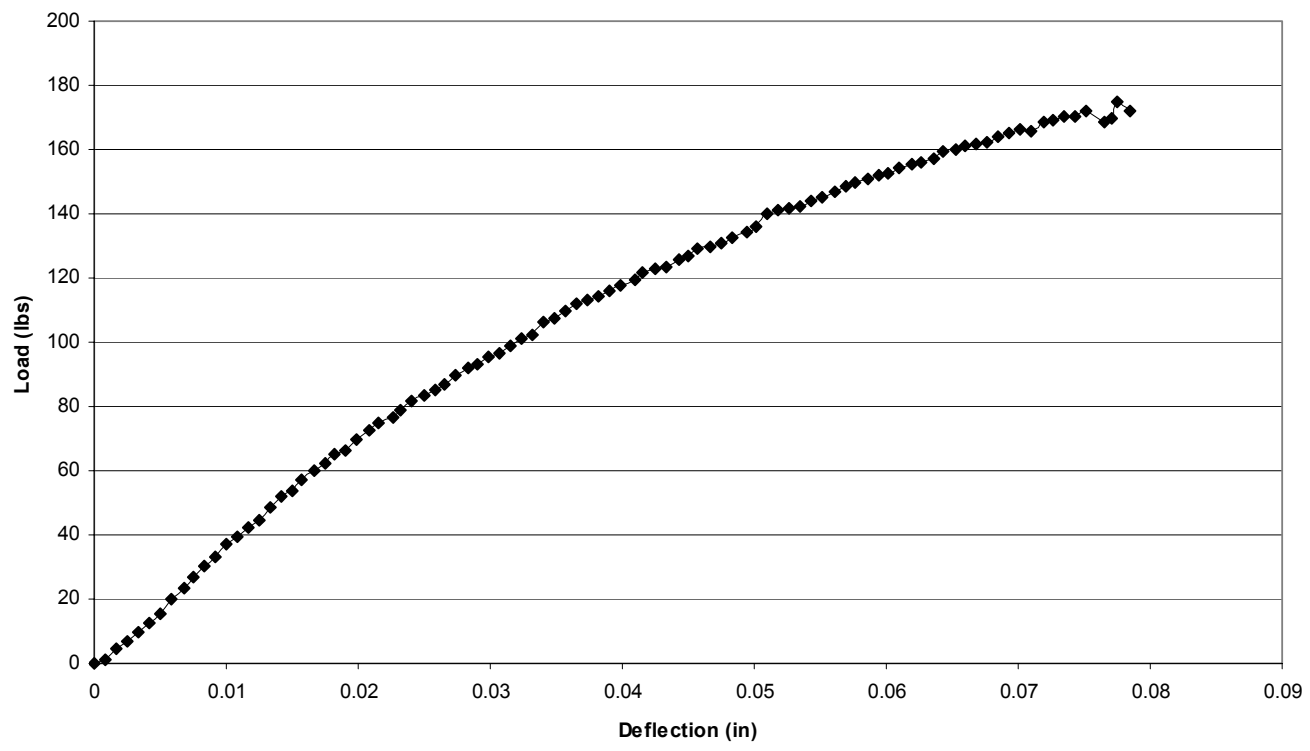

Fig: 3.10 Load deflection curve for three-point bend testing for MMC with 30\% reinforcement 


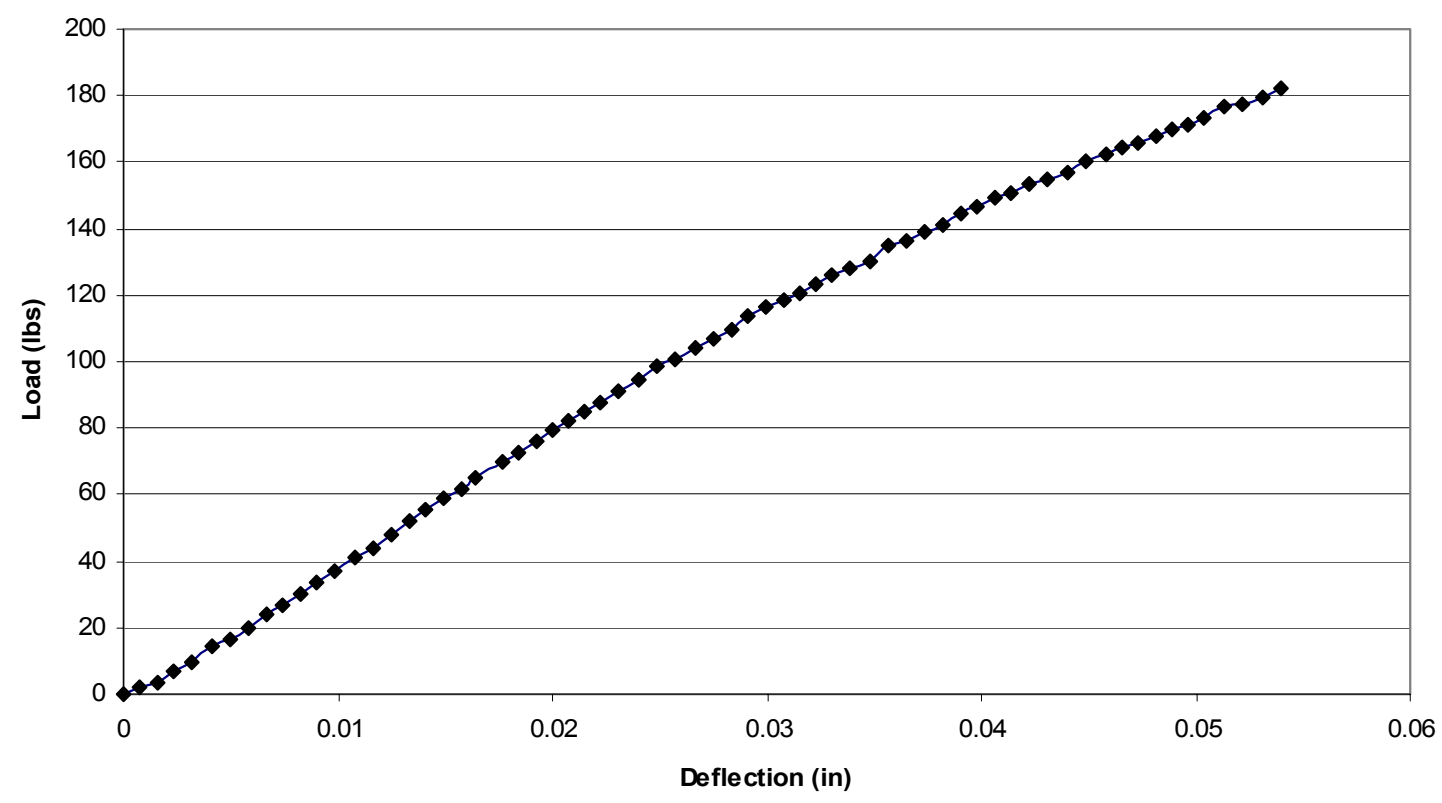

Fig: 3.11 Load deflection curve for three-point bend testing for MMC with $45 \%$ reinforcement 


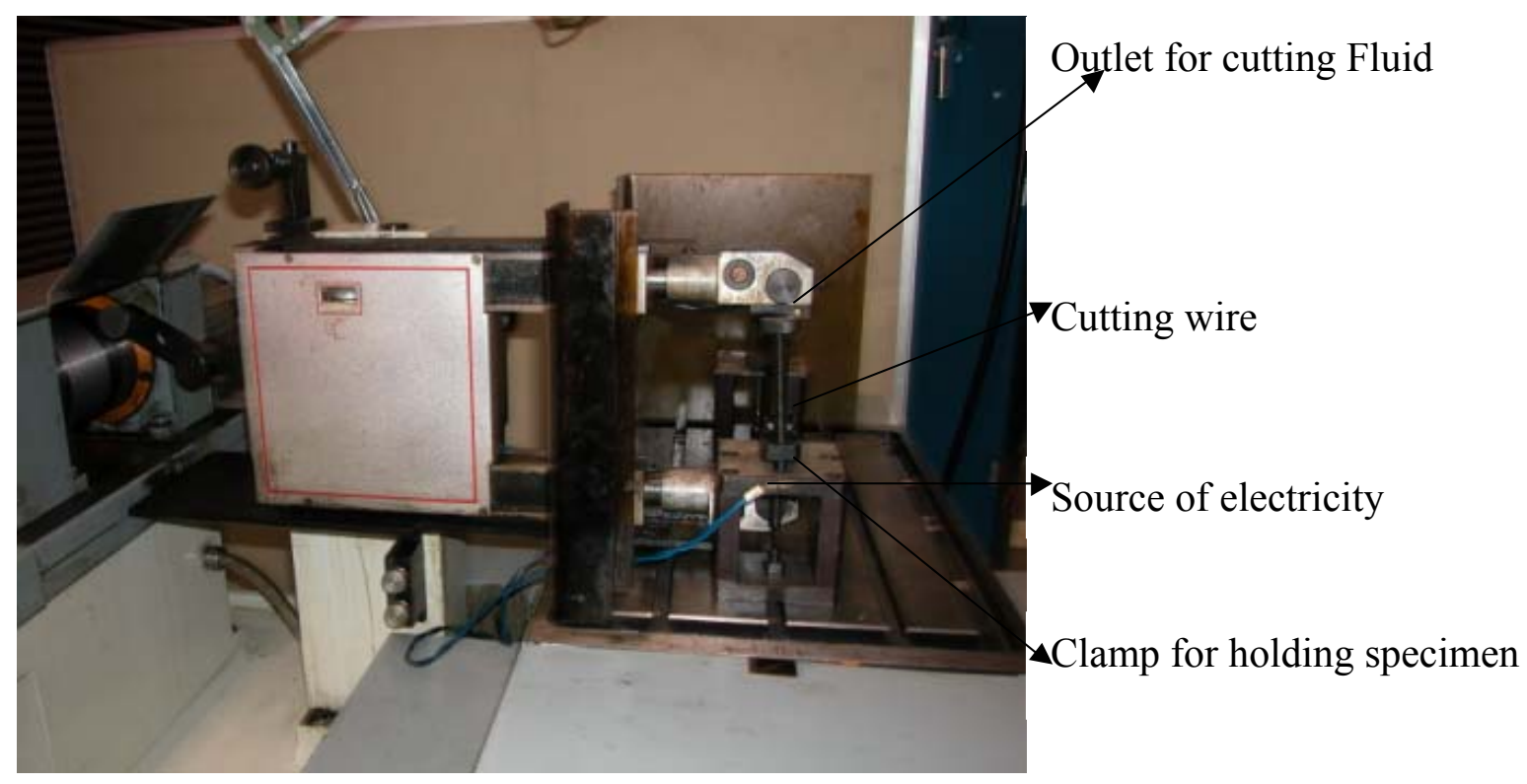

Fig: 3.12 Electro-Discharge Machine $(E D M)$ used for cutting test specimens

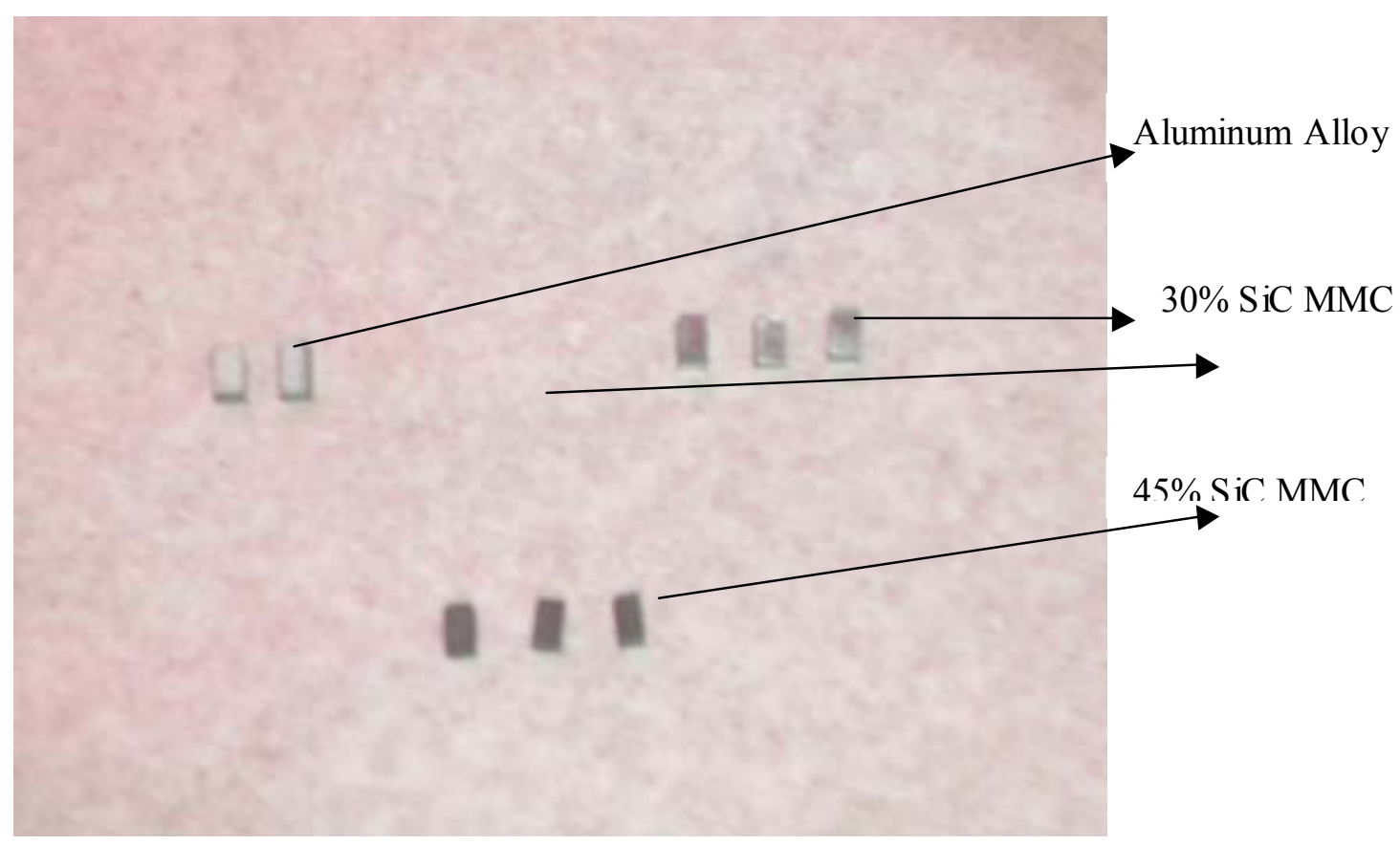

Fig: 3.13 Specimens cut by using the EDM for measuring coefficient of thermal expansion 


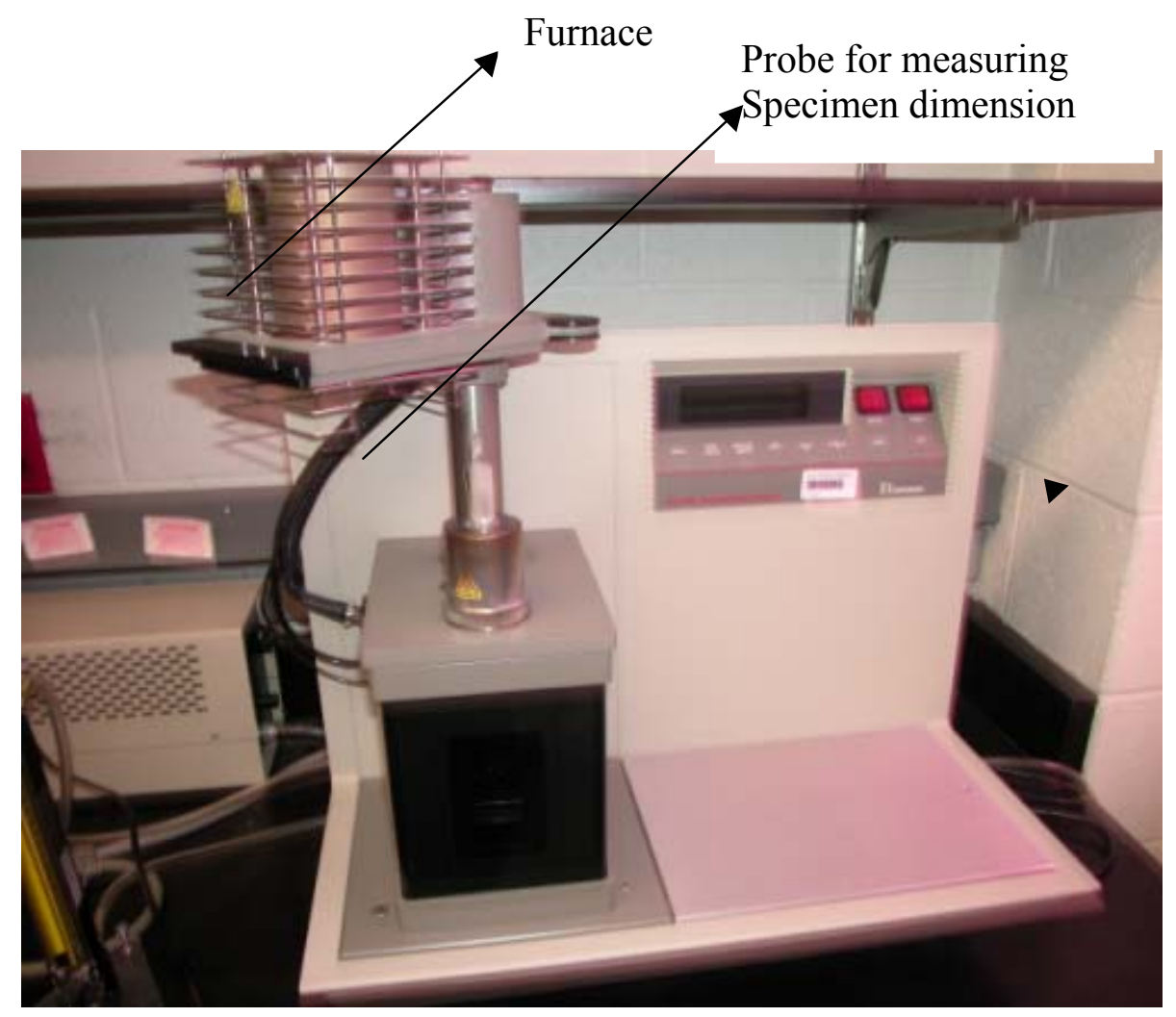

Fig 3.14 Thermo mechanical analyzer used for measuring coefficients of thermal expansion 


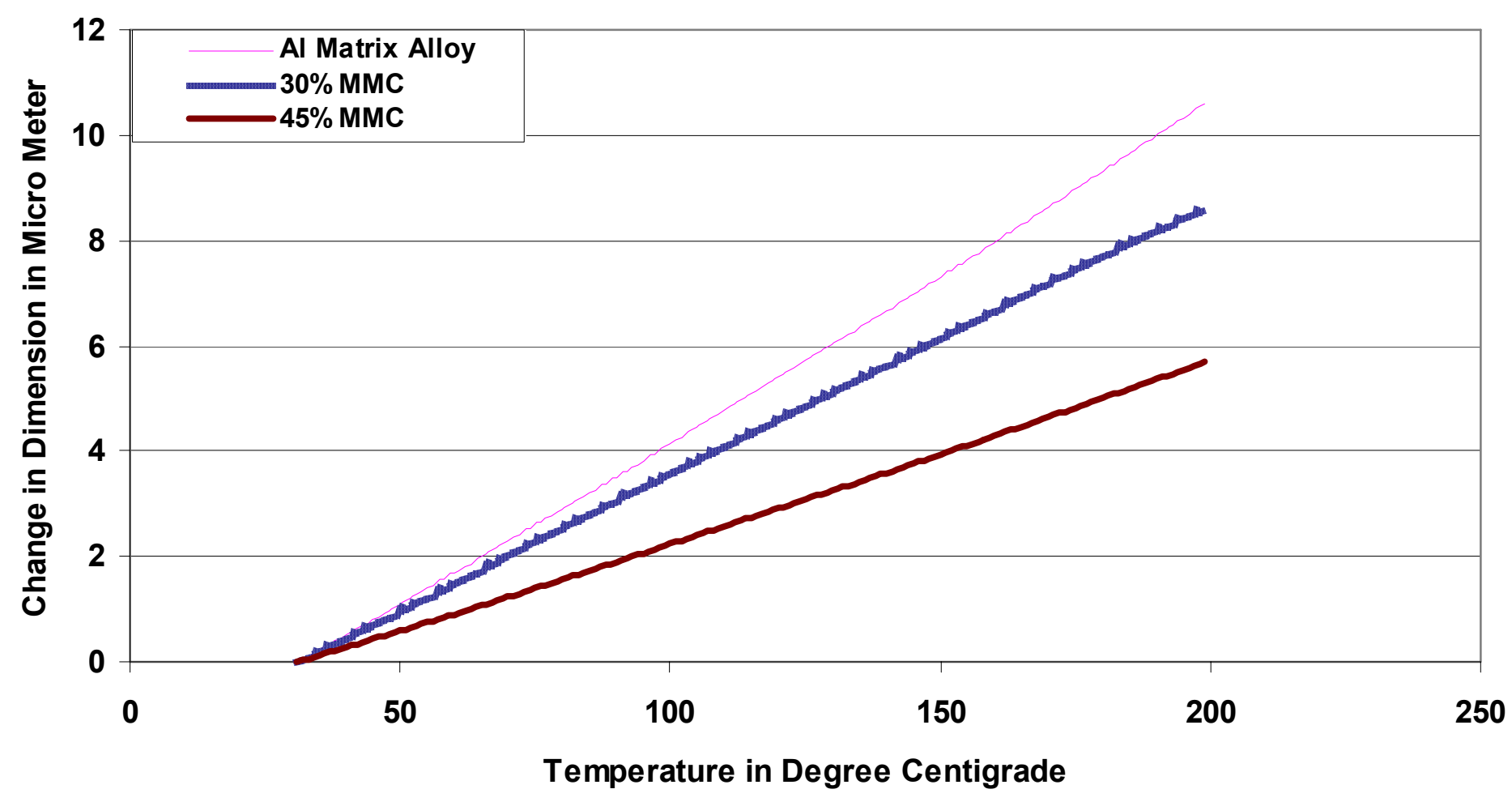

Fig: 3.15 Change in dimension vs. temperature for aluminum alloy and MMC material 


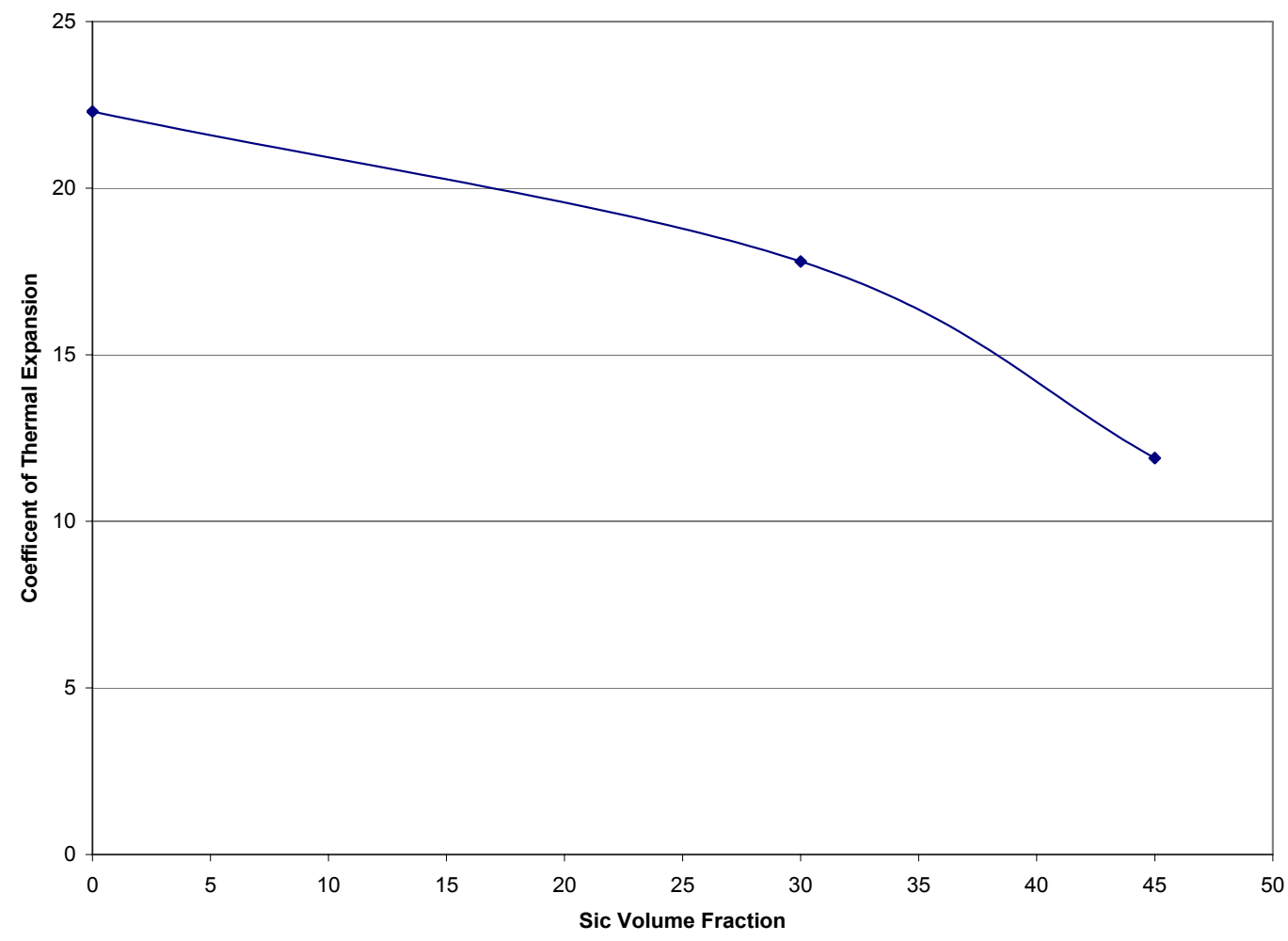

Fig: 3.16 Variation of coefficient of thermal expansion with volume fraction of reinforcing particles 


\section{CHAPTER 4 CHARECTERIZATION OF BOLTED JOINTS MADE OF PARTICULATE REINFORCED METAL MATRIX COMPOSITES}

\subsection{Introduction}

Unlike continuous fiber composites, where drilling of holes is avoided to prevent fiber damage, particulate MMC components are likely to be connected extensively through bolted joints. Joining performed by using mechanical fasteners offers several advantages in comparison to adhesive technique; there is no requirement for surface treatment, and the joining members may be disassembled without being damaged. Additionally, thick structures can be joined together by bolting whereas adhesive bonding is not effective in such cases.

One main objective of this thesis project is to test bolted joints made of PRMMC material, both for quality and durability of function. This investigation is performed by testing specimens under a wide variety of parameters like the stiffness of the material, clamping force exerted by the bolt, the edge to diameter ratio (e/d ratio) and the width to diameter ratio $(\mathrm{w} / \mathrm{d})$.

\subsection{Experimental design}

A double-lap bolted joint fixture was designed for testing the MMC specimen. A schematic representation of the fixture employed in these tests is depicted in Fig 4.1. The fixture allows the analysis of various failures expected during tensile loading of double lap joints made of MMC material.

The specimen was clamped between two steel plates as shown in Fig 4.1, and equal tension forces were applied on both ends, until the middle plate failed. The thickness of the steel plate, which is almost double the MMC test specimen prevents the supporting steel plates from failing during the test. A number of 36 different specimens of both aluminum alloy and MMC material were prepared in accordance with an experimental design matrix that included varying the edge distance "e" and the width "w" of the specimen. The clamping load was determined by using a miniature load cell, which could be attached to the bolted joint. 
The entire test setup was then mounted on an Instron machine for subsequent testing according to ASTM standards specified for steel and aluminum. The specimen exhibited a clearance of $1 / 16^{\text {th }}$ inch between the bolt and the hole, as recommended by ANSI (Euro Standards, AISI, ANSI).

\subsubsection{Specimen preparation}

The basic dimensions of the various specimens that are drawn to scale are depicted in Fig: 4.2.

Two main types of specimens were investigated in this study.

Material A: Aluminum alloy metal (A16061), prepared in thin strips, which were obtained by fine slicing of an aluminum metal sheet.

Material B: PRMMC material, containing 45\% volume fraction of reinforcing $\mathrm{SiC}$ particles. These were cut from cast blocks of material obtained from the manufacturers.

The preparation of PRMMC joint specimens was hindered by many mechanical problems. For example, repeated attempts to cut slices of the specimen were necessary by using ordinary and high strength carbide saw blades. The saw blades wore out frequently, as a result of their constant contact with the highly abrasive silicon carbide particles.

Specially manufactured diamond tipped tools has to be used eventually, in order to over come these difficulties (Appendix IV). Therefore, $(2 * 3 * * 1.5$ ') rectangular plates containing $45-55 \% \mathrm{SiC}$ in aluminum alloy, were ordered from the Lanxide corporation and specially ordered saw blades consisting of diamond bit patches placed at regular intervals were used to cut slices of the PRMMC specimen from $2 * 3 * 1.5$ rectangular plates of MMC material with $45-55 \%$ reinforcement of $\mathrm{SiC}$ particles. The sliced specimens were then milled on a milling machine using diamond tipped milling inserts to the desired thickness. Subsequently, the milled specimens were placed on a diamond surface-grinding wheel, to smoothen their surface and flatten it as accurately as possible. Finally, holes were drilled into the specimen by using the diamond drills. 


\subsection{Components of the bolted joint specimens}

\subsubsection{Load cell}

A important device for this experiment was the specially manufactured miniature thru hole compression load cell (Appendix III). A graphical representation of the load cell, along with its dimensions, is provided in Fig-4.3. The main purpose of the load cell was to determine the clamping force on the bolt during the tightening of the bolted joint. The pre-loading in a bolt has a significant effect on the strength of the bolted joint and thus is an important consideration in the design of such joints. Another important issue that had to be dealt with was the effect of variations in the clamping force during the application of uni-axial tension to the joint. The clamping force was measured by the miniature load cell via a digital monitor, DPM3, which had been calibrated to the characteristics needs of the load cell.

\subsubsection{Spherical, flat washer and bolt}

Fig 4.1 displays two spherical washer models, namely 91944a470 and 91944a032, which were used in the design, so that the load cell could be uniformly loaded. Additionally, the washers also prevented bending, which could occur during the tightening of the bolt. The main purpose of the flat washers was to decrease the stress concentration around the hole. The bolt was made of SAE grade- 8 steel, made from quenched and tempered medium carbon alloy. The maximum tensile strength of the bolt is therefore $150,000 \mathrm{psi}$, so that structural failure is expected to occur the failure occur in the MMC specimen first and not in the bolt.

\subsection{Experimental procedure}

First, the specimens were surface milled, in order to minimize friction between the surface of the MMC specimen and the steel grips. The load cell was then mounted onto the specimen through the bolt and was tightened using a torque wrench meter. Subsequently, the two ends of the bolted joint were mounted in an Instron machine and held between its wedge grips. Following that, the bolted joint was loaded under a constant displacement rate of .001-inch/min until the joint failed. Various parameters of the joint like the clamping force of the bolts, the Young's modulus of the material, the e/d 
ratio and $\mathrm{w} / \mathrm{d}$ ratios were changed from one specimen to the other in order to determine their effects on the strength of the bolted connection. The modes of failure corresponding to various values of the e/d and w/d ratios were identified, and their effects on the overall load-transfer capability of the joints were determined.

\subsection{Types of failure in bolted joints}

Four types of failure modes are encountered in bolted joints, as observed by Winter (Winter 1956) and depicted in Fig-4.4. These modes of failure are observed in all bolted joint connections between steel or aluminum components. They depend mainly on the e/d ratio, w/d ratio and material property of the connected plates. By varying these parameters, all these different modes of failure could be identified and the results used to improve the design of such joints.

1) Shear pull out- Shear pull out is a longitudinal shearing of the plate along two practically parallel planes, towards the edge of the specimen. This type of failure usually occurs for very short edge distances "e".

2) Bearing failure- Bearing failure is the longitudinal tearing along two distinctly inclined planes with considerable "piling up" of the material in front of the bolt. This type of failure occurs chiefly for longer edge distances " $\mathrm{e}$ ", so that the bearing strength is usually considered to be a function of e/d ratio.

3) Net-section failure-Net-section failure is the transverse tension tearing across the sheet. This usually occurs for very low bolt spacing and is characteristic of brittle materials. This mode of failure is a function of w/d ratio where " $w$ " is the bolt spacing.

4) Shearing of bolt- Prior to the shearing of the bolt, a more or less pronounced elongation of the hole is likely to be observed. The MMC bolted joint specimens were designed so as to avoid the last mode of failure.

\subsection{Equations for bearing and net section strength}

The parameters of the specimen design were set up within limits of the EC3 (European committee for standardization). All the prepared specimens had a minimum (e/d) ratio ranging from 1.2-5.0 and a minimum (w/d) ratio ranging from 2.0-8.0. The bearing strength and the net-section failure were calculated according to the EC3 as follows-: 
1) Bearing strength:

$$
\mathrm{F}_{\mathrm{b}}=2.5 \alpha \mathrm{tdf}_{\mathrm{u}}
$$

Where;

$\mathrm{F}_{\mathrm{b}}=$ Bearing strength

$\alpha=($ Minimum of either e/3d or 1 );

$\mathrm{t}=$ Thickness of the thinnest material in the joint;

$\mathrm{d}=$ Diameter of hole;

$\mathrm{f}_{\mathrm{u}}=$ Ultimate strength of the material;

2) Failure strength of net-section:

$\mathrm{F}_{\mathrm{n}}=\mathrm{A}_{\mathrm{n}} * \mathrm{f}_{\mathrm{u}}$

Where;

$\mathrm{F}_{\mathrm{n}}=$ Net-Section failure strength;

$\mathrm{A}_{\mathrm{n}}=$ Net section area;

$\mathrm{f}_{\mathrm{u}}=$ Ultimate strength of the material calculated from the formula;

$\mathrm{A}_{\mathrm{n}}=[2 *(\mathrm{e}-(\mathrm{d} / 2)) * \mathrm{t} * 0.6]$

Where;

$\mathrm{e}=$ Distance from center of hole to edge of specimen;

$\mathrm{d}=$ Diameter of hole;

$\mathrm{t}=$ Thickness of MMC specimen; 


\subsection{Experimental design layout}

The testing of the double lap joint specimens in accordance with the planning matrix is outlined in the following tables. The specimens tested were all manufactured from $45 \%$ $\mathrm{SiC}$ reinforced MMC materials. The bolted joints were tested at clamping forces for $50 \mathrm{lbs}$ (finger tight conditions), $1000 \mathrm{lbs}$ and $2000 \mathrm{lbs}$, with the e/d ratio varying from 1.25.0 and the w/d ratio varying from 3.0-8.0.A total number of 21 joint specimens were tested.

Table 4.1-Test plan for bolted joints with varying e/d and $\mathrm{w} / \mathrm{d}=4$

\begin{tabular}{|c|c|c|c|c|c|}
\hline No & $\begin{array}{l}\text { e } \\
\text { (in) }\end{array}$ & $\begin{array}{l}\text { d } \\
\text { (in) }\end{array}$ & $\begin{array}{l}\mathrm{e} / \mathrm{d} \\
\text { Ratio }\end{array}$ & $\begin{array}{l}\text { Maximum } \\
\text { clamping } \\
\text { force }=2640 \mathrm{lbs}\end{array}$ & $\begin{array}{l}\text { Predicted } \\
\text { mode of } \\
\text { failure }\end{array}$ \\
\hline $1 \mathrm{a}$ & 0.6 & 0.5 & 1.2 & 50 & Shear out \\
\hline $1 b$ & 0.6 & 0.5 & 1.2 & 1000 & Shear out \\
\hline $1 \mathrm{c}$ & 0.6 & 0.5 & 1.2 & 2000. & Shear out \\
\hline $1 d$ & 0.6 & 0.5 & 1.2 & 50 & Shear out \\
\hline $2 \mathrm{a}$ & 1 & 0.5 & 2 & 1000 & $\begin{array}{l}\text { Shear out } \\
\text { or Bearing }\end{array}$ \\
\hline $2 b$ & 1 & 0.5 & 2 & 50 & $\begin{array}{l}\text { Shear out } \\
\text { or Bearing }\end{array}$ \\
\hline $2 c$ & 1 & 0.5 & 2 & 1000 & $\begin{array}{l}\text { Shear out } \\
\text { or Bearing }\end{array}$ \\
\hline $2 d$ & 1 & 0.5 & 2 & 2000 & $\begin{array}{l}\text { Shear Out } \\
\text { or Bearing }\end{array}$ \\
\hline $3 a$ & 1.5 & 0.5 & 3 & 50 & Bearing \\
\hline $3 b$ & 1.5 & 0.5 & 3 & 1000 & Bearing \\
\hline $3 c$ & 1.5 & 0.5 & 3 & 2000 & Bearing \\
\hline $4 a$ & 2 & 0.5 & 4 & 50 & Bearing \\
\hline $5 a$ & 2.5 & 0.5 & 5 & 50 & Bearing \\
\hline
\end{tabular}


Table 4.2-Test plan for bolted joints with varying e/d and w/d=3

\begin{tabular}{|l|l|l|l|l|l|}
\hline No: & $\begin{array}{l}\mathrm{e} \\
\text { (in) }\end{array}$ & $\begin{array}{l}\mathrm{d} \\
\text { (in) }\end{array}$ & $\begin{array}{l}\text { e/d } \\
\text { Ratio }\end{array}$ & $\begin{array}{l}\text { Maximum } \\
\text { clamping } \\
\text { force=2640lbs }\end{array}$ & $\begin{array}{l}\text { Predicted } \\
\text { mode of } \\
\text { failure }\end{array}$ \\
\hline $1 \mathrm{a}$ & 0.6 & 0.5 & 1.2 & 50 & Shear out \\
\hline $2 \mathrm{a}$ & 1 & 0.5 & 2 & 50 & Net Section \\
\hline $3 \mathrm{a}$ & 1.5 & 0.5 & 3 & 50 & Net Section \\
\hline $4 \mathrm{a}$ & 2 & 0.5 & 4 & 50 & Net Section \\
\hline $5 \mathrm{a}$ & 2.5 & 0.5 & 5 & 50 & Net Section \\
\hline
\end{tabular}

Table 4.3- Test plan for bolted joints with varying e $/ \mathrm{d}$ and $w / \mathrm{d}=8$

\begin{tabular}{|l|l|l|l|l|l|}
\hline No: & $\begin{array}{l}\mathrm{e} \\
\text { (in) }\end{array}$ & $\begin{array}{l}\mathrm{d} \\
\text { (in) }\end{array}$ & $\begin{array}{l}\mathrm{e} / \mathrm{d} \\
\text { Ratio }\end{array}$ & $\begin{array}{l}\text { Maximum } \\
\text { clamping } \\
\text { force=480lbs }\end{array}$ & $\begin{array}{l}\text { Predicted } \\
\text { mode of } \\
\text { failure }\end{array}$ \\
\hline $1 \mathrm{a}$ & 0.6 & 0.25 & 1.2 & 50 & Shear out \\
\hline $2 \mathrm{a}$ & 1 & 0.25 & 2 & 50 & Bearing \\
\hline $3 \mathrm{a}$ & 1.5 & 0.25 & 3 & 50 & Bearing \\
\hline $4 \mathrm{a}$ & 2 & 0.25 & 4 & 50 & Bearing \\
\hline $5 \mathrm{a}$ & 2.5 & 0.25 & 5 & 50 & Bearing \\
\hline
\end{tabular}




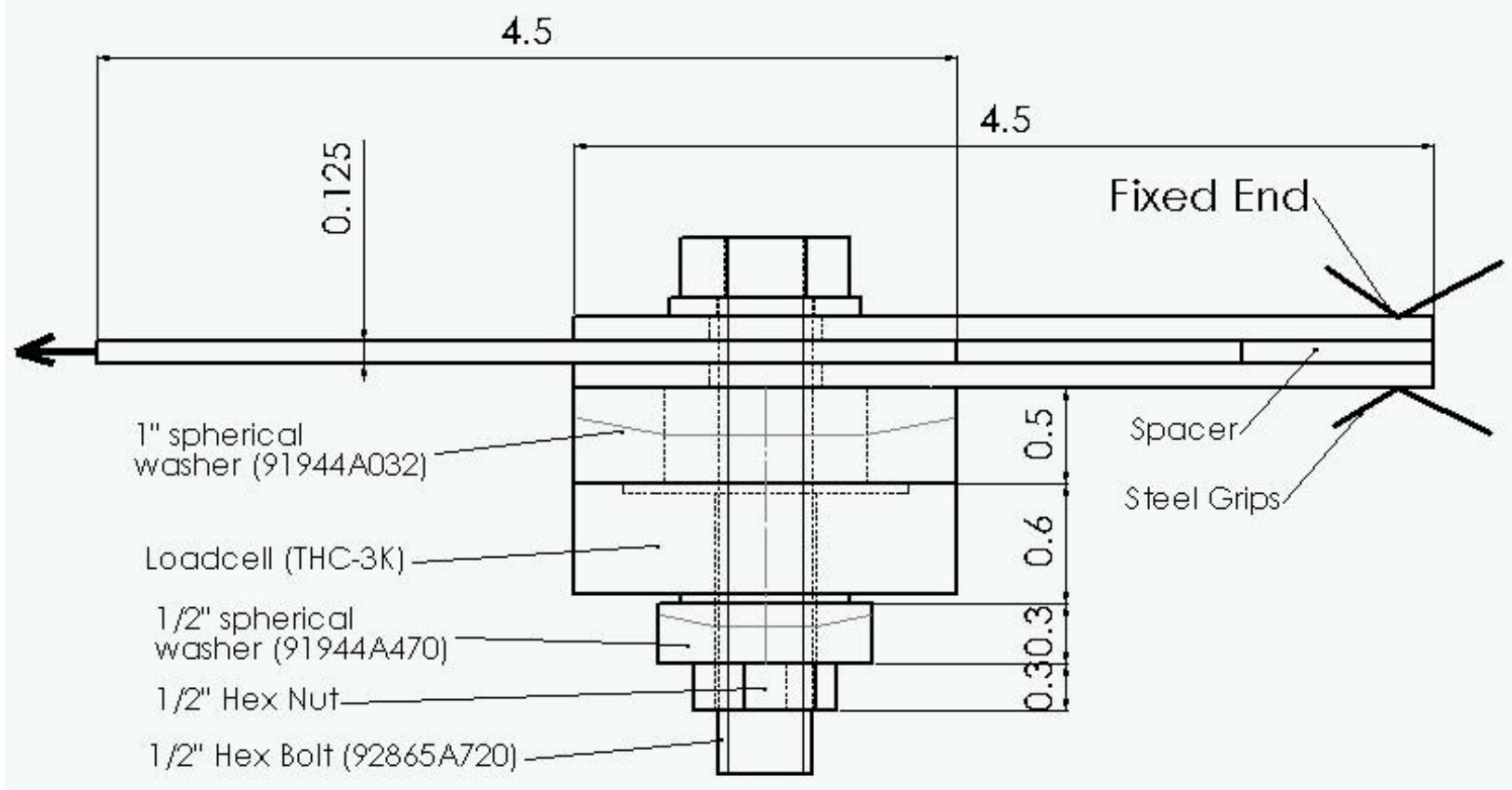

Note:

The setup will be vertical

in the Tension Machine

Fig: 4.1 Test Fixtures for Bolted Joints 

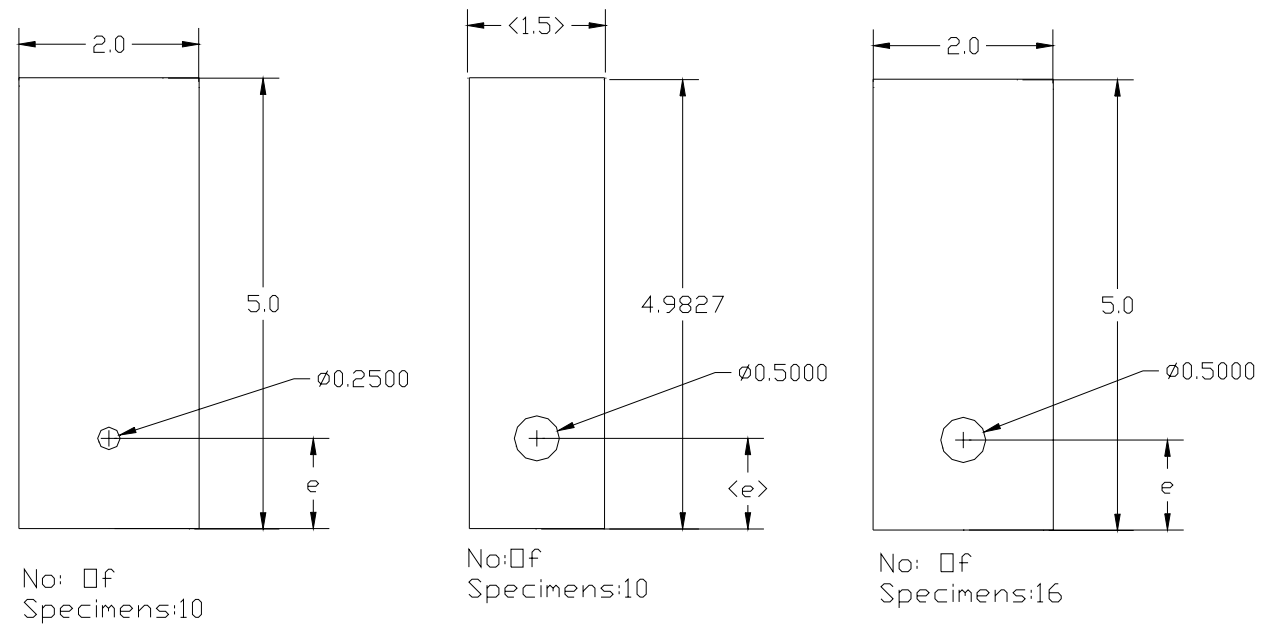

All Dimensions In inches

Figure 4.2 Specimen dimensions for bolted joint testing 
Loadcell (THC-3K)
Dimension Details

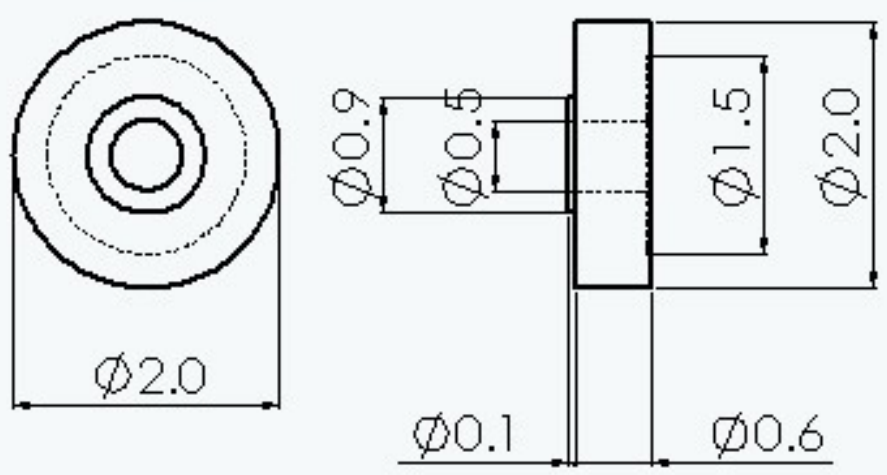

Fig: 4.3 Load Cell Dimensions 


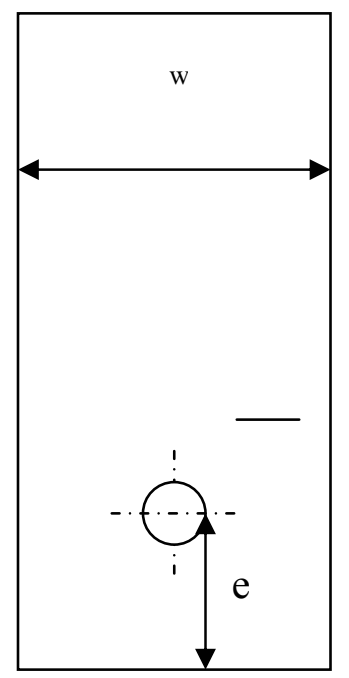

Specimen

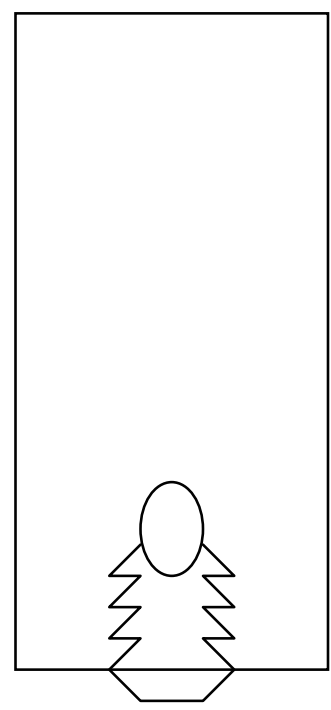

Shear Pull

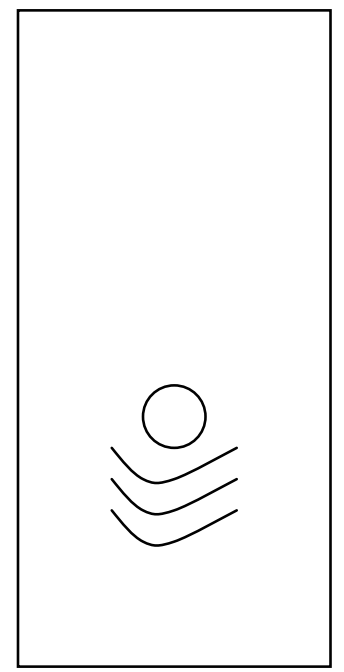

Bearing failure

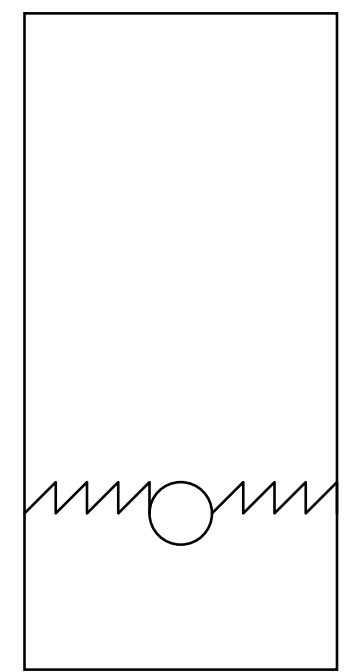

Net-tension

Fig: 4.4Types of Failure in Bolted Joints 


\section{CHAPTER 5-RESULTS AND DISCUSSION FOR BOLTED JOINTS}

\subsection{Specimen preparation and defects}

The MMC specimens were tested in accordance with the plan and procedures described in the previous chapter. Before analyzing the test results, problems encountered in the specimen preparation and critical inherent defects of the material must be defined and discussed.

Fig 5.1 shows the rough surface of a MMC specimen, before it is machined. As mentioned earlier in the text, this surface was finished by employing specially manufactured diamond tipped tools. Furthermore, large surface defects in the specimens could be observed after the surface milling, as shown in Figs 5.2.and 5.3.The defects were seen in 13 out of 36 specimens that were prepared for testing purposes. A microscopic analysis was performed at the regions of defect as shown in Fig 5.4 and it was clearly visible that these regions did not contain any $\mathrm{SiC}$ particles and this can be attributed as a processing defect. In order to confirm the microscopic analysis, Vickers indentation tests were performed at the regions of defect as shown in Fig 5.5 as well as in areas containing uniformly distributed $\mathrm{SiC}$ particles. It was found that the $\mathrm{H}$.V value at the area with out any SiC particles was 61 while the H.V value over the rest of specimen was found to be 123 , clearly indicating the absence of $\mathrm{SiC}$ particles in the region of defect. Fig 5.7 shows the fully processed MMC samples, in accordance with all the width and edge distance ratio specifications given in tables 4.1-4.3.

\subsection{Load displacement curves}

Typical load displacement curves of the double-lap joints made of MMC are presented in Figs 5.9-5.10.These curves have been generated under displacement controlled loading for a clamping force value of 501bs (finger tight conditions). The results show that the load rises steadily to an ultimate value, where the joint fails without any yielding. One may notice that for higher values of the e/d ratio, the ultimate failure load increases with the specimen still failing in the net-section mode, but without with out any yielding. Fig 5.11 displays the load deflection curves of MMC joint specimens under different clamping conditions. One can infer from these results that upon increasing the clamping 
force, the slip load also increases. Slip load is the load at which friction at the joints becomes negligible and slipping of the specimens occurs. For specimens tested with a clamping force of $1000 \mathrm{lbs}$, the slip load about $600 \mathrm{lbs}$ is almost half of that observed in specimens tested those tested with $2000 \mathrm{lbs}$ clamping force about $1200 \mathrm{lbs}$. However no slip occurs when the bolted joint is tested under finger tight conditions. This is because, under finger tight conditions there is no frictional support for the bolted joint and the slip is negligible. The load carried by a bolted joint can be divided into three stages. Initially the applied load is transferred by the frictional force until the bolts develop direct bearing contact with the plates inside the clearance of the holes .Eventually the applied tension is carried out by bearing loads plus friction along the contact surface between the jointed plates. Most of the slip occurred between 40 and 80 percent of the ultimate strength of the material. The load displacement curve of aluminum double lap joint is shown in Fig 5.12 , where one can easily notice the yielding of aluminum before failure. The load deflection curves for aluminum joints show considerable amount of yielding of the aluminum material before failure occurs for all $\mathrm{e} / \mathrm{d}$ ratios.

\subsection{Types of failure}

The different failure modes observed in tension loading of MMC joints are shown in Figs 5.13 and 5.14. All the MMC specimens exhibit net section mode of failure near the holes. Even for samples with e/d ratios and w/d ratios which were expected to fail in the bearing mode, the material failed in the net-section mode. For specimens in which the edge pullout failure ( $(\mathrm{e} / \mathrm{d} \leq 1.2)$ was supposed to occur, the specimen shattered at the ends, clearly indicating the brittle nature of the MMC specimens. However, in case of aluminum, considerable piling up of the material was noticed on one side of the hole.Fig-5.15 illustrates such bearing failure which is characteristic of ductile materials. In summary, the prevailing mode of failure in double lap joints made of MMC material is that of netsection, while aluminum joints fail usually through the bearing mode of failure.

\subsection{Effect of clamping force}

The effect of the clamping force magnitude on the tensile strength of bolted joints is an important parameter in bolted joint design. The load cell attached to the bolted joint can 
measures the applied by tightening the bolt and display it via a monitor. Three different clamping conditions were used in the tests, corresponding to clamping levels of 50lbs (finger tight condition), $2000 \mathrm{lbs}$ and $3000 \mathrm{lbs}$. The ultimate strength of bolted connections increases when the clamping force increases as shown in Table 5.1. This increased load bearing capacity of the joint can be attributed to the increased friction between the joined plates by the bolts which enables them to spread the high stresses around the hole over a larger area and thus reduce the bearing contact stresses between the bolt and the hole. However, it is noticed that the clamping pressure does not change the mechanism of failure for MMC's which remains to be "net-section "failure for the three different values of clamping pressure.

\subsection{Variation of clamping force with uniaxial tension}

Variations of the clamping force while the bolted joint was loaded in tension were monitored on a DPM3 monitor, which is connected to the load cell. Fig5.16 shows the variation of the clamping force with tension loading for $\mathrm{MMC}$ and aluminum specimens. One can clearly notice that the clamping force remains initially constant as the tension load is increased for both MMC and aluminum. However when the applied tension load increases beyond a certain limit, the clamping force also increases. In the case of the MMC material, the increase in clamping force is small, up to a maximum value ranging from 50 to 60lbs. However, this is not the case with the aluminum alloy where the mode of failure is bearing and the clamping force rises up to a maximum value ranging from 600 to $7001 \mathrm{bs}$.

The time history of the clamping force during the loading process can be divided into three main stages, as a function of the applied tension load. Initially the clamping force grows linearly with the increase of the applied load while the tension load deflection curve also appears to be linear. This behavior is maintained until non-linearity is clearly visible in the load deflection curve, which indicates the initiation of damage within the material. This non-linearity can be attributed to the accumulation of bearing damage at the contact surface between the bolt and the hole wall. Finally, as the applied tension load nears the ultimate load, the bearing damage is amplified and the clamping force increases rapidly. This is clearly visible in the case of the aluminum material, in which failure 
occurs by bearing modes and there is accumulation of crashed material on one side of the hole. In the case of MMC material, where failure occurs through net-section, there is little variation of the clamping force as the applied tension approaches ultimate failure level.

\subsection{Effect of the e/d ratio}

Table 5.2 shows experimental values of the ultimate failure load for double-lap joints made of MMC and ordinary aluminum materials, as compared to the theoretical failure loads calculated from the Euro standards(eqs.4.1 and 4.2). For the bearing failure mode of the aluminum material, the Euro equations provide a lower bound to the experimental values. However, the net section failure loads of MMC joints are very low compared to theoretical values most likely due to the brittle nature of the $\mathrm{MMC}$ materials. At $\mathrm{e} / \mathrm{d}=1.2$ the MMC specimen fails by edge shear pull-out and for values grater than $\mathrm{e} / \mathrm{d}=1.2$ the mode of failure is net-section failure. Fig 5.17 displays the effect of the e/d ratio on the ultimate strength of the bolted joint, for varying values of the w/d ratios. It is seen that the ultimate failure loads increase almost parabolically with the e/d ratios up to 5.0, but further increase in the e/d does not increase further the failure load. All the bolted joints that provided the data shown in Fig 5.17 are tested under finger tight conditions in order to eliminate the effect of lateral clamping pressure. Tables 5.1, 5.3 and 5.4 show the different ultimate tension loads for double-lap joints made of MMC materials by varying $\mathrm{e} / \mathrm{d}$ ratios, while keeping the $\mathrm{w} / \mathrm{d}$ ratios constant. It is clearly seen that for e/d greater than 1.2 , the ultimate load increases until it reaches a maximum value beyond which there is

no further increase with the e/d ratio. Therefore, for an ideal bolted joint the e/d ratio should be chosen such as to avoid edge shear-pullout. The maximum net section fracture is obtained at $\mathrm{e} / \mathrm{d}=5.0$, beyond which there is no increase in the ultimate failure load. 
Table 5.1-Variation of the failure load of MMC joint specimens with the e $/ \mathrm{d}$ for $\mathrm{w} / \mathrm{d}=4.0$

\begin{tabular}{|l|l|l|l|l|l|l|}
\hline No: & $\begin{array}{l}\mathrm{e} \\
\text { (in) }\end{array}$ & $\begin{array}{l}\mathrm{d} \\
\text { (in) }\end{array}$ & $\begin{array}{l}\mathrm{e} / \mathrm{d} \\
\text { Ratio }\end{array}$ & $\begin{array}{l}\text { Maximum } \\
\text { clamping } \\
\text { force=2640lbs }\end{array}$ & $\begin{array}{l}\text { Mode of } \\
\text { failure }\end{array}$ & $\begin{array}{l}\text { Failure } \\
\text { Load } \\
\text { (lbs) }\end{array}$ \\
\hline $1 \mathrm{a}$ & 0.6 & 0.5 & 1.2 & 50 & $\begin{array}{l}\text { Shear } \\
\text { Pull-out }\end{array}$ & 516 \\
\hline $1 \mathrm{~b}$ & 0.6 & 0.5 & 1.2 & 1000 & $\begin{array}{l}\text { Shear } \\
\text { Pull-out }\end{array}$ & 916.42 \\
\hline $1 \mathrm{c}$ & 0.6 & 0.5 & 1.2 & 2000 & $\begin{array}{l}\text { Shear } \\
\text { Pull-out }\end{array}$ & 1597.31 \\
\hline $2 \mathrm{a}$ & 1 & 0.5 & 2 & 50 & $\begin{array}{l}\text { Net } \\
\text { Section }\end{array}$ & 1493.63 \\
\hline $2 \mathrm{~b}$ & 1 & 0.5 & 2 & 1000 & $\begin{array}{l}\text { Net } \\
\text { Section }\end{array}$ & 2144.51 \\
\hline $2 \mathrm{c}$ & 1 & 0.5 & 2 & 2000 & $\begin{array}{l}\text { Net } \\
\text { Section }\end{array}$ & 2494.91 \\
\hline $3 \mathrm{a}$ & 1.5 & 0.5 & 3 & 50 & $\begin{array}{l}\text { Net } \\
\text { Section }\end{array}$ & 1739.57 \\
\hline $3 \mathrm{~b}$ & 1.5 & 0.5 & 3 & 1000 & $\begin{array}{l}\text { Net } \\
\text { Section }\end{array}$ & 2095.06 \\
\hline $3 \mathrm{c}$ & 1.5 & 0.5 & 3 & 2000 & $\begin{array}{l}\text { Net } \\
\text { Section }\end{array}$ & 2949.42 \\
\hline $4 \mathrm{a}$ & 2 & 0.5 & 4 & 50 & $\begin{array}{l}\text { Net } \\
\text { Section }\end{array}$ & 2120.65 \\
\hline $5 \mathrm{a}$ & 2.5 & 0.5 & 5 & 50 & $\begin{array}{l}\text { Net } \\
\text { Section }\end{array}$ & 2277.19 \\
\hline
\end{tabular}

Table 5.2-Variation of the failure load of MMC joint specimens and aluminum joint specimens with $\mathrm{e} / \mathrm{d}$ ratio for $\mathrm{w} / \mathrm{d}=4.0$

\begin{tabular}{|l|l|l|l|l|l|}
\hline $\begin{array}{l}\text { No of } \\
\text { specimens }\end{array}$ & $\begin{array}{l}\text { e/d } \\
\text { ratio }\end{array}$ & $\begin{array}{l}\text { Net-failure } \\
\text { load for } \\
\text { Aluminum } \\
\text { (experimental) } \\
\text { (lbs) }\end{array}$ & $\begin{array}{l}\text { Net-failure } \\
\text { Load for } \\
\text { Aluminum } \\
\text { (Euro } \\
\text { Code) } \\
\text { (lbs) }\end{array}$ & $\begin{array}{l}\text { Net-failure load for } \\
\text { MMC(Experimental) } \\
\text { (lbs) }\end{array}$ & $\begin{array}{l}\text { Net-failure } \\
\text { load for } \\
\text { MMC(Euro } \\
\text { code) } \\
\text { (lbs) }\end{array}$ \\
\hline 1 & 1.2 & 3229.518 & 1230.9 & 516 & 1512.40 \\
\hline 2 & 2 & 5443.54 & 3395.87 & 1493.635 & 3288.6 \\
\hline 3 & 3 & 7465.67 & 5093.75 & 1739.571 & 5489.1 \\
\hline 4 & 4 & 7557.73 & 5093.75 & 2120.651 & 7673.4 \\
\hline 5 & 5 & 7641.977 & 5093.75 & 2277.198 & 9880.38 \\
\hline
\end{tabular}


Table 5.3-Variation of the failure load of MMC joint specimens with the e/d ratio for $\mathrm{w} / \mathrm{d}=3.0$

\begin{tabular}{|l|l|l|l|l|l|l|}
\hline No: & $\begin{array}{l}\mathrm{e} \\
\text { (in) }\end{array}$ & $\begin{array}{l}\mathrm{d} \\
\text { (in) }\end{array}$ & $\begin{array}{l}\mathrm{e} / \mathrm{d} \\
\text { ratio }\end{array}$ & $\begin{array}{l}\text { Maximum } \\
\text { clamping } \\
\text { force=2640lbs }\end{array}$ & $\begin{array}{l}\text { Predicted } \\
\text { mode of } \\
\text { failure }\end{array}$ & $\begin{array}{l}\text { Failure } \\
\text { load } \\
\text { (lbs) }\end{array}$ \\
\hline $6 \mathrm{a}$ & 0.6 & 0.5 & 1.2 & 50 & $\begin{array}{l}\text { Shear } \\
\text { out }\end{array}$ & 489.64 \\
\hline $7 \mathrm{a}$ & 1 & 0.5 & 2 & 50 & $\begin{array}{l}\text { Net } \\
\text { section }\end{array}$ & 1157.02 \\
\hline $8 \mathrm{a}$ & 1.5 & 0.5 & 3 & 50 & $\begin{array}{l}\text { Net } \\
\text { section }\end{array}$ & 1661.53 \\
\hline $9 \mathrm{a}$ & 2 & 0.5 & 4 & 50 & $\begin{array}{l}\text { Net } \\
\text { section }\end{array}$ & 1998.75 \\
\hline $10 \mathrm{a}$ & 2.5 & 0.5 & 5 & 50 & $\begin{array}{l}\text { Net } \\
\text { section }\end{array}$ & 2120.56 \\
\hline
\end{tabular}

Table 5.4-Variation of the failure load of MMC joint specimens with the e/d ratios for $\mathrm{w} / \mathrm{d}=8.0$

\begin{tabular}{|l|l|l|l|l|l|l|}
\hline No: & $\begin{array}{l}\mathrm{e} \\
\text { (in) }\end{array}$ & $\begin{array}{l}\mathrm{d} \\
\text { (in) }\end{array}$ & $\begin{array}{l}\text { e/d } \\
\text { Ratio }\end{array}$ & $\begin{array}{l}\text { Maximum } \\
\text { clamping } \\
\text { force=2640lbs }\end{array}$ & $\begin{array}{l}\text { Predicted } \\
\text { mode of } \\
\text { failure }\end{array}$ & $\begin{array}{l}\text { Failure } \\
\text { load } \\
\text { (lbs) }\end{array}$ \\
\hline $11 \mathrm{a}$ & 0.6 & 0.5 & 1.2 & 50 & $\begin{array}{l}\text { Shear } \\
\text { out }\end{array}$ & 1066.75 \\
\hline $12 \mathrm{a}$ & 1 & 0.5 & 2 & 50 & $\begin{array}{l}\text { Net } \\
\text { section }\end{array}$ & 1604 \\
\hline $13 \mathrm{a}$ & 1.5 & 0.5 & 3 & 50 & $\begin{array}{l}\text { Net } \\
\text { section }\end{array}$ & 1967.69 \\
\hline $14 \mathrm{a}$ & 2 & 0.5 & 4 & 50 & $\begin{array}{l}\text { Net } \\
\text { section }\end{array}$ & 2210.78 \\
\hline $15 \mathrm{a}$ & 2.5 & 0.5 & 5 & 50 & $\begin{array}{l}\text { Net } \\
\text { section }\end{array}$ & 2312 \\
\hline
\end{tabular}




\subsection{Effect of w/d ratio}

An increase in the $\mathrm{w} / \mathrm{d}$ ratio also increases the ultimate net section failure load of the bolted joints made of MMC material. The joints were tested for $\mathrm{w} / \mathrm{d}=2.0,4.0$ and 8.0, and all the specimens failed in the net section mode. For $\mathrm{w} / \mathrm{d}=4.0$ and $\mathrm{w} / \mathrm{d}=8.0$ the expected mode of failure was bearing as in the case of aluminum. However, because of the brittle nature of the MMC material, all the specimens failed in transverse shearing at the holes. The maximum net section failure strength was obtained at $\mathrm{w} / \mathrm{d}=8.0$, beyond which the increase in maximum failure load with the w/d ratio was minimal. Tables 5.5, 5.6, 5.7 and 5.8 show the variation of the net-section failure load with increasing values of the $\mathrm{w} / \mathrm{d}$ ratios.

Table 5.5-Variation of the tension failure load of MMC specimens with $\mathrm{w} / \mathrm{d}=1.2$

\begin{tabular}{|l|l|l|l|l|}
\hline No: & $\begin{array}{l}\text { w/d } \\
\text { ratio }\end{array}$ & $\begin{array}{l}\text { Maximum } \\
\text { clamping } \\
\text { force=26401bs }\end{array}$ & $\begin{array}{l}\text { Predicted } \\
\text { mode of } \\
\text { failure }\end{array}$ & $\begin{array}{l}\text { Failure } \\
\text { Load } \\
(\mathrm{lbs})\end{array}$ \\
\hline 1 & 3 & 50 & $\begin{array}{l}\text { Shear } \\
\text { out }\end{array}$ & 489.64 \\
\hline 2 & 4 & 50 & $\begin{array}{l}\text { Shear } \\
\text { out }\end{array}$ & 516 \\
\hline 3 & 8 & 50 & $\begin{array}{l}\text { Shear } \\
\text { out }\end{array}$ & 1066.75 \\
\hline
\end{tabular}

Table 5.6-Variation of the tension failure load of MMC specimens with w/d =2

\begin{tabular}{|l|l|l|l|l|}
\hline No: & $\begin{array}{l}\text { w/d } \\
\text { ratio }\end{array}$ & $\begin{array}{l}\text { Maximum } \\
\text { clamping } \\
\text { force=26401bs }\end{array}$ & $\begin{array}{l}\text { Predicted } \\
\text { mode of } \\
\text { failure }\end{array}$ & $\begin{array}{l}\text { Failure } \\
\text { Load } \\
(\mathrm{lbs})\end{array}$ \\
\hline 1 & 3 & 50 & $\begin{array}{l}\text { Net } \\
\text { section }\end{array}$ & 1157.02 \\
\hline 2 & 4 & 50 & $\begin{array}{l}\text { Net } \\
\text { section }\end{array}$ & 1493.63 \\
\hline 3 & 8 & 50 & $\begin{array}{l}\text { Net } \\
\text { section }\end{array}$ & 1604 \\
\hline
\end{tabular}


Table 5.7-Variation of the tension failure load of MMC specimens with $\mathrm{w} / \mathrm{d}=3$

\begin{tabular}{|l|l|l|l|l|}
\hline No: & $\begin{array}{l}\text { w/d } \\
\text { ratio }\end{array}$ & $\begin{array}{l}\text { Maximum } \\
\text { clamping } \\
\text { force=2640lbs }\end{array}$ & $\begin{array}{l}\text { Predicted } \\
\text { mode of } \\
\text { failure }\end{array}$ & $\begin{array}{l}\text { Failure } \\
\text { Load } \\
\text { (lbs) }\end{array}$ \\
\hline 1 & 3 & 50 & $\begin{array}{l}\text { Net } \\
\text { section }\end{array}$ & 1661.53 \\
\hline 2 & 4 & 50 & $\begin{array}{l}\text { Net } \\
\text { section }\end{array}$ & 1739.57 \\
\hline 3 & 8 & 50 & $\begin{array}{l}\text { Net } \\
\text { section }\end{array}$ & 1967.69 \\
\hline
\end{tabular}

Table 5.8-Variation of the tension failure load of MMC specimens with $\mathrm{w} / \mathrm{d}=4$

\begin{tabular}{|l|l|l|l|l|}
\hline No: & $\begin{array}{l}\text { w/d } \\
\text { ratio }\end{array}$ & $\begin{array}{l}\text { Maximum } \\
\text { clamping } \\
\text { force=2640lbs }\end{array}$ & $\begin{array}{l}\text { Predicted } \\
\text { mode of } \\
\text { failure }\end{array}$ & $\begin{array}{l}\text { Failure } \\
\text { Load } \\
\text { (bs) }\end{array}$ \\
\hline 1 & 3 & 50 & $\begin{array}{l}\text { Net } \\
\text { section }\end{array}$ & 1998.75 \\
\hline 2 & 4 & 50 & $\begin{array}{l}\text { Net } \\
\text { section }\end{array}$ & 2120.65 \\
\hline 3 & 8 & 50 & $\begin{array}{l}\text { Net } \\
\text { section }\end{array}$ & 2210.56 \\
\hline
\end{tabular}

Table 5.9-Variation of the tension failure load of MMC specimens with $\mathrm{w} / \mathrm{d}=5$

\begin{tabular}{|l|l|l|l|l|}
\hline No: & $\begin{array}{l}\text { w/d } \\
\text { ratio }\end{array}$ & $\begin{array}{l}\text { Maximum } \\
\text { clamping } \\
\text { force=2640lbs }\end{array}$ & $\begin{array}{l}\text { Predicted } \\
\text { mode of } \\
\text { failure }\end{array}$ & $\begin{array}{l}\text { Failure } \\
\text { Load } \\
\text { (bs) }\end{array}$ \\
\hline 1 & 3 & 50 & $\begin{array}{l}\text { Net } \\
\text { section }\end{array}$ & 2120.56 \\
\hline 2 & 4 & 50 & $\begin{array}{l}\text { Net } \\
\text { section }\end{array}$ & 2277.19 \\
\hline 3 & 8 & 50 & $\begin{array}{l}\text { Net } \\
\text { section }\end{array}$ & 2312 \\
\hline
\end{tabular}



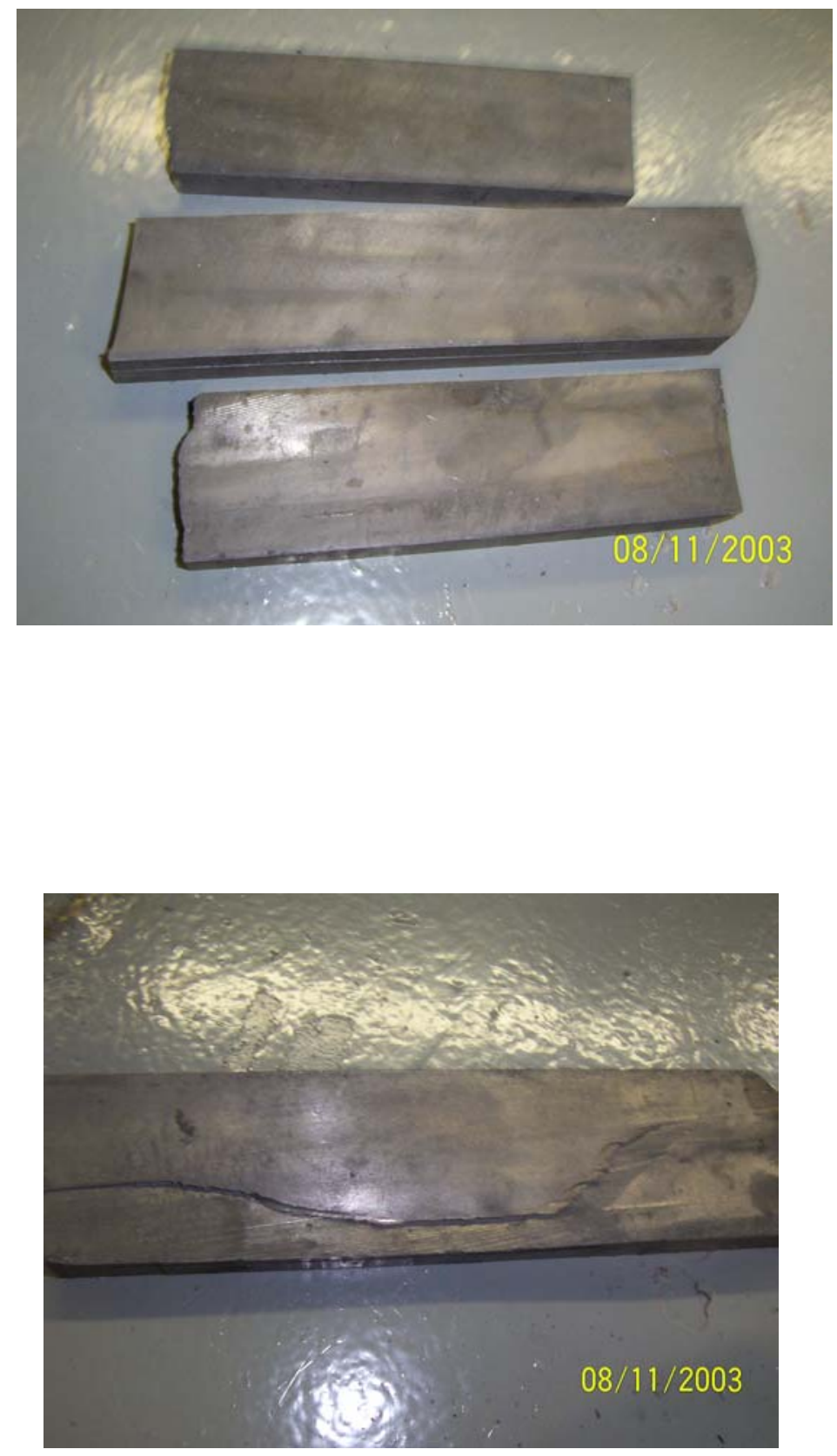

Fig: 5.1 MMC specimens as cut from cast block 

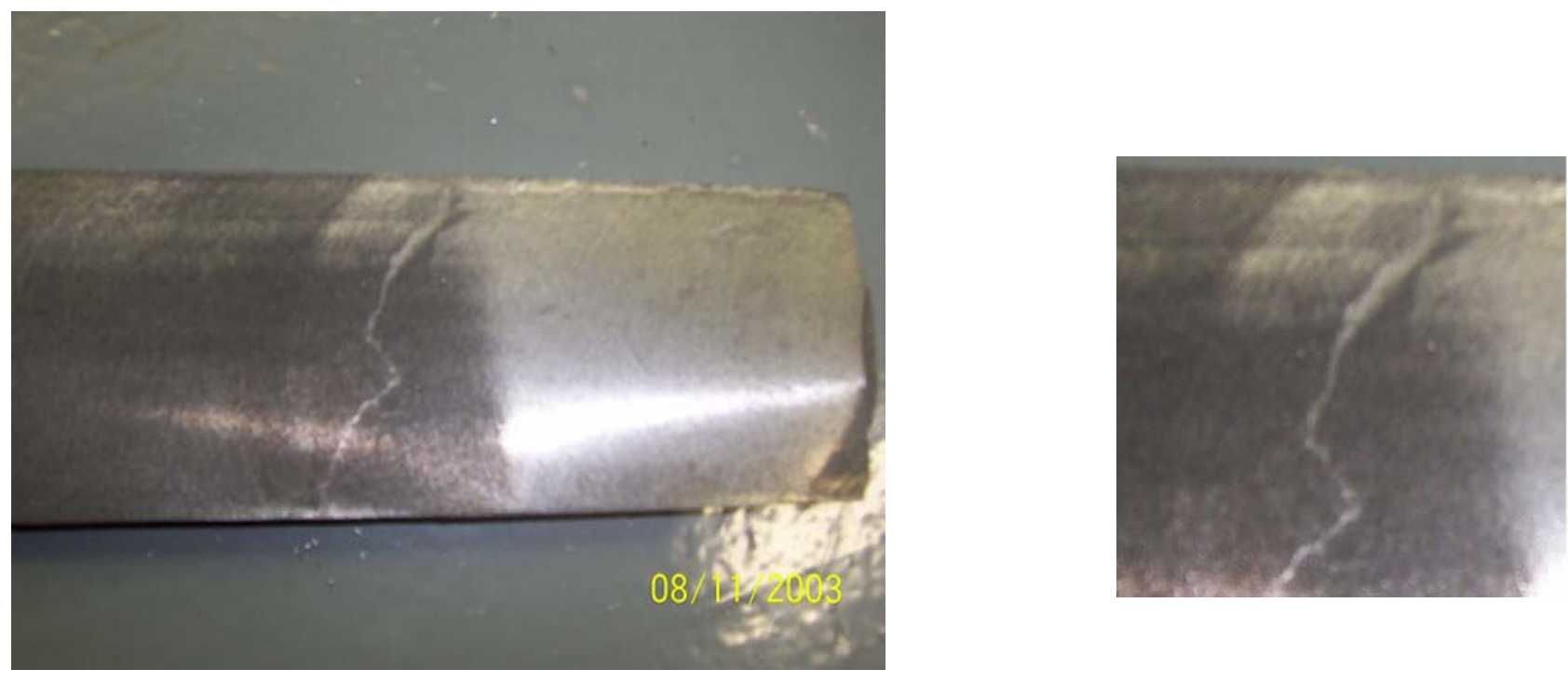

Fig: 5.2 MMC specimens with initial defect in the transverse direction
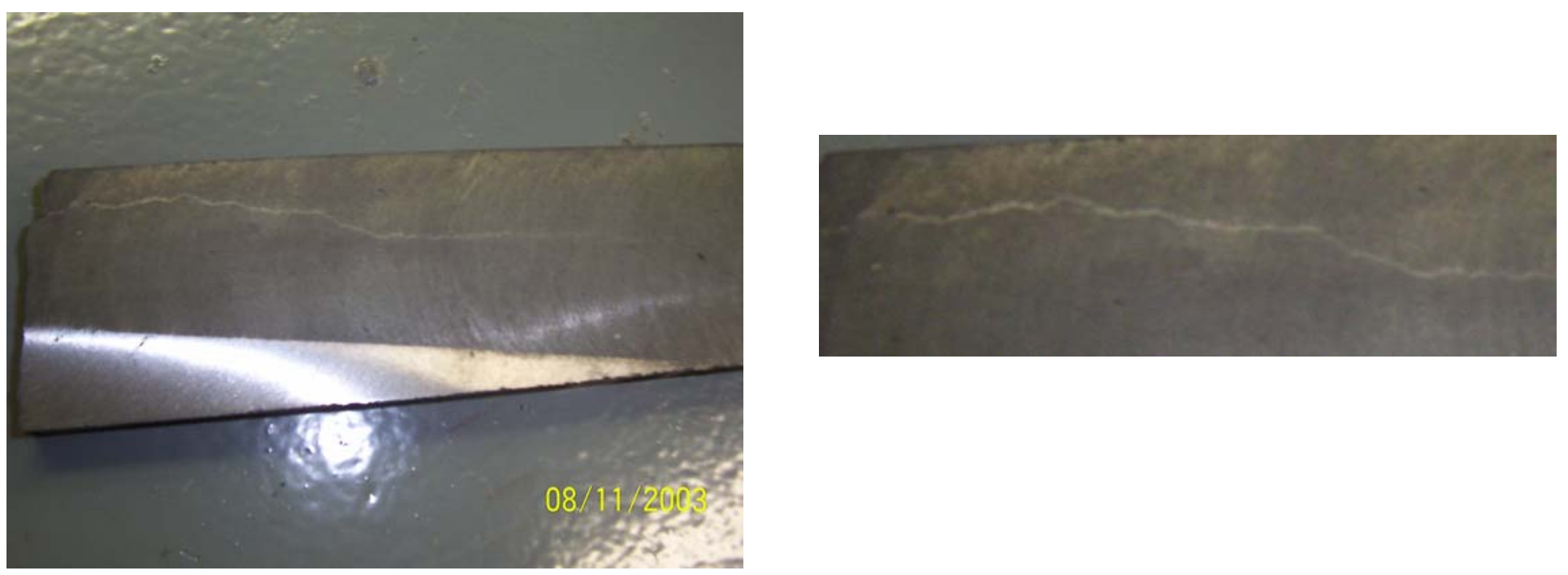

Fig: 5.3 MMC specimens with defect in the longitudinal direction 

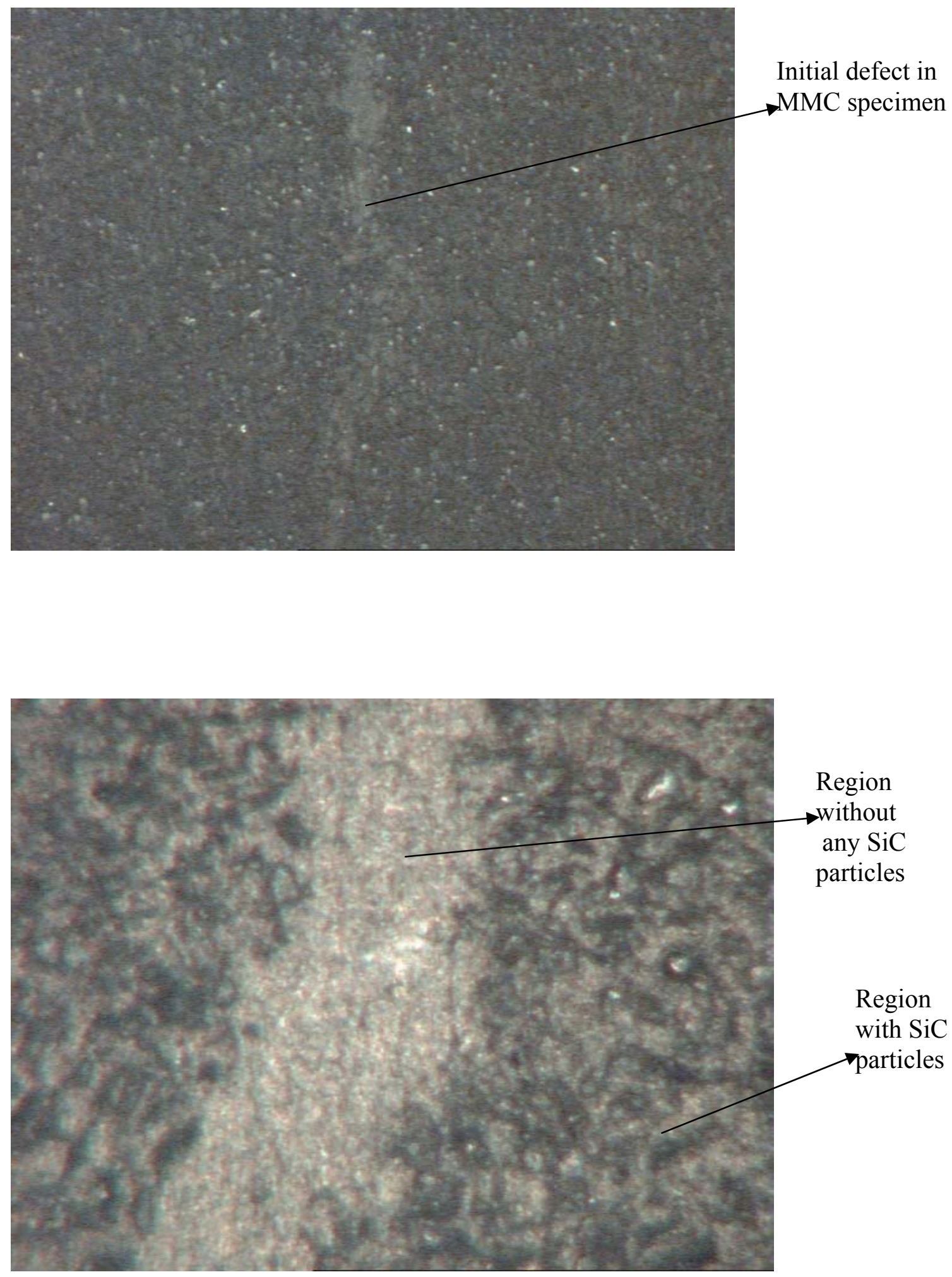

Fig: 5.4 Microscopic views of MMC specimens showing region without any $\mathrm{SiC}$ particles 

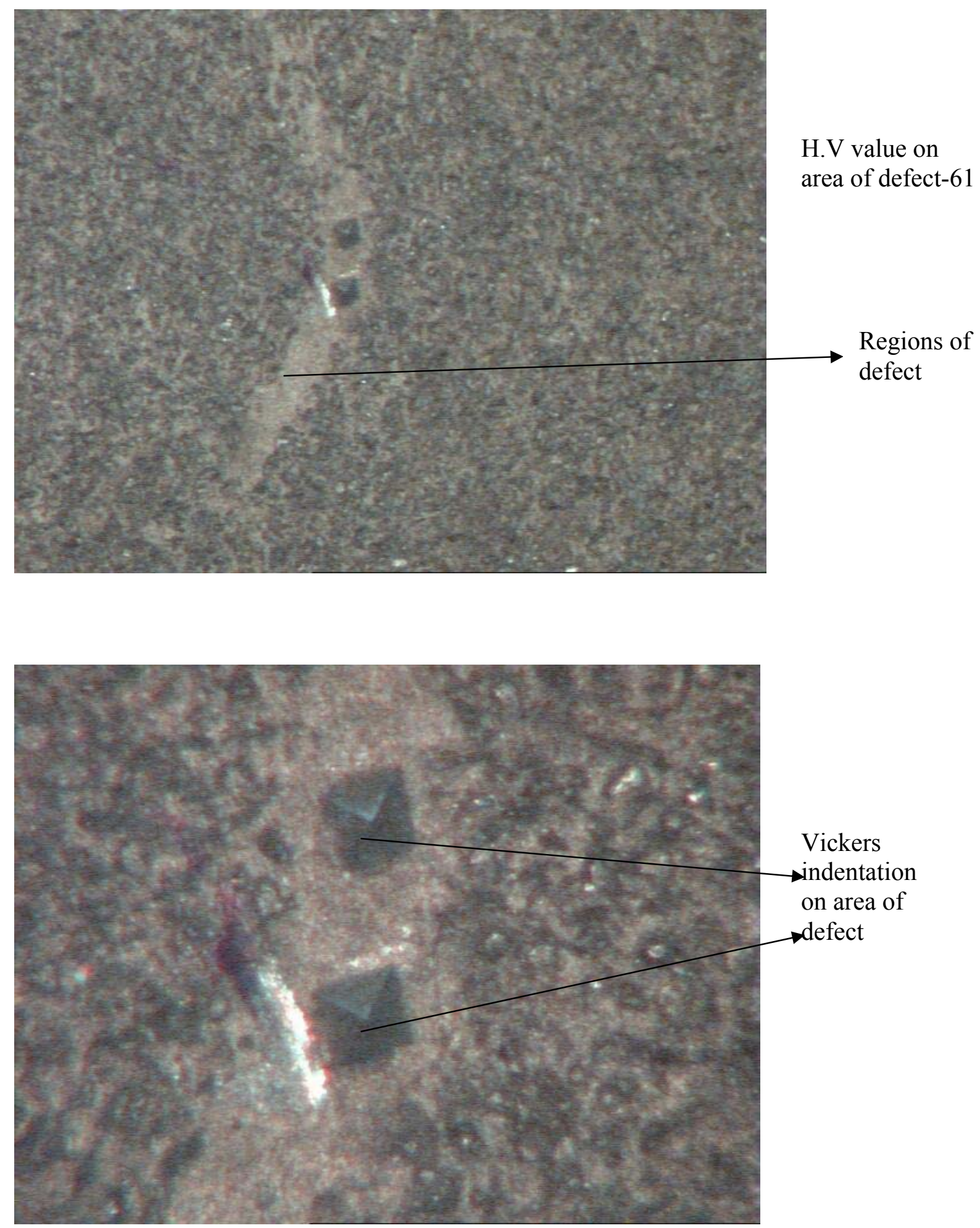

Fig: 5.5 Microscopic views of MMC specimens with Vickers indentation on regions of defect 


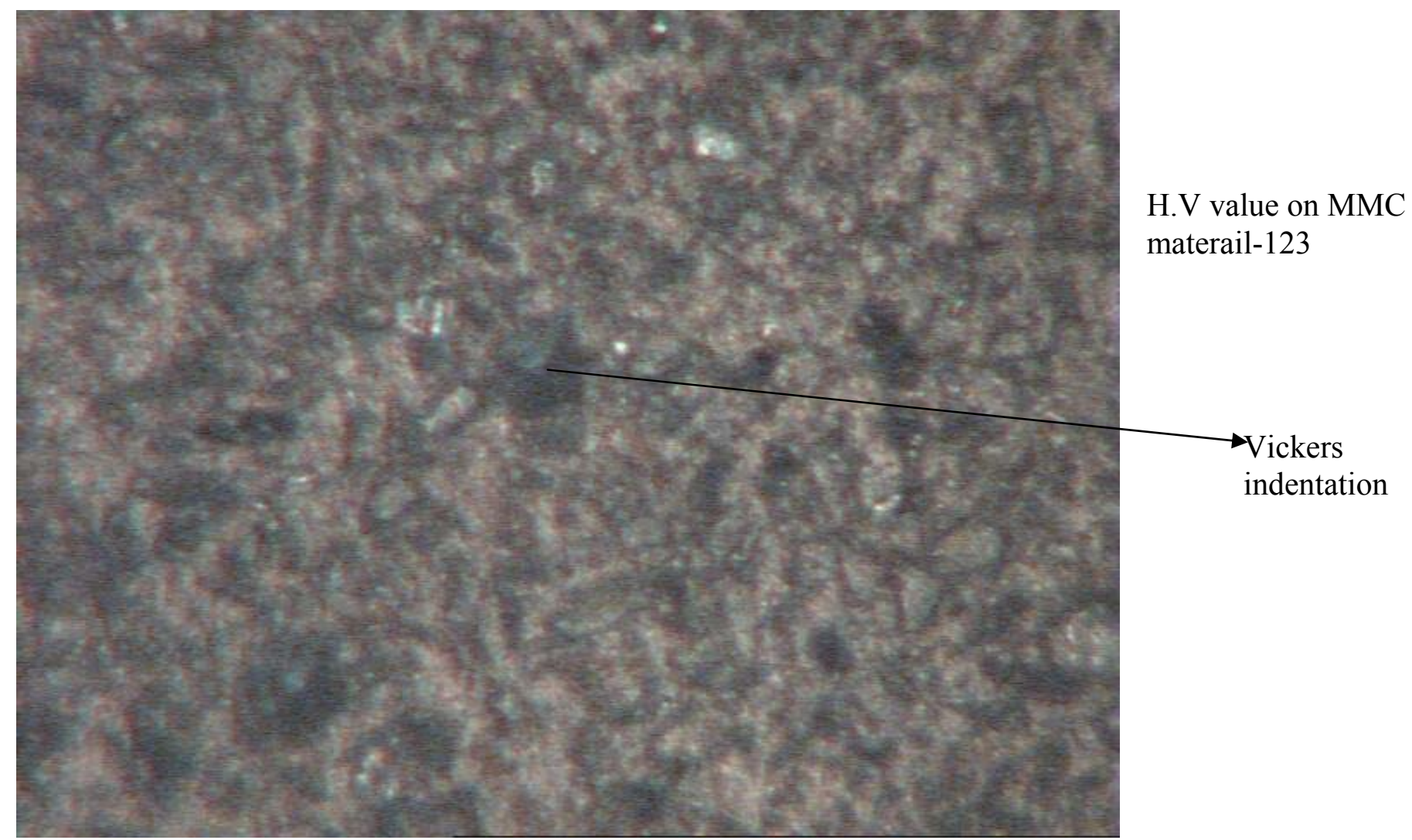

Fig: 5.6 Microscopic views of MMC specimens with Vickers indentation on regions with uniform distribution of $\mathrm{SiC}$ particles 


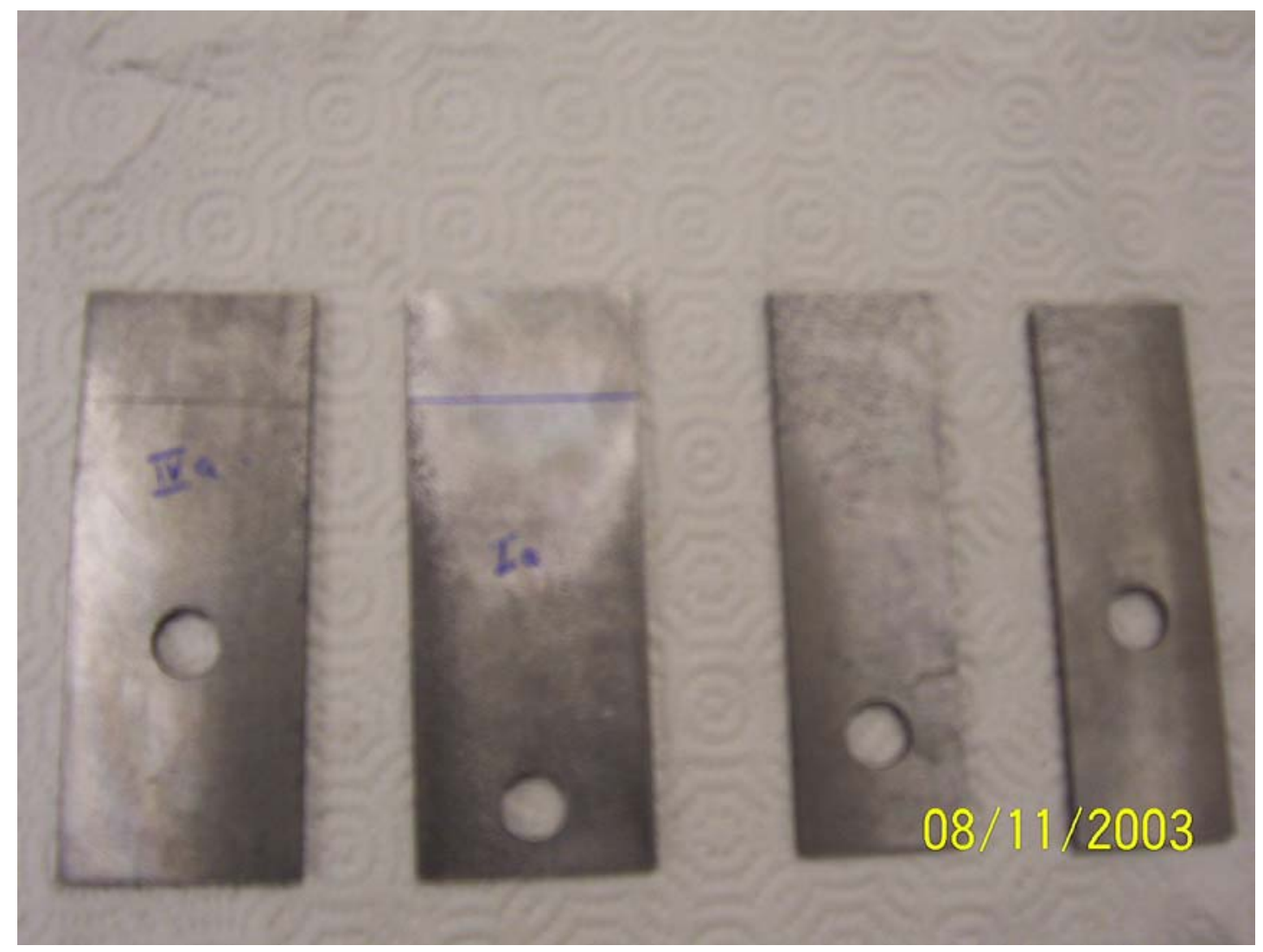

Fig: 5.7 MMC specimens prepared for bolted joint testing 


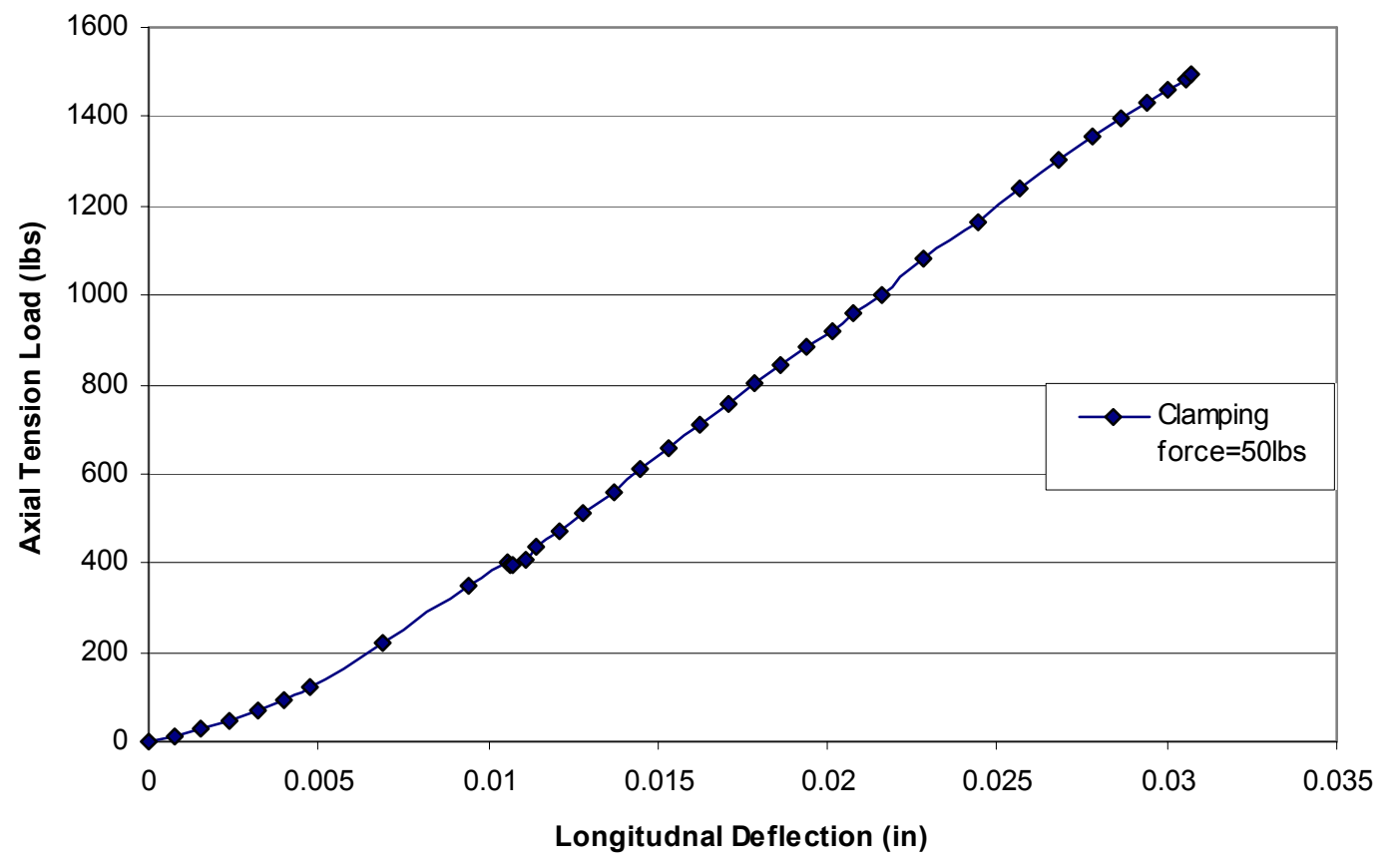

Fig: 5.8 Load deflection curve of MMC joint for $\mathrm{e} / \mathrm{d}=2$ and $\mathrm{w} / \mathrm{d}=4$ 


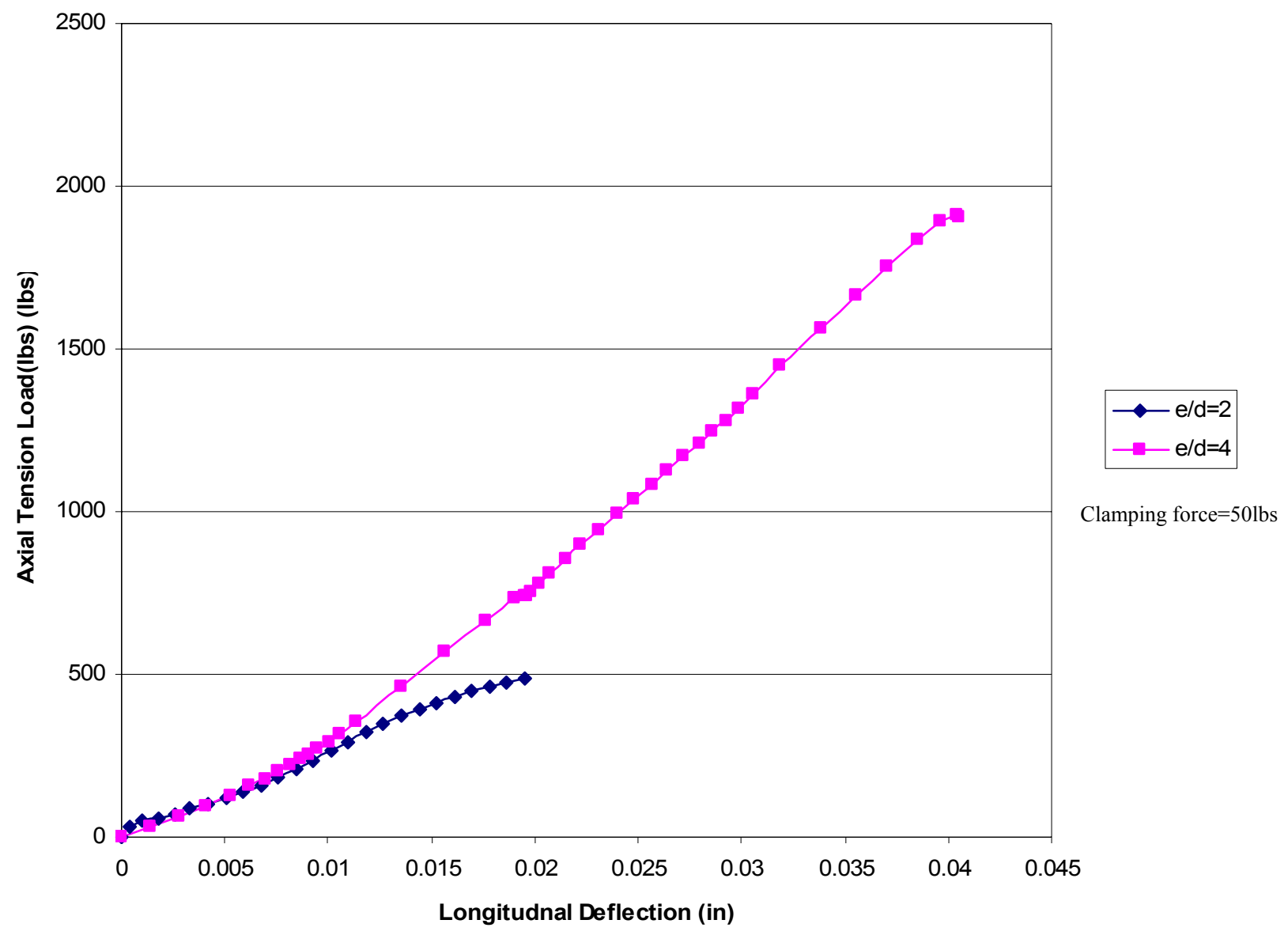

Fig: 5.9 Load deflection curve of MMC joint specimen for $\mathrm{w} / \mathrm{d}=3$ 


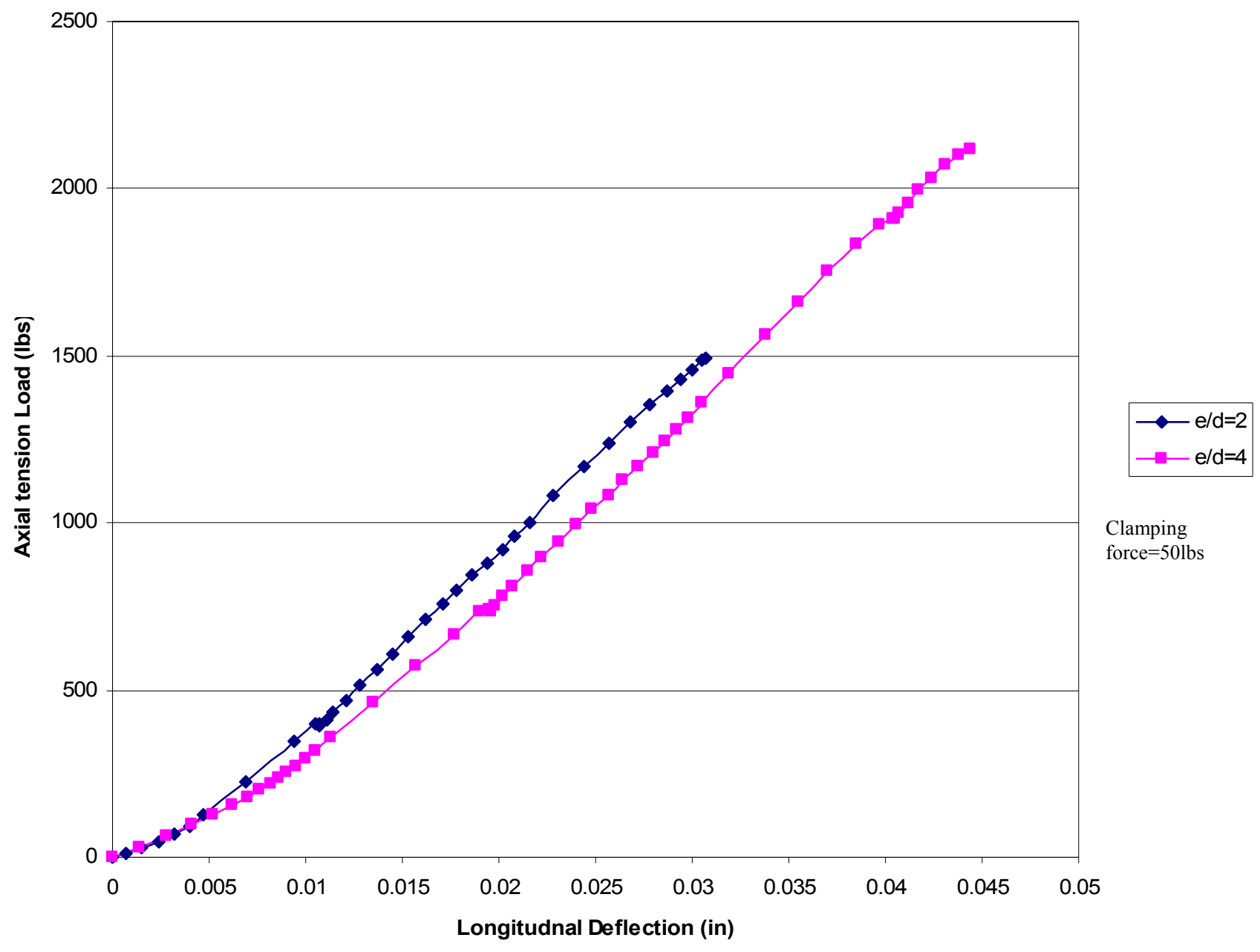

Fig: 5.10 Load deflection curve of MMC joint specimen for $\mathrm{w} / \mathrm{d}=4$ 


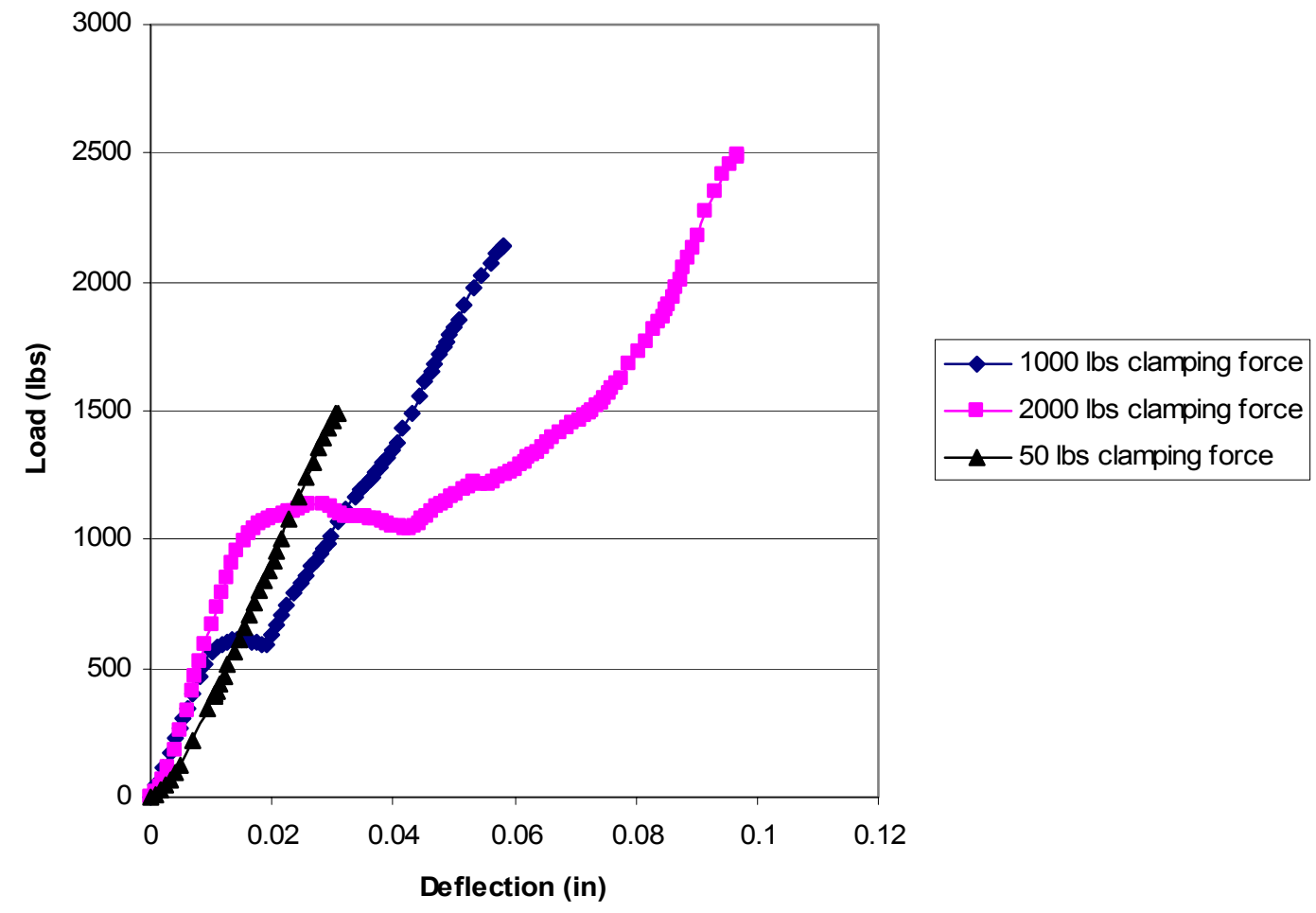

Fig: 5.11 Load deflection curve of MMC joint specimen for different clamping loads for $\mathrm{e} / \mathrm{d}=2$ and $\mathrm{w} / \mathrm{d}=4$ 


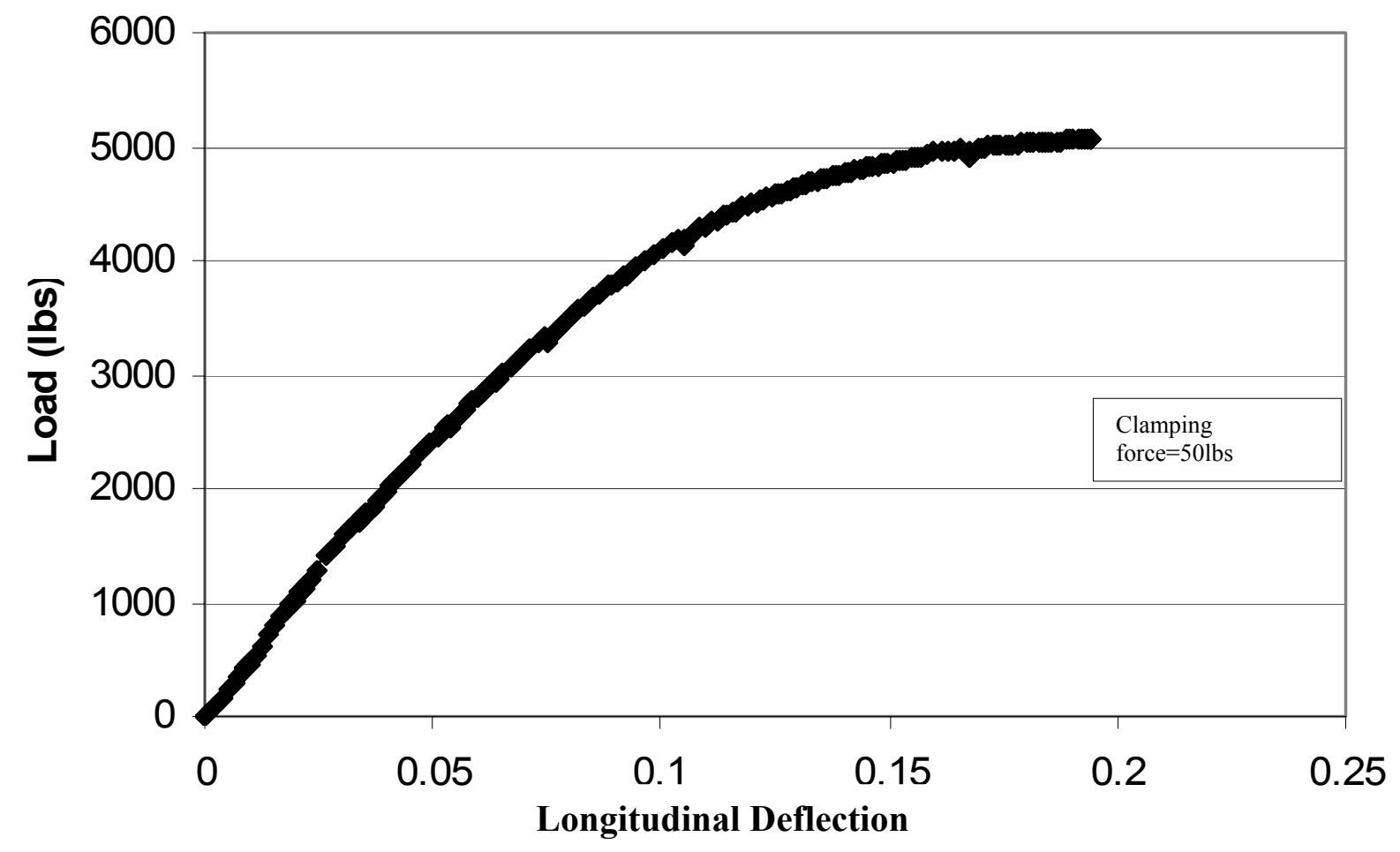

Fig: 5.12 Load deflection curve of aluminum material for $\mathrm{e} / \mathrm{d}=2$ and $\mathrm{w} / \mathrm{d}=4$ 


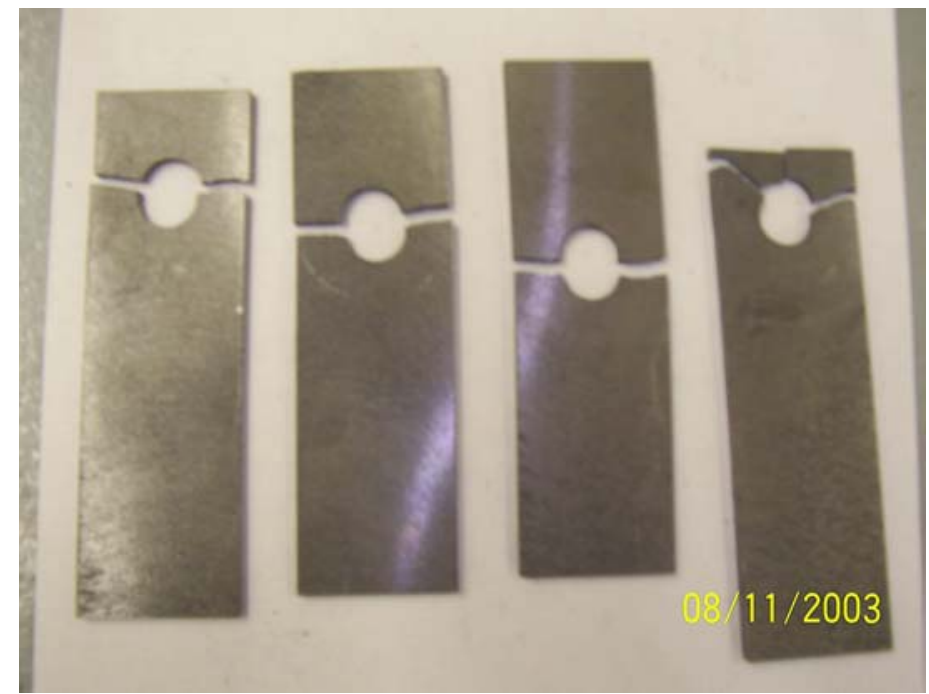

Fig: 5.13 Net-section failure in MMC joints for $\mathrm{w} / \mathrm{d}=3$

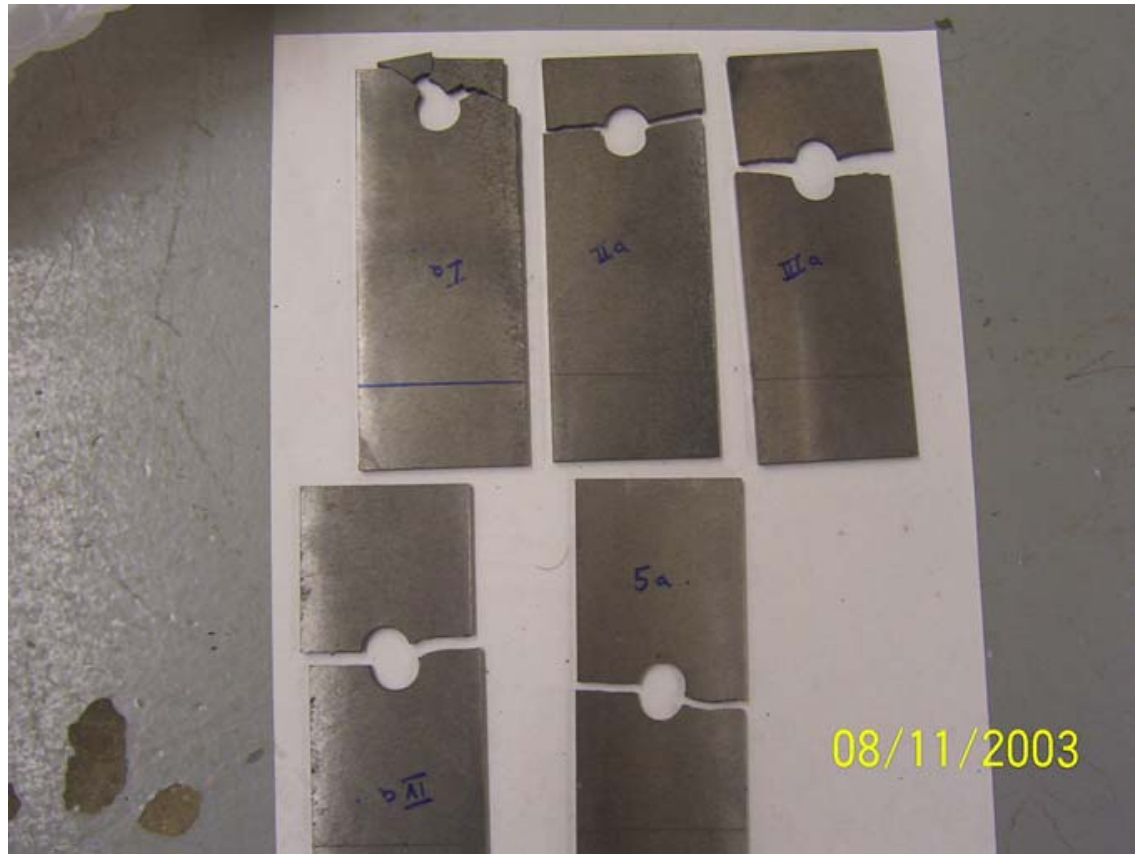

Fig: 5.14 Net-section failure in MMC joints for $\mathrm{w} / \mathrm{d}=4$ 

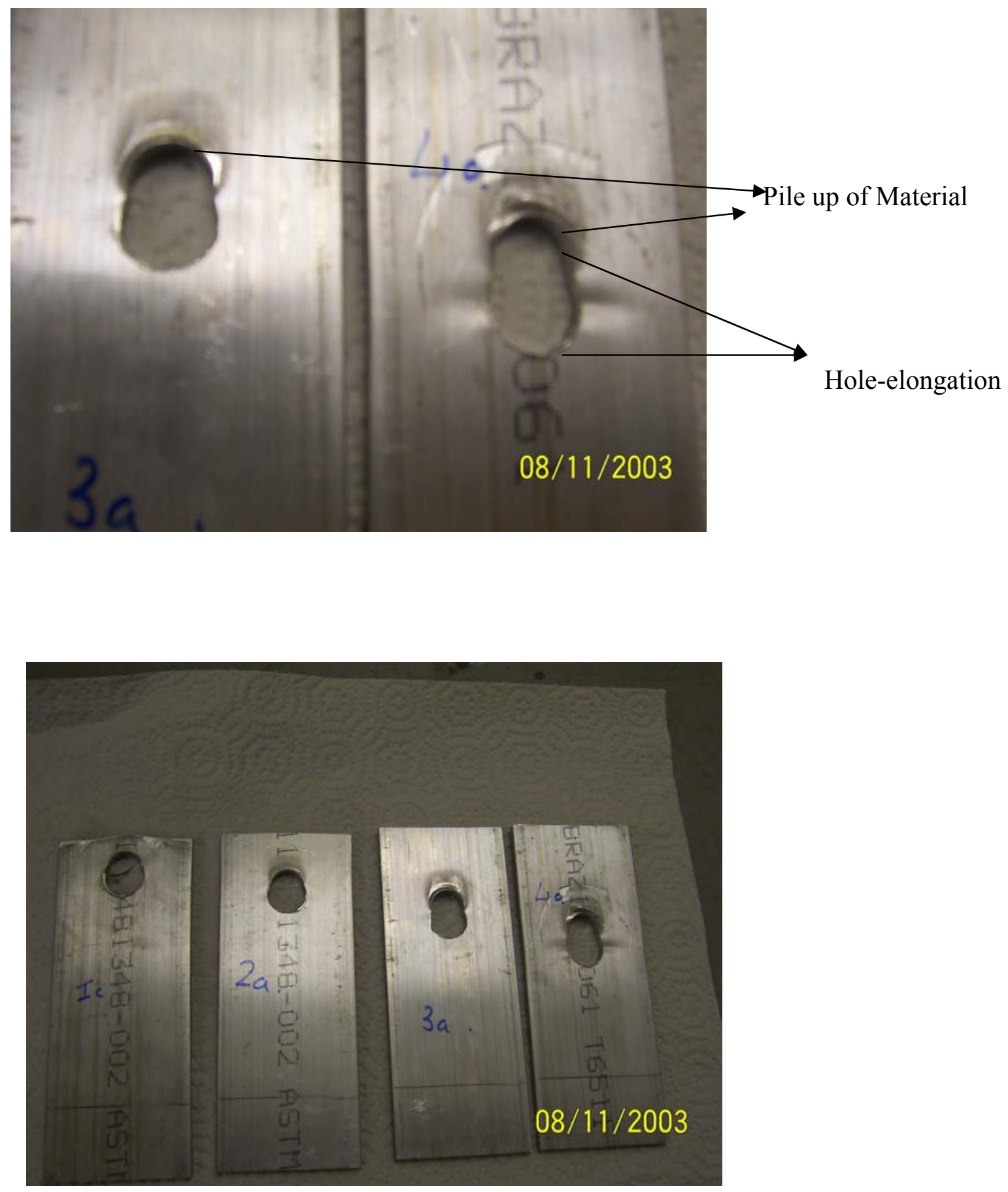

Fig: 5.15 Bearing Failure in Aluminum Joints for $\mathrm{w} / \mathrm{d}=4$ 


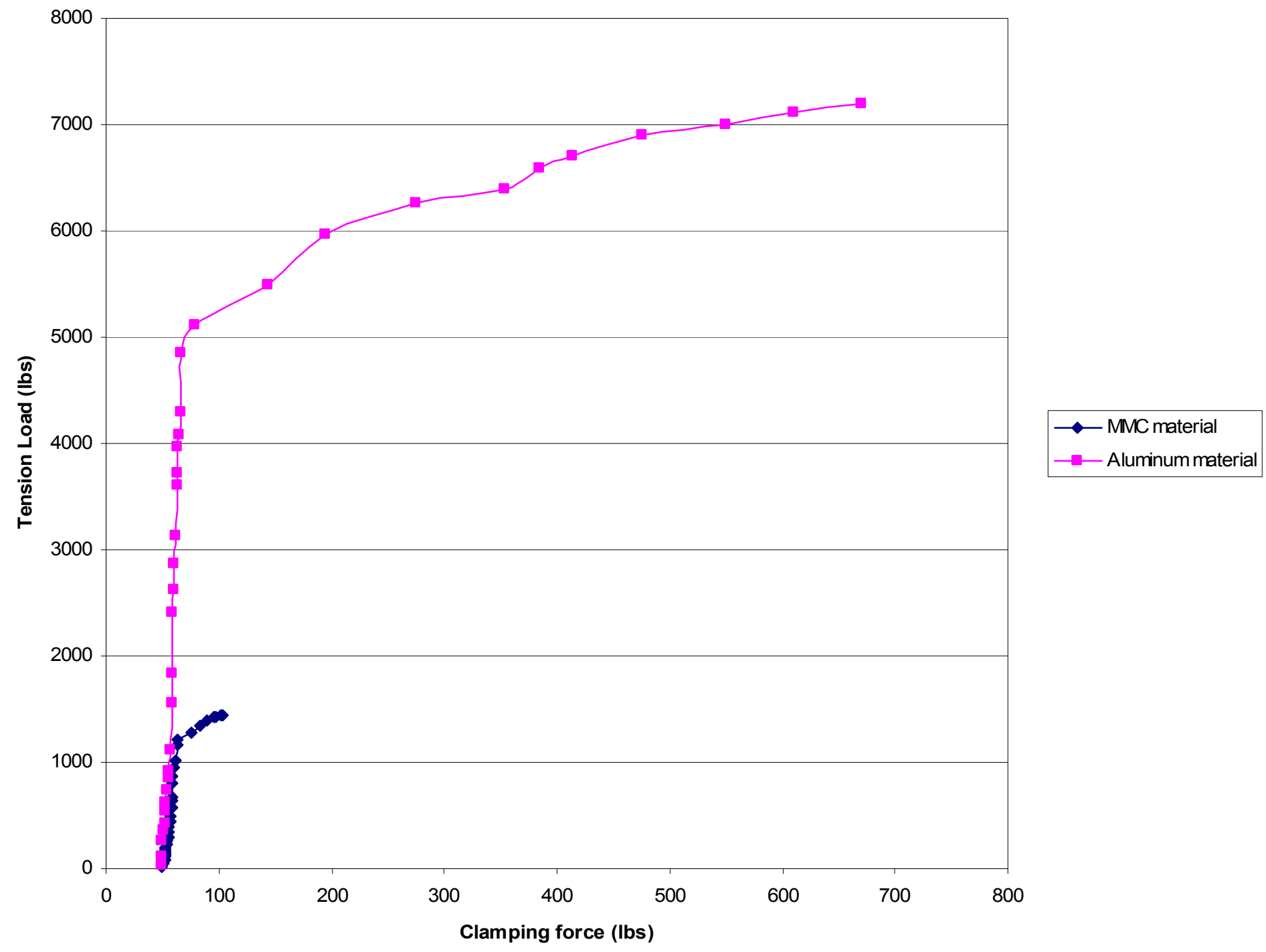

Fig: 5.16 Variation of clamping force with applied tension loading 


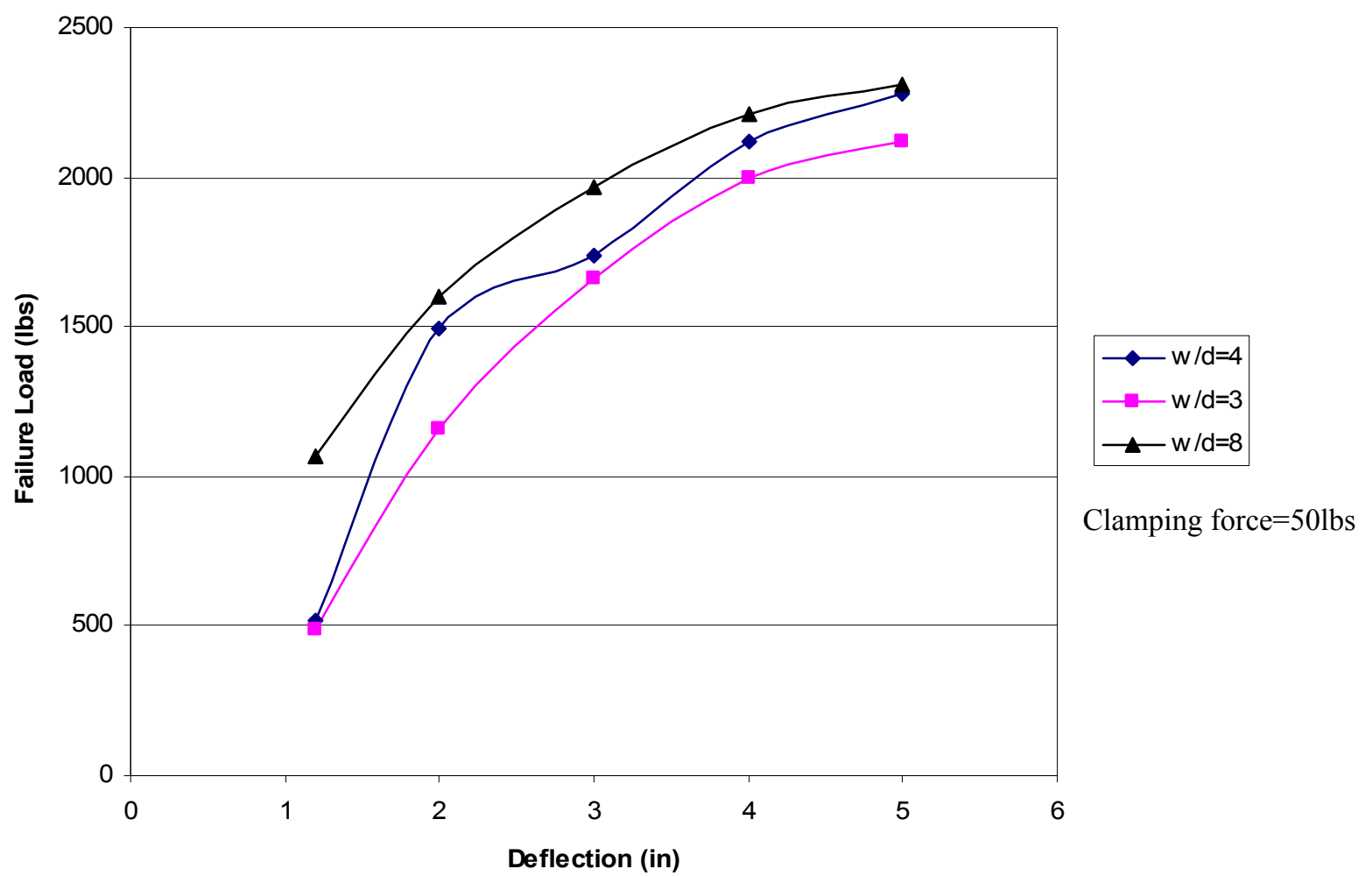

Fig: 5.17 Variation of net-failure load of MMC joints with the e/d ratio 


\subsection{Conclusions}

\section{CONCLUSIONS AND FUTURE WORK}

This study focuses primarily on the experimental characterization of $\mathrm{Al} / \mathrm{SiC}$ particulate metal matrix composite with $30-45 \%$ volume fraction of $\mathrm{SiC}$ particles. Various experiments, like tension, three-point bending, coefficient of thermal expansion and hardness tests, were conducted on specimens of the PRMMC material as well as on specimens of its original matrix alloy, according to the relevant ASTM standards. Following the characterization of the basic material properties, the behavior of double-lap joints was analyzed for various values of such parameters like e/d, w/d ratios, and clamping force magnitude. The test results were utilized for comparison of basic MMC materials and structural characteristics with those of the aluminum matrix including the differences between their typical modes of failure. From the test results generated by this study the following conclusions can be withdrawn.

1) The overall hardness of the material increases with any increase in the volume fraction of $\mathrm{SiC}$ particles.

2) The coefficient of thermal expansion of the MMC material decreases with increasing volume fraction of the $\mathrm{SiC}$ particles.

3) The Young's modulus of the MMC material also increases with an increase in the volume fraction of $\mathrm{SiC}$ particles. However, the ductility of the material decreases thus making the material very brittle when the volume fraction of $\mathrm{SiC}$ particles is increased.

4) Double-lap joints made of MMC material fail by net-section failure rather than the bearing mode of failure which is common for aluminum joints. Even for such a large w/d ratio as $\mathrm{w} / \mathrm{d}=8.0$, when the material was expected to fail through bearing, it actually failed through net-section failure and edge shear pull out.

5) The clamping force on a joint made of the MMC material does not increase during uniaxial loading as much as in case of aluminum joints. The tension load displacement curve of MMC joints shows that the material does not yield before failure and the fracture is sudden, as opposed to aluminum, where considerable yielding is noticeable.

6) Slip between the jointed plates is noticeable at clamping force levels larger than $1000 \mathrm{lbs}$, when the friction force affects the failure strength of the bolted joints. 
7) It is noticed that that when the clamping force is increased to 1000 or $2000 \mathrm{lbs}$ the net section failure load also increases, which proves again the effect of lateral clamping pressure on failure strength of a double-lap joint.

8) The net section failure load increases with increasing the values of e/d and w/d until it becomes almost a constant. The highest values of the net section failure load was observed at $\mathrm{e} / \mathrm{d}=5.0$ and $\mathrm{w} / \mathrm{d}=8.0$ configuration of the double-lap joint.

\subsection{Recommendation}

The current study has investigated basic material properties of PRMMC materials, as well as the failure mechanism of PRMMC bolted joints.

1) The MMC materials tested in this study are found to be highly brittle and that is why other techniques of the pressure less infiltration method should be developed and evaluated.

2) Strain gages could not be mounted around the hole of the joint specimen due to difficulties encountered in machining of the MMC plates specimen. A design of the test specimen and set up that includes strain gages mounted around the holes of the bolted joint ought to be developed.

3) Microscopical studies involving crack propagation within the material ought to be conducted.

4) The testing of MMC bolted joints did not take into account the effect of friction between the steel grips and the MMC material A new model ought to be developed in order to incorporate the frictional effects.

6) Additional tests are necessary have to be done in order to derive an empirical equation for the failure load of a double-lap joint made of MMC material, as a function of the e/d and $\mathrm{w} / \mathrm{d}$ ratios. 


\section{BIBLIOGRAPHY}

1) T.W.Clyne and P.J Withers, An introduction to metal matrix composites, Cambridge university press, Cambridge, U.K; 1993

2) B.G.Park, A.G.Crosky and A.K Hellier, Material characterization and mechanical properties of $\mathrm{Al}_{2} \mathrm{O}_{3}$ metal matrix composites, J.Mater.Sci.36 (2001)

3) Manoj K.Jain, Velidandla V.Bhanuprasad, Samir V.Kamat, Avadh B.Pandey, Vijay K Varma, B.V Radhakrishna Bhat and Yashwant R.Mahajan, Processing, microstructure and properties of 2124Al-SiC composites, Engineering and technology (1993).

4) Mingzhao Tan, Qibin Xin, Zhenghua Li, B.Y.Zong, Influence of $\mathrm{SiC}$ and $\mathrm{Al}_{2} \mathrm{O}_{3}$ particulate reinforcements and heat treatments on mechanical properties and damage evolution of Al-2618 metal matrix composites.

5) L.M Tham, L.Su, L.Cheng and M.Gupta, Micromechanical modeling of processinginduced damage in Al-SiC metal matrix composites synthesized using the disintegrated melt deposition technique. Materials research bulletin, 34, (1999).

6) J.Yang, S.M.Pickard, C.Cady, A.G.Evans and R.Mehrabian, The stress/strain behavior of Aluminum matrix composites with discontinuous reinforcements, Acta metal, mater, Vol 39, (1991).

7) T.W.Lee, C.H.Lee, Statstical analysis for strength and spatial distribution of reinforcement in $\mathrm{SiC}$ particulate reinforced aluminum alloy fabricated by die-casting, J.Mater.Sci.35 (2000).

8) George Winter, Test on bolted joints in light gage steel, Journal structural division, Proceedings of the American society of civil engineers, paper 920, (1956).

9) Ken P.Chong, M.ASCE and Robert Matlock. Light-gage steel bolted connections with out washers, Journal of structural division, July (1975).

10) Colin.A.Rogers and Gregory J.Hancock, Failure modes of bolted-sheet -steel connections loaded in shear, Journal of structural engineering, March (2000).

11) R.Puthli and O.Fleisher, Investigations on bolted connections for high strength steel members, Journal of constructional steel research (2001). 
12) C.Cooper and G.J.Turvey, Effects of joint geometry and bolt torque on the structural performance of single bolt tension joints in pultruded GRP sheet material, Composite structures 32 (1995).

13) C.C Menzemer, L.Fei and T.S Srivatsan, Design criteria for bolted connection elements in Aluminum alloy 6061,Transactions of the ASME, Vol 121, September (1999). 14) C.C Menzemer, R.Ortiz-Morgado, R.Iascone and T.S Srivatsan, Bearing strength of selected Aluminum alloys, Aluminum 2001-Proceedings of the TMS (2001).

15) A.Toma, G.Sedlacek and K.Weynand, Connections in cold formed steel, Thin-walled structures 16 (1993).

16) E.R Bryan, The design of bolted joints in cold-formed steel connections, Thin-walled structures 16 (1993).

17) S.Seleim and R.LaBoube, Behavior of low ductility in cold-formed steel connections, Thin-walled structures.

18) S.Seleim and R. LaBoube, Behavior of low ductility steels in cold-formed steel connections, Thin-walled structures, Vol 25, No 2, (1996).

19) Hong-Sheng Wang, hang-Li Hung and Fu-Kuo Chang, Bearing failure of bolted composite joints.Part1 


\section{APPENDIX I}

\section{Instruments and tools used for microscopic analysis}

1) Sand Paper

Vendor: Buehler, Ph: 18002834537

Available: Hitachi Lab, MRB

Product Description: Sand paper grit sizes 240,320,400 and 600

2) Optical Microscope

Vendor: Brudersen Instrument

Address: 218 Mars-Valencia Rd,

Valenica, PA16059 Ph: 412-625-2920

Product Description: Magnification-75,100,200,300,400,500

Image Capturing Software: Optimas

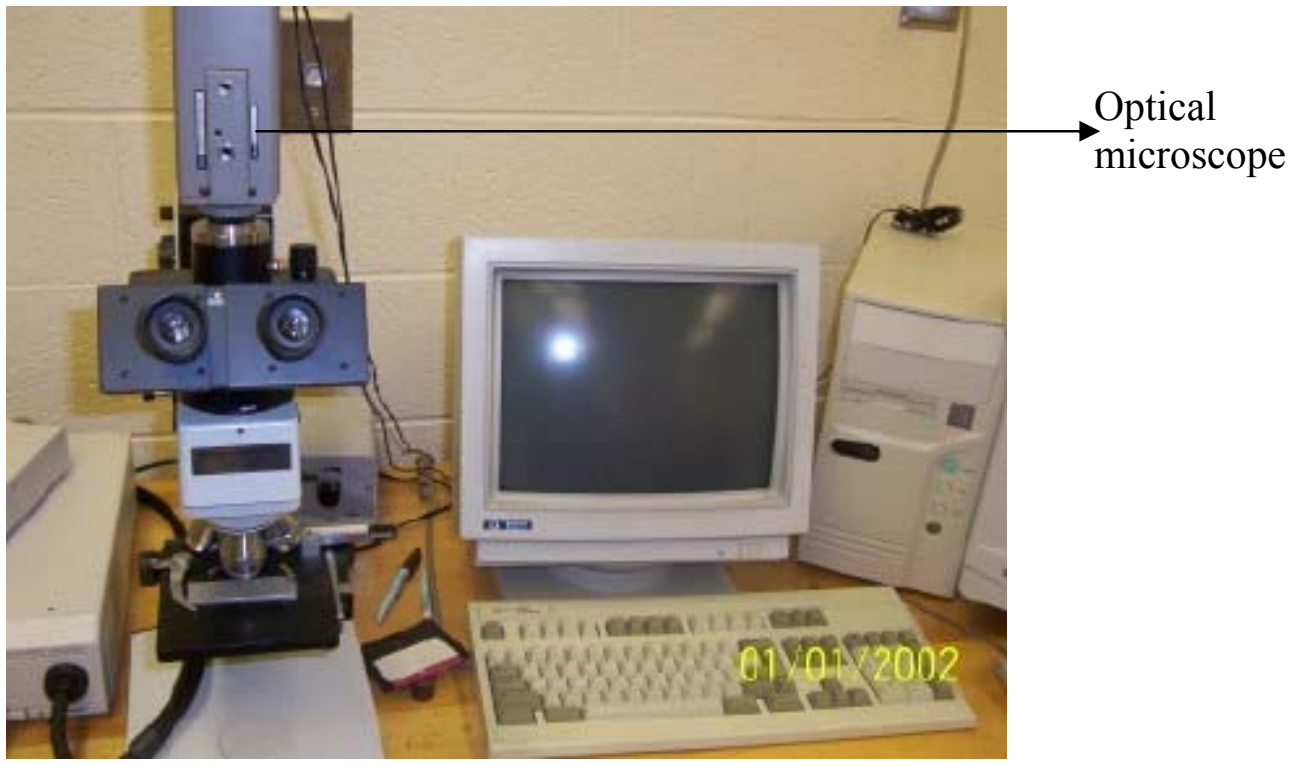

Fig Ia: Photo of optical microscope used to obtain microscopic view of MMC specimens 


\section{APPENDIX II}

\section{Specifications of extensometer used for measuring strain}

Extensometer Model: INSTRON 2620-826

Serial NO: X232

Tension F/S Travel: 0.1000 in

Compression F/S Travel: 0.1000 in

Gage Length: 0.5000

Range: \pm 0.1 in

Calibration Date: 04/08/1999

Calibration Method: Micrometer in extensometer calibartion frame

Available: ESB, B 60
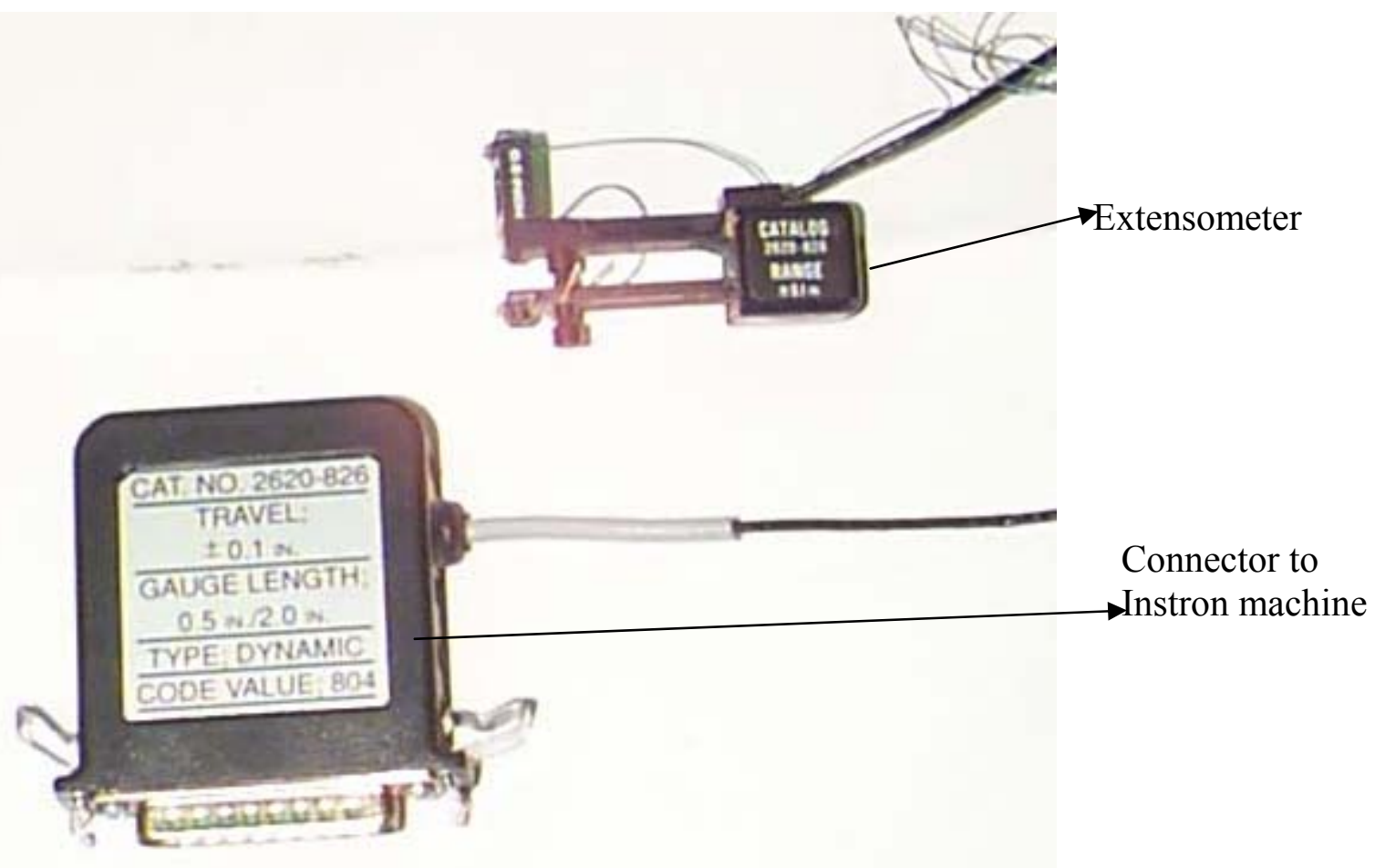

Fig IIa: Photo of Extensometer used for measuring strain 


\section{APPENDIX III}

\section{Specifications of Load cell}

Vendor: Transducer techniques

Address: 42480 Rio Nedo, Temecula, CA 92590,

(909) 719-3965 Fax (909) 719-3900

Serial Number: 127391

Sensor Model: THC-5K-T

Date of Calibration 05/16/2003

Date of Recalibration: 05/16/2003

$\begin{array}{lll}\text { Compression } & \begin{array}{l}\mathrm{MV} / \mathrm{V} \\ \text { Load }\end{array} & \begin{array}{l}\mathrm{MV} / \mathrm{V} \\ \mathrm{INC}\end{array} \\ \text { LBS } & & \\ 0.000 & 0.000 & 0.000 \\ 2500 & 1.1999 & 1.2001 \\ 5000 & 2.3958 & \end{array}$

$\begin{array}{lcc}\text { Non-Linearity } & -0.08 & \text { PCT FS } \\ \text { Non-Repeatability } & 0.09 & \text { PCT FS } \\ \text { Hystersis } & 0.01 & \text { PCT FS }\end{array}$

Shunt calibration

\begin{tabular}{llllc} 
Pct & load & signal & shunt & shunt \\
Load & lbs & MV/V & K ohms & pins \\
42.05 & 2102.40 & 1.0074 & 87.325 & $(-\mathrm{e},-\mathrm{s})$ \\
84.10 & 4204.81 & 2.0148 & 43.575 & $(-\mathrm{e},-\mathrm{s})$ \\
& \multicolumn{2}{c}{ Dpm-2 scale factor } & 0.6261 &
\end{tabular}

Calibration computed from three runs increasing and decreasing traceable to nist test \#63339 
Calibration performed at $10 \mathrm{vdc}$

Maximum bridge excitation $12 \mathrm{vdc}$

\begin{tabular}{|c|c|c|}
\hline \multicolumn{3}{|c|}{ Wiring } \\
\hline Pin & Color & Code \\
\hline $\mathrm{n} / \mathrm{a}$ & red & +excitation \\
\hline $\mathrm{n} / \mathrm{a}$ & black & -excitation \\
\hline $\mathrm{n} / \mathrm{a}$ & green & + signal \\
\hline$n / a$ & white & -signal \\
\hline & shield & ground \\
\hline
\end{tabular}

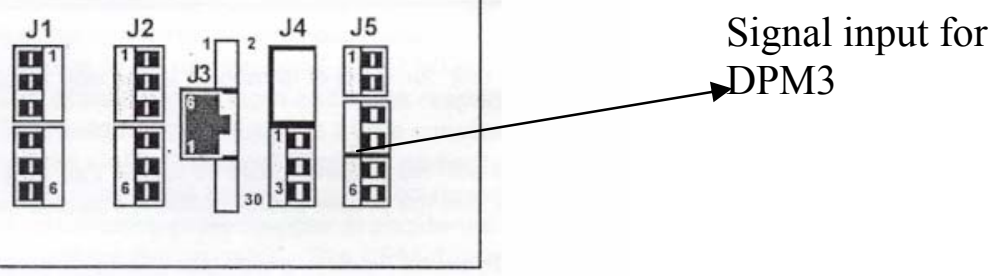

$4.3 \quad$ J5 - SIGNAL INPUT

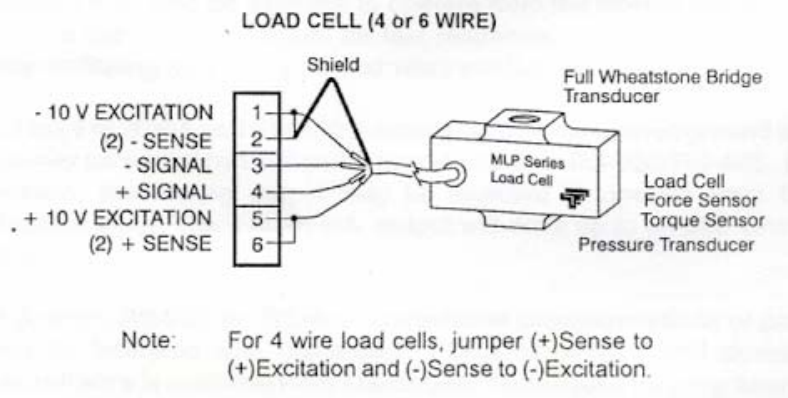

Fig IIIa: Photo of Extensometer used for measuring strain 


\section{APPENDIX IV}

\section{Diamond tools used for cutting MMC specimens}

1) Diamond saw

Vendor: DO ALL Pittsburgh

Address: 905 Lincoln HWY Rt30 East,

East McKeesport, PA, 15035-0170, Ph: 1800-92-DoALL

Product Description: Segmented diamond band saw, 40/50 grit

Dimensions: $(3 / 4 " * 0.20 " * 11$ '.6”)

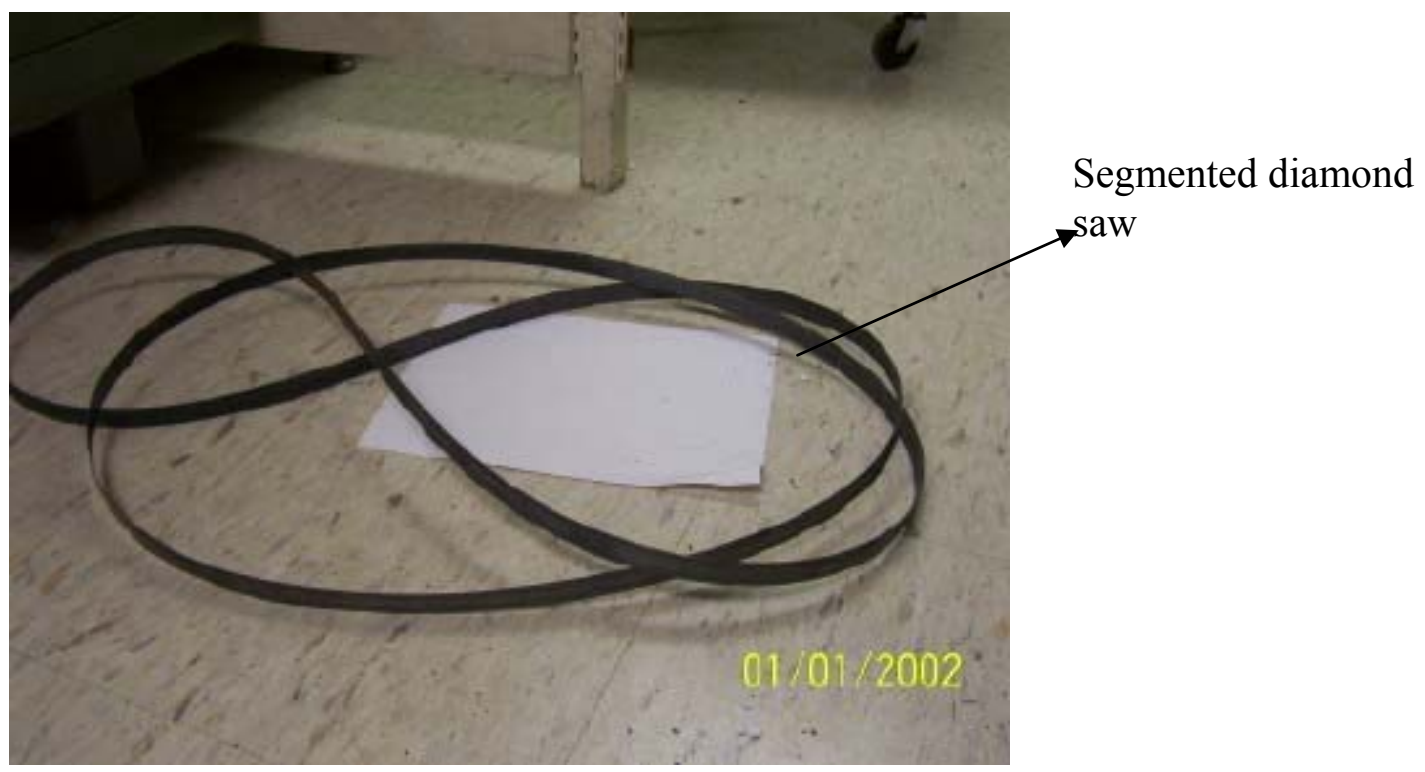

Fig IVa: Segmented diamond saw used for cutting MMC specimens

2) Dressing stick

VENDOR: DOALL Pittsburgh

Address: 905 Lincoln HWY Rt30 East,

East McKeesport, PA, 15035-0170, Ph: 1800-92-DoALL

Product Description: Dressing stick, 400 grit *bs*

3) Diamond inserts

Vendor: MSC Industrial Supply

Address: 100 MSC Drive Ph: 1800-645-7270 
Account Number: 1622846

Jonestown, PA 17038

Catalog item\# 82982950

Product Description: tpg3222g 728 valenite ped insert

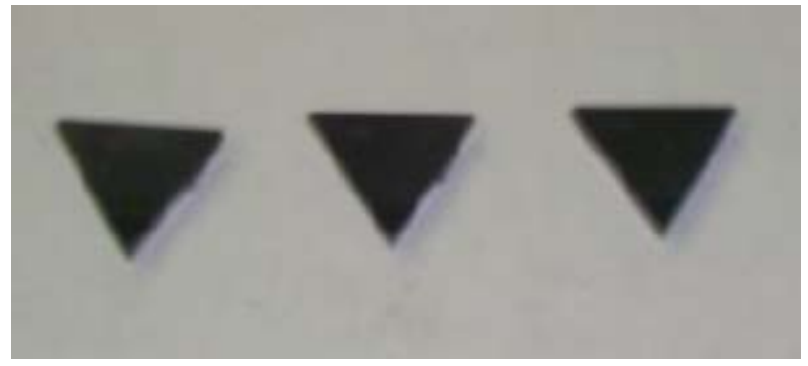

Fig IVb: Diamond inserts used for surface milling

4) Indexable End Mill

Vendor: MSC Industrial Supply

Address: 100 MSC Drive Ph: 1800-645-7270

Account Number: 1622846

Jonestown, PA 17038

Catalog Item\#73118200

Product Description: 1/4*3*4 Flute LCT Indexable End Mills

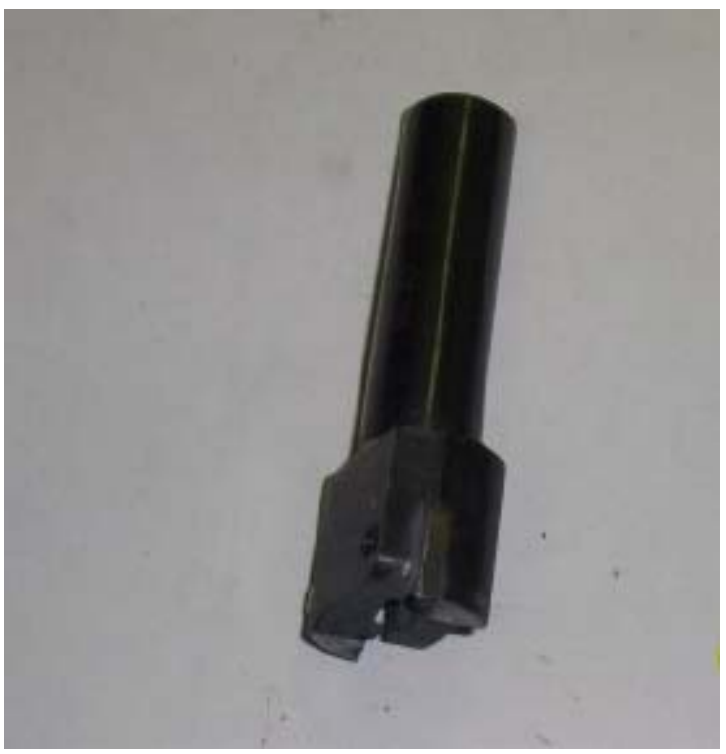

Fig IVc: Indexable end mill 
5) Surface Mill

Available: Civil work shop (Attn: Dave Turner)

R.P.M used: 130

Maximum Cutting Depth: 1/50,000 inch

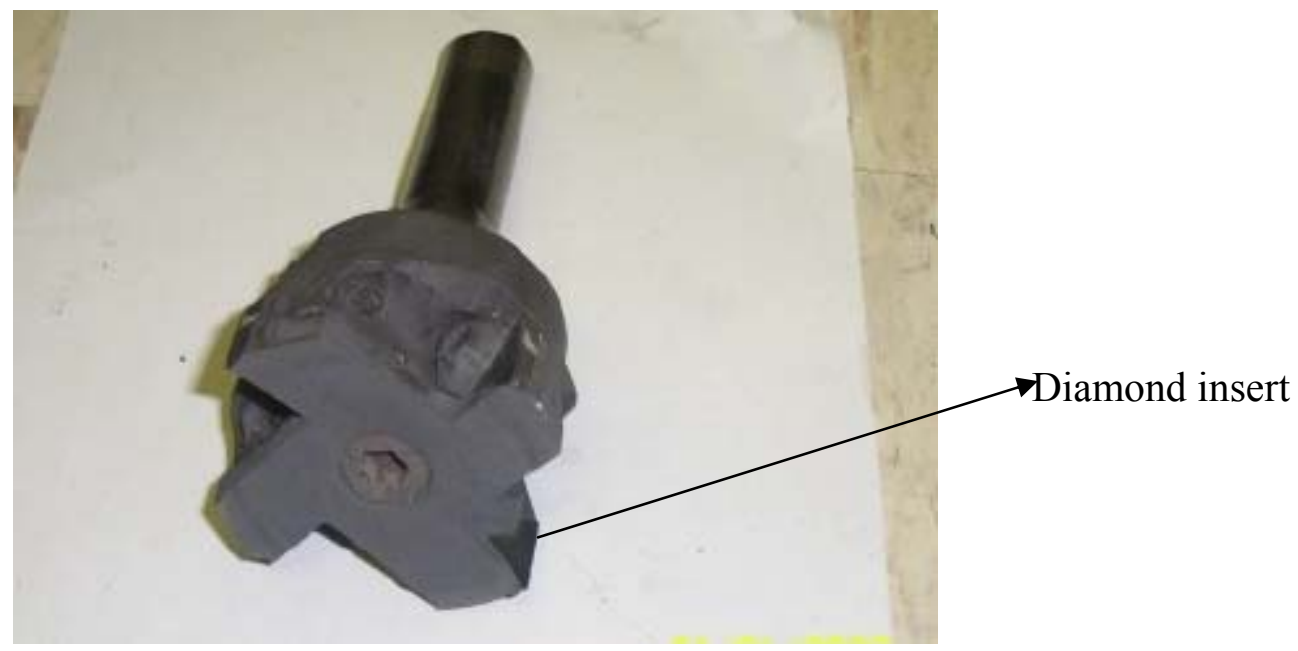

Fig IVd: Surface mill used for holding diamond inserts

6) Cutting Fluid

Available: Mechanical work shop (Attn: Cliff)

Product Description: Dasco1110 Super Soluble Base 


\section{APPNEDIX V}

Material property of $\mathbf{3 0} \% \mathrm{SiC}$ reinforcement from Lanxide Corporation

\begin{tabular}{|l|l|l|}
\hline Material property & Test temperature & Typical properties \\
\hline Matrix- (vol \%) & $21^{\circ} \mathrm{C}$ & Al-10Si-1Mg (70\%) \\
\hline Reinforcement- (vol \%) & $21^{\circ} \mathrm{C}$ & $\mathrm{SiC} \mathrm{(30 \% )}$ \\
\hline Bulk Density-(gm/ cm $\left.{ }^{3}\right)$ & $21^{\circ} \mathrm{C}$ & 2.80 \\
\hline Ultimate Tensile Strength-Mpa & $21^{\circ} \mathrm{C}$ & 225 \\
\hline YieldStrength,0.2\% Off-set-Mpa & $21^{\circ} \mathrm{C}$ & 177.6 \\
\hline Young's Modulus-Msi & $21^{\circ} \mathrm{C}$ & 18.4 \\
\hline Ductility & $21^{\circ} \mathrm{C}$ & 0.62 \\
\hline Coefficient of Thermal Expansion & $-55-125^{\circ} \mathrm{C}$ & 14.8 \\
\hline
\end{tabular}

Address: HPMG, MSE, INC

1300 Marrows Road, Newark DE 19711

$\mathrm{Ph}:(302) 456-1712$ 


\section{APPENDIX VI}

Comparison of experimental results of MMC material with literature data

Table Va- Properties of 2124 Al-SiC composites produced using powder metallurgy

\begin{tabular}{|c|c|c|c|c|}
\hline V/O SiC & $\begin{array}{c}\text { Hardness Value } \\
(\mathrm{H.V})\end{array}$ & $\begin{array}{c}\text { Young's } \\
\text { Modulus }(\mathrm{GPa})\end{array}$ & $\begin{array}{c}\text { Ultimate } \\
\text { Strength }(\mathrm{MPa})\end{array}$ & Ductility \\
\hline 0 & 107 & 70 & 280 & 8.6 \\
\hline 10 & 123 & 85 & 326 & 3.0 \\
\hline 20 & 157 & 107 & 394 & 2.5 \\
\hline 30 & 196 & 120 & 382 & 1.5 \\
\hline
\end{tabular}

(Manoj et al1993)

Table Vb- Properties of Al-MMC's produced using Infiltration method

\begin{tabular}{|c|c|c|c|c|}
\hline $\mathrm{V} / \mathrm{O} \mathrm{SiC}$ & $\begin{array}{c}\text { Density } \\
\left(\mathrm{g} / \mathrm{cm}^{3}\right)\end{array}$ & $\begin{array}{c}\text { Tensile } \\
\text { Strength } \\
(\mathrm{MPa})\end{array}$ & $\begin{array}{c}\text { Coefficient of } \\
\text { thermal } \\
\text { expansion } \\
\left(10^{-6} / \mathrm{K}\right)\end{array}$ & $\begin{array}{c}\text { Fabrication } \\
\text { Process }\end{array}$ \\
\hline $54 \%$ & 2.96 & - & 9.5 & Infiltration \\
\hline $64 \%$ & 3.01 & - & 7.5 & Infiltration \\
\hline $70 \%$ & 2.99 & - & 6.6 & $\begin{array}{c}\text { Pressure } \\
\text { Infiltration }\end{array}$ \\
\hline $63 \%$ & 3.01 & 253 & 7.9 & Pressure \\
& & & & Infiltration \\
\hline $68 \%$ & 3.03 & 207 & $6.3-7.3$ & Pressure \\
& & $225-250$ & $11.9-16$ & Prfiltration \\
\hline $55-70 \%$ & 2.90 & - & & Primex \\
\hline $18-40 \%$ & $2.77-2.87$ & & & \\
\hline
\end{tabular}

(David et al, Dept of Energy) 